
Effect of fire occurrence and frequency on topsoil properties and soil (fertility) losses by runoff 


\section{Thesis committee}

\section{Promotors}

Prof. Dr V. Geissen

Personal chair at the Soil Physics and Land Management Group

Wageningen University \& Research

Prof. Dr C.J. Ritsema

Professor of Soil Physics and Land Management

Wageningen University \& Research

\section{Co-promotors}

Dr J.J. Keizer

Principal Researcher, Centre for Environmental and Marine Studies, Department of

Environment and Planning, University of Aveiro, Portugal

\section{Other members}

Prof. Dr G.M.J. Mohren, Wageningen University \& Research

Dr L.H.E. Cammeraat, University of Amsterdam, the Netherlands

Dr J.H.M. Wösten, Wageningen University \& Research

Dr A. Valdecantos, Fundacion CEAM, Valencia, Spain

This research was conducted under the auspices of the Research School for SocioEconomic and Natural Sciences of the Environment (SENSE) 


\title{
Effect of fire occurrence and frequency on topsoil properties and soil (fertility) losses by runoff
}

\author{
Mohammadreza Hosseini
}

Thesis

submitted in fulfilment of the requirements for the degree of doctor at Wageningen University

by the authority of the Rector Magnificus,

Prof. Dr A.P.J. Mol, in the presence of the

Thesis Committee appointed by the Academic Board

to be defended in public

on Monday 9 April 2018

at 11 a.m. in the Aula. 
Mohammadreza Hosseini

Effect of fire occurrence and frequency on topsoil properties and soil (fertility) losses by runoff, 132 pages.

PhD thesis, Wageningen University, Wageningen, NL (2018)

With references, with summary in English

ISBN: 978-94-6343-745-5

DOI: https://doi.org/10.18174/441931 


\section{Table of contents}

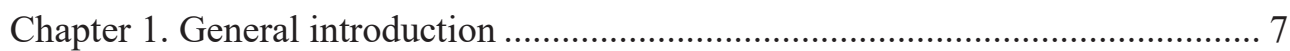

Chapter 2. Effect of fire frequency on runoff, soil erosion, and loss of organic matter at the micro-plot scale in north-central Portugal.

Chapter 3. Effects of fire occurrence and recurrence on nitrogen and phosphorus losses by overland flow in maritime pine plantations in north-central Portugal.....

Chapter 4. The short-term effectiveness of surfactant seed coating and mulching treatment in reducing post-fire runoff and erosion

Chapter 5. Developing generalized parameters for post-fire erosion risk assessment using the revised Morgan-Morgan-Finney model: a test for north-central Portuguese pine stands

Chapter 6. Synthesis 97

Literature cited. 109

English summary 123

Acknowledgements 125

About the author 127 







\section{General introduction}




\subsection{Why study wildfire?}

A massive wildfire ripped through a section of Portugal on Sunday, June 18, 2017 killing more than 60 people and injuring hundreds more (CNN.com). In addition to the tragic loss of life, the damage and impacts of this and other fires reach far beyond the obvious loss of vegetation.

Every year, around 45,000 forest fires break out in southern Europe, burning around half a million hectares of forests (Moreira et al., 2011). In Portugal, between 1980 and 2010, an average of 110,000 hectares burned every year (Stoof et al., 2015; Giglio et al., 2010; FAO, 2007; Giglio et al., 2006). Fires in Portugal are often one of the major reasons contributing to forest disruption and renovation (Cerdà and Robichaud, 2009).

Besides the obvious loss of forests and the socioeconomic consequences, fires can create smoke pollution, release greenhouse gases, and damage ecosystems (NASA). Fires can also increase surface temperatures and soil hydrophobicity as well as impact nutrient cycling (Richards et al. 2012). The increased frequency and severity of fires over the past few decades have considerable negative ecological consequences in terms of soil erosion, decreasing soil fertility (Stoof et al., 2015; Cerdà and Robichaud, 2009; Certini, 2005) and forest productivity. The effects of one single forest fire on runoff and soil erosion are well known, especially in terms of overland flow and soil loss until the vegetation recovers (Shakesby, 2011). However, the effects of repeated fires and their impacts on maritime pine plantations, which are widespread in Portugal, have received less attention (Malkisnon et al., 2011). Correct identification of the areas sensitive to fire, in addition to better knowledge and understanding of the impacts of wildfires on plant-water-soil interactions, and the application of proper restoration methods will help to better manage the effects of fires in order to decrease the susceptibility of these areas to repeated fires.

Compared to prior studies on the effects of single and recurrent fires, the present study is advance in the sense that it will investigate:

- The impact of recurrent vs. single event wildfires on runoff, erosion, soil fertility and nutrient losses, including comparing them to long-unburnt areas;

- The effectiveness of the use of surfactant-coated seeds and pine needle mulch on reducing erosion under field conditions;

- The testing of a model aimed at developing parameters of erosion after a fire. 


\subsection{Characteristics and causes of wildfires}

Increases in temperature can make vegetation dry to the point that just a spark ignites a flame. Humans, either through accident or arson, cause most of the wildfires around the world, although natural causes such as lightning strikes can also trigger a blaze (Aponte et al., 2016). For a wildfire to burn, the following three elements need to exist: (i) Fuel in the form of trees, organic matter and vegetation, (ii) oxygen, and (iii) heat. These three elements combine and interact to establish a fire's characteristics such as fire spread rate, duration, intensity and a fire's heat.

How does wildfire effect soil? The main changes of the soil status after a fire is shown in (Figure 1.1).

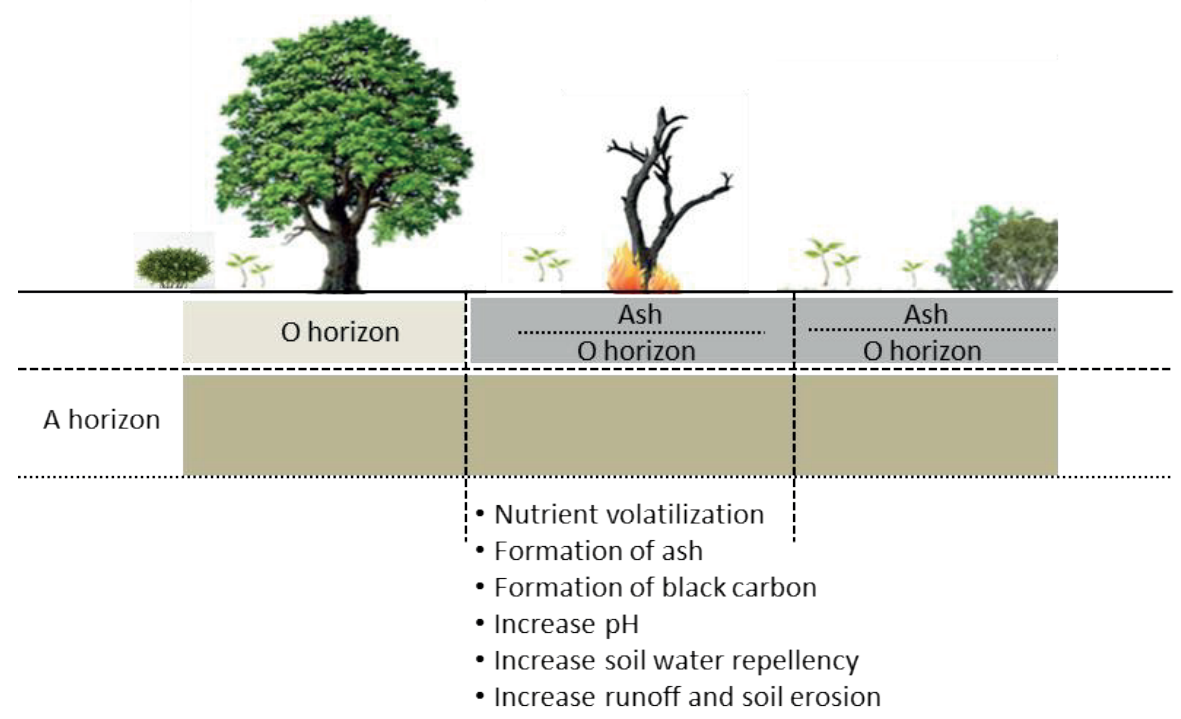

Figure 1.1 Short-term ( $\approx 1-2$ years) soil and vegetation cover changes after a single wildfire (Adapted after: Caon et al., 2014).

The main factors involved in causing a wildfire are:

1) An ignition source ignites combustible material such as trees, shrubs, and/or the humus layer on forest soils which then starts to burn, generating heat and igniting additional material in the forest. The fire's range is increased as heat is released and the temperature of the surroundings increases. The fire grows to such an extent that the whole fire load decomposes with the evolution of a flammable gas mixture. 
2) Weather conditions are crucial for the development of a fire and for determining the danger to a region once a wildfire starts. The wildfire season in Southern Europe generally occurs during the dry season from April to October. Catastrophic fires tend to occur during periods of extended drought and/or wind storms. The term fire regime refers not only to the fire intensity, type and behaviour, but also the factors that influence a fire event such as: fuel type, topography, weather conditions and severity of the fire ( Fernandes et al., 2016; Christensen, 1993).

3) Air humidity is affects forest fire behaviour. If the humidity is low, the potential fuel for a fire becomes dryer. If the humidity is high, the fuel will absorb moisture thus making ignition quite difficult. Rainfall can also cause the fuel to become wet, but not all fuels absorb the same amount of moisture. Decreased precipitation is the main factor that affects the moisture content of fuel (Piñol et al., 1998). The surface area and the amount of fuel on a surface influences how quickly a fuel will catch fire and burn (Scott and Burgan, 2005). Different fuels catch fire at different temperatures. For instance, eucalyptus and dry sticks catch fire quickly but large wet pieces of wood take longer to absorb enough heat to ignite. The less moisture in the fuel, the greater the chance that it will burn (Wittenberg et al., 2014; Scott and Burgan, 2005).

4) Wind is another factor in determining the spread of fire. Wind affects the supply of oxygen to the burning fuel such that unburned fuel can receive energy via radiation and convection at an increased speed as the wind increases. Wind can also dry out the fuel thus reducing moisture (De Haan and Icove, 2011).

5) Insufficient land management causes the accumulation of fuel in the forests. The practice of planting non-fire resistant tree species close together also influences the fire regime of an area (Fernandes et al., 2016).

6) The shape of the land (terrain) has an important impact on wildfire behaviour. Steep slopes increase the speed of a fire since fuels are essentially preheated from the fire below through radiation. Rough terrain with narrow valleys affects the direction of a fire and increases the speed of fire spread. The direction that a slope is facing also effects how a fire spreads since the fuel on slopes facing the sun are drier thus they burn faster (Pierson et al., 2002). 


\subsection{Effects of wildfires}

\subsubsection{Vegetation cover}

The hazards posed to vegetation will depend on the fire and the characteristics of the plants exposed to a specific fire. The chance of a plant being killed by a fire depends on the duration of the fire and the fire's temperature. Plant cover is linked to the time interval between fires which differs among different plant groups (Tessler et al.,2016). Ash cover in the burnt sites averaged approximately $10 \mathrm{~cm}$ deep and the depth of the 0 horizon in the unburnt sites was $7-10 \mathrm{~cm}$. There was no vegetation that remained in the repeatedly $(4 \times)$ burnt sites. The shrub layer and some pine trees were destroyed in the sites which burned only once. Annual vegetation, pine trees, and shrub layers covered the unburnt sites.

These results suggest that plant regeneration after recurrent fires occurs faster when the time intervals between fires are longer whereas high fire frequency might suppress vegetation regeneration (Tessler et al.,2016). Through the burning of the vegetation the following processes can occur: (1) the mineralization of nutrients and carbon stored in the vegetation (Moreira et al.,2013), (2) the formation of charcoal as well as ash with nutrients and carbon, (3) the volatilization of nutrients and $\mathrm{CO}_{2}$.

\subsubsection{Soil properties}

The soil properties can change after a fire which can be short-, long-, or permanent changes, depending on which property and the frequency and severity of the fire (Certini, 2005). The burning of the litter layer of forest soils by wildfires results in losses of nutrient and organic matter (OM), decreased evapotranspiration and infiltration and increased runoff (Samanta et al., 2010). The direct consequences of burning soil has many effects including: (1) the formation of an ash layer which includes the nutrients and carbon from the burnt vegetation and increases soil pH (Moreira et al. 2013), (2) the loss via volatilization of the carbon and nutrients stored in the soil layer, (3) the reduction of soil fauna and flora, (4) the destruction of soil structure and the increase of soil water repellency, and (5) the leaching of nitrate.

Nutrient volatilization is considered the main cause of nutrient loss from both the $O$ and the A horizons immediately after a fire (Caon et al., 2014). If the ash is not washed away by surface runoff or blown away by wind, higher amounts of nitrogen and phosphorus could be found in the burned soil than in the unburned soil (Caon et al., 2014).

A porous well-structured soil is essential for the movement of water, air, and nutrients through soils. The soil organic matter contributes directly to the productivity and 
sustainability of wild land ecosystems (Neary et al., 2005). Organic matter burns have several ecological and environmental impacts and biomass burning is a significant global source of atmospheric gases (González-Pérez et al., 2004).

The strength of post-fire soil water repellency depends on various factors such as fire severity and timing, vegetation type, soil texture, and soil moisture ( Gralewicz et al., 2012; Woods et al., 2007). Vertical water movement is severely limited in dry water repellent soil and as a consequence, infiltration rates can be strongly reduced ( Granged et al., 2011a; Dekker et al., 2000; DeBano, 1981). Soil hydrophobic characteristics can play an important role in the potential for increased runoff and erosion after a fire. Some factors commonly cause the formation of a water repellent layer: the thickness of the litter layer prior to the fire, the high intensity of surface and crown fires, the prolonged periods of intense heat, and the coarseness of the soil texture (NRCS, 2000; Doerr et al., 1996).

\subsubsection{Runoff and soil erosion}

Repeated forest fires effect eco-geomorphic processes and decrease ecosystem resilience. Observations after a fire event revealed that vegetation recovery was significantly lower after a repeated fire than after a single fire. Repeated fires reduce surface cover causing more soil to be exposed which can lead to higher runoff and erosion rates (Malkisnon et al., 2011; Wittenberg and Inbar, 2009a). Reduced vegetational canopy (Stoof et al., 2012), and the absence of any surface-water storage capacity, can contribute to erosion. A wildfire can decrease the retention of soil water (Stoof et al., 2015) and reduce infiltration which increases runoff and soil erodibility (Stoof et al., 2015; Moody and Ebel, 2014; Onda et al., 2008; Nunes et al., 2005).

\subsection{Restoration techniques and post fire management}

A good understanding of post-fire vegetation recovery is needed for defining strategies to decrease nutrient losses, runoff and erosion (Lozano et al., 2012). The application of actual fire management techniques on a field scale, such as keeping burnt woody materials on the soil surface as well as sowing and mulching is vital in protecting soil fertility and supporting vegetation recovery (Fernandez-Manso et al., 2016). A measure like post-fire seeding, either with or without mulching, can also contribute to reducing erosion risk. Mulching aims at directly reducing runoff and soil erosion (Díaz-Raviña et al., 2012) whereas seeding aims at reducing it indirectly through improving vegetation recovery. Madsen et al. (2013a) and 
Prats et al. (2013) showed the effectiveness of using surfactant-coated seeds and mulching to decrease runoff, soil erosion and OM losses.

In addition, some other possible techniques to decrease post-fire erosion on the slope and catchment scale could be weed control (noxious weeds displace native plants and affect plant productivity and diversity), contouring log terraces (creation of channels on the slopes to delay water and sediment transported by water downslope), silt fences, straw bale check dams, water bars and culverts (Moench and Fusaro, 2012).

\subsection{Post-fire erosion risk assessment, using revised Morgan-Morgan- Finney (MMF) model}

Post-fire erosion is an important concern because of the potential impacts on soil and water resources which also have consequences for the people in adjacent areas. Increases in wildfire frequency and burned areas are expected when considering probable future climate scenarios for the Mediterranean region (Fernández et al., 2010). Accurate predictions of post-fire erosion rates are needed to estimate the potential impacts of wildfires on on-site ecosystem services as well as on downstream aquatic habitats while at the same time accessing the potential benefits of post-fire rehabilitation treatments (Larsen and MacDonald, 2007).

Modelling is a common approach for making predictions. In wildfire science, there is still a need to advance the representation of burned areas in models and the determination of fitting model parameters, especially since model applications tend to focus on specific study sites and the parameters are not tested for general applications elsewhere. The present study focused on developing generalized parameters for the Morgan-Morgan-Finney (MMF) model to improve the prediction of the impact of recurrent wildfires on runoff and erosion. The MMF model affords a stronger physical base than the universal soil loss equation. The MMF model has proved to be simple to use and is reputed to give reasonable estimates of annual runoff and erosion (Morgan, 2001) for conditions similar to those in this research study.

\subsection{Objective of the research}

The overall aim of this study is to contribute to a better knowledge and understanding of the impacts of repeated vs. individual wildfires on runoff and soil erosion and the related nutrient losses occurring in maritime pine plantations in north-central Portugal (Figure 1.2). 
This will increase understanding of the effects of fire and contribute to efforts to decrease the vulnerability of an area to repeated fires.

The specific questions of this research are the following:

- What is the effect of fire frequency on runoff, soil erosion, and loss of organic matter at the micro-plot scale in maritime pine plantations in north-central Portugal?

- What is the effect of fire frequency on nitrogen and phosphorus losses by runoff?

- What is the short-term effectiveness of seeding with surfactant-coated seeds and mulching with pine needles for reducing post-fire runoff and erosion?

- Is the MMF model sufficient for developing generalized parameters for post-fire erosion risk assessment?

To address these questions, we selected nine sites in a maritime pine plantation following a large wildfire in September 2012 that affected roughly 3000 ha of the Viseu municipality in north-central Portugal. Three of the sites had not been burned (0x) since 1975 and acted as controls and were covered with pine trees, shrubs, and annual vegetation. Three sites had burned only in 2012 (1x) and contained burnt pines but no shrubs or annual vegetation. Lastly, three degraded sites were chosen that had been burned four times (4x) since 1975 and had no vegetation cover. 


\subsection{Thesis outline}

Figure 1.2 summarizes the outline of the thesis and specifies the topics that are discussed in each chapter.

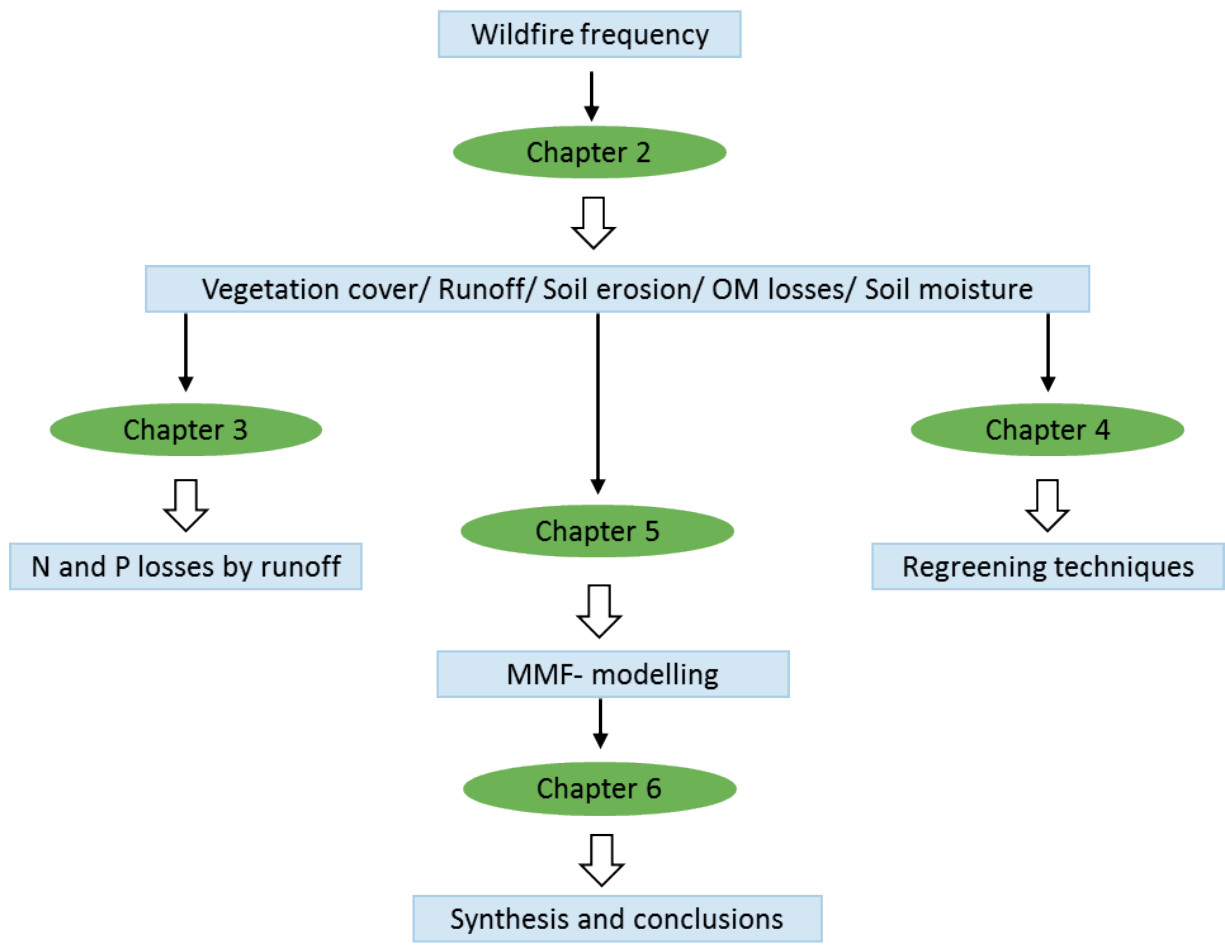

Figure 1.2 Thesis outline, indicating the Chapters and topics of study.

Chapter 2 addresses: (i) the effect of the frequent recurrence of fire on the generation of overland flow and related sediment and OM losses at the micro-plot scale, (ii) temporal and spatial variations on the runoff and erosive response at the micro-plot scale, and (iii) the role of ground cover, soil moisture content, and soil water repellency (SWR) in runoff and associated sediment and OM losses at the micro-plot scale.

Chapter 3 addresses total (i.e. dissolved plus particulate forms) nitrogen and phosphorus losses caused by runoff in maritime pine plantations suffering different fire frequencies. The specific objectives were to: i) assess total $\mathrm{N}$ and $\mathrm{P}$ losses from topsoil by runoff, due to fire history of sites and, ii) assess the effect of fire frequency on $\mathrm{N}$ and $\mathrm{P}$ losses by runoff for a better understanding of $\mathrm{N}$ and $\mathrm{P}$ cycles after fire. 
Chapter 4 deals with the effectiveness of 4 different erosion mitigation techniques and postfire restoration measures to reduce runoff and erosion after repeated wildfires in a maritime pine forest. These measures include: i) application of pine seed, ii) sowing of pine seeds combined with the use of pine needle mulch, iii) sowing grass seed and iv) sowing surfactant-coated grass seed to reduce runoff and erosion.

Chapter 5 focuses on developing generalized parameters to improve the prediction of the impacts of recurrent wildfires on runoff and erosion using the revised Morgan-MorganFinney (MMF) model and on furthering the understanding of the underpinning model parameters, in particular those related to soil physical properties.

Finally, chapter 6 presents a synthesis of the research, presenting the main conclusions as well as recommendations for further research.

\subsection{Study Area}

The data collection was conducted in an area containing Pinus pinaster that was burned by a wildfire in September 2012 and, based on existing burnt area maps, had burned on three other occasions since 1975 (Figure 1.3). Since the ashes were black, the litter layer and the understory vegetation were most affected by the fire and the tree crowns were only partially destroyed (Keeley, 2009; Shakesby and Doerr, 2006). The study area was mainly surrounded and covered by stands of $P$. pinaster, which is a highly flammable tree species with a rotation cycle of 40 years ( Moreira et al., 2013; Keeley, 2009) and had Pterospartum tridentatum as the predominant shrub species (Cunningham et al., 2008).

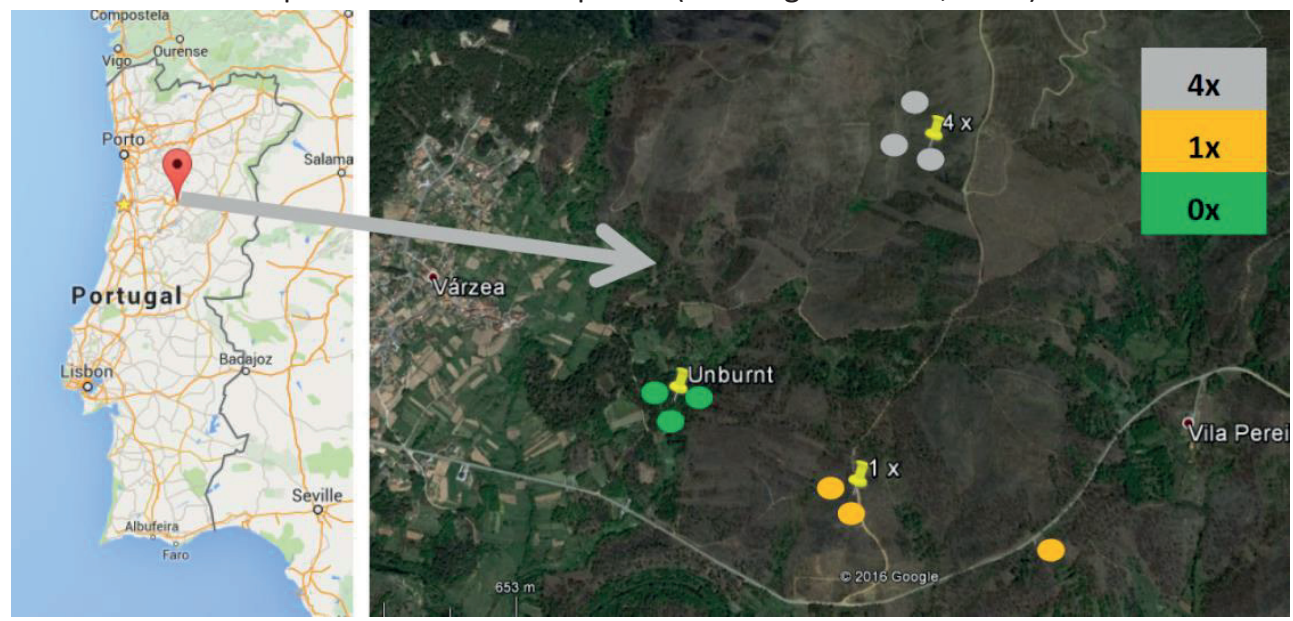

Figure 1.3 Locations of study area in the Viseu municipality-Portugal. Site abbreviation: $4 x$ burnt, $1 x$ burnt and unburnt. 
Nine slopes with similar gradients and covered with maritime pine were selected. Three were in sites that had burned four times (4x) between 1975 and 2012 (1978, 1985, 2005, and 2012). Three were in sites which had only burned in September 2012 (1x), and three sites that had not burned since 1975 (0x) but were near a burnt area that acted as long unburnt. Ash cover in the burnt sites averaged approximately $10 \mathrm{~cm}$ deep, and the depth of the $O$ horizon in the unburnt sites was $7-10 \mathrm{~cm}$. There was no vegetation that remained in the repeatedly $(4 \times)$ burnt sites, and the shrub layer and some pine trees were destroyed in the sites which burned only once.

Annual vegetation, pine trees, and shrub layers covered the unburnt sites. The study area is located in north-central Portugal and is part of the Vouga River Basin which drains into the Ria de Aveiro coastal lagoon. According to Köppen's system, the climate can be classified as temperate $\mathrm{Csb}$, i.e. as humid meso-thermal with a prolonged dry and warm summer, or a humid Mediterranean climate. Annual rainfall ranges from 1200 to more than $2000 \mathrm{~mm}$ year $^{-1}$ and mean monthly temperatures range from $9^{\circ} \mathrm{C}$ in January to $23^{\circ} \mathrm{C}$ in July (SNIRH, 2014). The terrain has a relief with steep slopes of around $20-30^{\circ}$. The bedrock consists of schists and the soils are mainly humic Cambisols and epileptic Umbrisols and, to a smaller extent, umbric Leptosols. As elsewhere in the region, soils are shallow, less than $30 \mathrm{~cm}$ deep, and are susceptible to degradation by soil erosion and land use. 


\section{Effect of fire frequency on runoff, soil erosion, and loss of organic matter at the micro-plot scale in north-central Portugal}

Wildfire is a natural phenomenon that is a common ecological factor in Mediterranean ecosystems. The increase in occurrence in recent decades has raised widespread concern about the impact of repeated wildfires on runoff and erosion, a topic that has not been widely studied. We addressed these concerns in an area of north-central Portugal by comparing runoff at the micro-plot scale and the associated transport of sediments and organic matter (OM) in unburnt, once burnt, and repeatedly burnt plantations of maritime pine. We selected nine sites following a large wildfire in September 2012 that affected roughly 3000 ha of the Viseu municipality. Three of the sites had not burnt since 1975 and acted as controls, with covers of pine trees, shrubs, and annual vegetation; three sites had burnt only in 2012 and contained burnt pines but no shrubs or annual vegetation; and three degraded sites had suffered from three wildfires prior to 2012 and contained no vegetation. We established nine micro-plots $\left(0.25 \mathrm{~m}^{2}\right)$ at each site and collected runoff, eroded soil, and OM losses in tanks after each rain from October 2012 to September 2014. The repeated wildfires strongly increased the runoff coefficient and the risk of downstream flooding after heavy rains. OM losses were nearly half the volume of the eroded soil in the degraded sites due to the transport of ash in the runoff. Runoff and soil losses occurred not only after erosive rainstorms following a fire but also after a subsequent period of drought. Soil cover, rain intensity, and soil moisture were key factors in the amount of runoff and erosion. The insights provided by this study can contribute to pre-and post-fire activities and management in protect areas and can thus improve post-fire recovery.

Based on:

Hosseini, M., Keizer, J.J., Pelayo, O.G., Prats, S.A., Ritsema, C.J. and Geissen, V., 2016. Effect of fire frequency on runoff, soil erosion, and loss of organic matter at the micro-plot scale in north-central Portugal. Geoderma, 269, pp.126-137. 


\subsection{Introduction}

Fire is a serious and frequent disturbance in forest ecosystems, especially in Mediterranean regions due to their dry, hot summers followed by frequent and high-intensity rain in the autumn immediately after the summer wildfires (Badía et al., 2014; Bento-Gonçalves et al., 2012; Shakesby, 2011). Wildfires regularly occur in north-central Portugal and are thought to be a serious contributor to erosion and land degradation (Prats et al., 2014; BentoGonçalves et al., 2012; Shakesby, 2011). Changes in land use, forest plantations, and human activities have increased the flammable biomass. These changes have rendered our research area in Portugal increasingly susceptible to both wildfire and the accompanying ecosystemic degradation (Carreiras et al., 2014). New areas prone to wildfires have concurrently increased in number (Nunes et al., 2005), therefore, improving forest management to decrease soil losses has become increasingly important (Badía et al., 2014).

Repeated fires reduced vegetation cover followed by a higher exposure of the soil surface which is leading to higher runoff rates, and cause more soil erosion (Malkisnon et al., 2011; Wittenberg and Inbar, 2009a). Therefore, the present study is focused on and contributes to a better understanding of the impact of repeated wildfires on runoff and physical soil properties such as erodibility and OM losses in plantations of maritime pine (Pinus pinaster Ait.).

Heat, which is a direct effect of fire on soil, can change the physiochemical properties of the soil, depending on the temperature reached during a fire and the duration of the fire (Stoof et al., 2015; Caon et al., 2014; Mataix-Solera et al., 2011; Stoof, 2011; Keeley, 2009). Some of the physical change that occurred can causes a decrease in soil porosity and increase in bulk density (Aznar et al., 2016; Stoof et al., 2015; Stoof et al., 2011; Alauzis et al., 2004; García-Corona et al., 2004) and can decrease the retention of soil water (Stoof et al., 2015; Ebel, 2012; Shakesby, 2011; Stoof, 2011) and infiltration (Stoof et al., 2015; García-Corona et al., 2004; Martin and Moody, 2001). Soil structure is consequently affected by fire (Stoof et al., 2015; Léonard and Richard, 2004) and burnt organic matter (OM) and ash form a hydrophobic coating on soil surface (Stoof et al., 2015; González-Pelayo et al., 2010), which reduces infiltration, increases runoff and soil erodibility (Stoof et al., 2015; Moody and Ebel, 2014; Onda et al., 2008; Nunes et al., 2005).

Also, chemical changes can be occurred by fire, such as decrease in calcium content that would lead to change of the $\mathrm{pH}$ on the top soil horizons, nutrients leaching caused by precipitation after the fire and also, a decrease in cation exchange capacity and an increase in the electrolyte concentration. Fire also causes a decrease in sodium adsorption ratio, which prevents clay dispersion and strong micro aggregate formation to reduce infiltration 
rate and an increase in runoff and soil erosion (Inbar et al., 2014; Giovannini et al., 1990). Fire decreases ground cover, which changes soil roughness so that water can flow more easily and runoff increases (Stoof et al., 2015; Mataix-Solera et al., 2011; García-Corona et al., 2004). The depth of soil organic matter changes after fires due to volatilization and/or due to the transport of surface ash and sediments (Caon et al., 2014). The intensity of this change depends on soil-moisture (SM) content, soil type, surface cover, and the type, duration, and intensity of a fire (Caon et al., 2014).

Post-fire runoff, sediment transport, and OM losses have been studied (Stoof et al., 2015; Ebel, 2012; Shakesby, 2011; Stoof, 2011). But, much less attention has been paid to the consequences of repeated fires on these processes. Repeated forest fires, effect on ecogeomorphic processes and also, decrease ecosystem resilience. Observations after fire in the field bring the conclusion that; vegetation recovery was significantly lower after the repeated fire than after one fire. As pointed before, much less attention has been paid to the consequences of repeated fires on runoff, soil erosion, and loss of organic matter. Therefore, our main objective was to assess the effect of fire frequency on runoff and associated sediment and OM losses at the micro-plot scale by comparing pine plantations those have experienced single vs. recurrent wildfires. Specific objectives were to assess the effect of frequent recurrence of fire on generation of i) runoff and related sediment and OM losses at micro-plot scale, ii) the effect of both temporal and spatial variations on the runoff and erosive response at micro-plot scale, and iii) the effect of ground cover, soil moisture content, and soil water repellency (SWR) on runoff and associated sediment and OM losses at micro-plot scale.

\subsection{Materials and methods}

\subsubsection{Study site}

The study area is located in the basin of the Vouga River, which drains into the Ria de Aveiro coastal lagoon, in north-central Portugal (Figure 2.1). The climate is classified in Köppen's system as temperate Csb, humid meso-thermal with prolonged dry and warm summers. Annual rainfall ranges from 1200 to $>2000 \mathrm{~mm} \mathrm{y}^{-1}$, and mean monthly temperatures range from $9{ }^{\circ} \mathrm{C}$ in January to $23{ }^{\circ} \mathrm{C}$ in July (SNIRH, 2014). The soils, classified in 2012 as loam and sandy loam, are shallow Epileptic Umbrisols and Umbric Cambisols with a depth $<30 \mathrm{~cm}$ developed on schist parental material (WRB, 2014) and susceptible to degradation by erosion due to the land use and lack of vegetation. $5000 \mathrm{~m}^{2}$ of fire occurrence area selected for this study. The study area was mainly covered by stands of $P$. pinaster, which is a highly flammable tree species with a rotation cycle of 40 years (Maia et al., 2014; Moreira et al., 
2013), and with Pterospartum tridentatum as the predominant shrub species (Cunningham et al., 2008). Ash cover in the burnt sites averaged approximately $10 \mathrm{~cm}$, and the depth of the $O$ horizon in the unburnt sites was $7-10 \mathrm{~cm}$. Repeated fires reduced tree and shrub cover, the soil cover of the burnt and unburnt sites at the beginning of the experiment are shown in Figure 2.2. There was no vegetation remained in the repeatedly (4x) burnt sites, and the shrub layer and some pine trees were eliminated in the sites which burnt only once. Annual vegetation, pine trees, and shrub layers covered the unburnt sites.

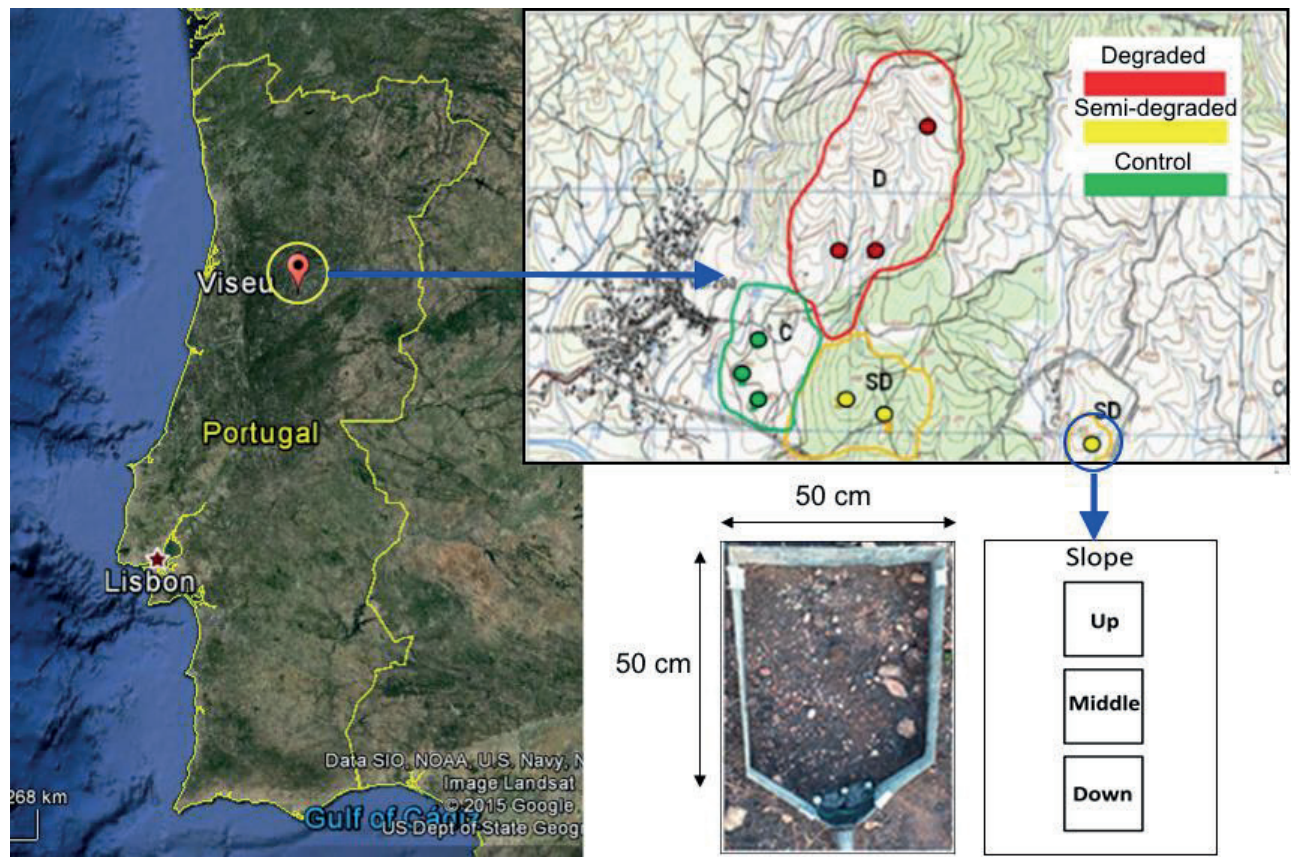

Figure 2.1 Locations of study sites in Viseu municipality and the micro-plot design.

\subsubsection{Experimental set-up}

The study was conducted in a forested area that had burnt in September 2012. Nine slopes (Table 2.1) of similar gradients and covered with maritime pine were selected. Three were in 4x burnt sites that had burnt four times between 1975 and 2012 (1978, 1985, 2005, and 2012). Three were in $1 x$ burnt sites, which had only burnt in September 2012. Three sites that had not burnt since 1975 but were near the burnt area acted as long unburnt. In this research, we used the terms of degraded (D) for $4 x$ burnt, semi-degraded (SD) for $1 x$ burnt and control (C) for long unburnt sites. Small plots can help to understand the connectivity 
of sediment and water transport (Baartman et al., 2013). Therefore, samples of runoff and eroded sediments were collected from $0.25 \mathrm{~m}^{2}$ micro-plots at the lower, middle, and upper sections of the slopes, using the same design as various prior studies in the region (Malvar et al., 2015a; Martins et al., 2013) (Figure 2.1). Plots were installed immediately after the fire of 2012, in areas without vegetation. This methodology is specially applied in areas where the generation of runoff is fast (Cerdà, 1999). On the control slopes, two micro-plots were established at the lower and upper sections, because the pine trees, litters and shrubs protected the soil from runoff and sediment losses and low variability was expected. Each plot was protected from upslope runoff by iron plates and was connected to a hose that carried the surface runoff to a 70-L tank.
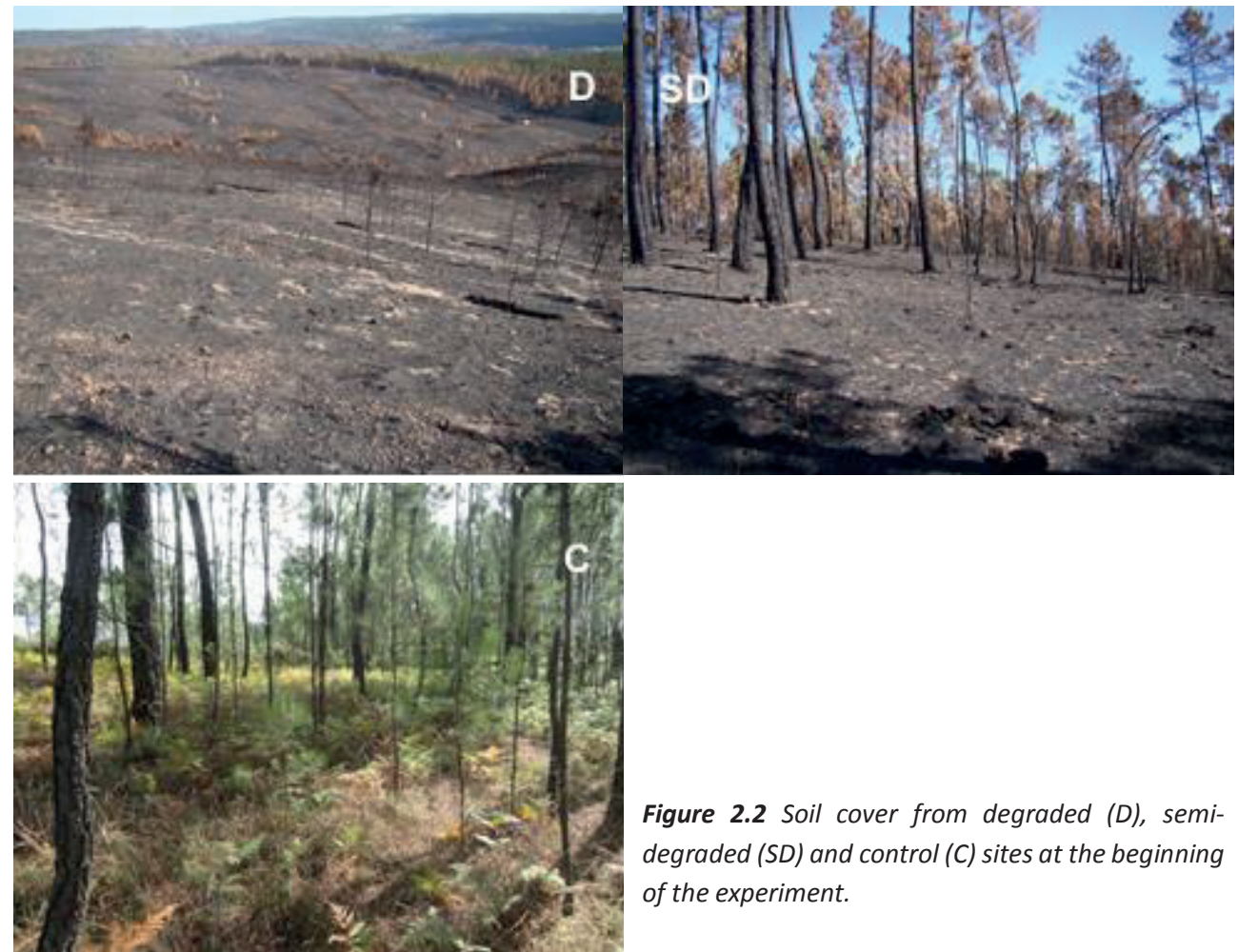

Figure 2.2 Soil cover from degraded (D), semidegraded (SD) and control (C) sites at the beginning of the experiment. 
Table 2.1 Experimental design of the sites

\begin{tabular}{|c|c|c|c|c|c|}
\hline Treatment & $\begin{array}{l}\mathrm{N}^{\circ} \text { of wildfires } \\
\text { (Since 1975) }\end{array}$ & Abbreviation* & $\begin{array}{l}\text { № of } \\
\text { micro- } \\
\text { plots }\end{array}$ & $\begin{array}{c}\text { Mean slope angle } \\
\left({ }^{\circ}\right)\end{array}$ & $\begin{array}{l}\text { Veg cover/Ash } \\
\text { layer } \\
\text { (cm) }\end{array}$ \\
\hline \multirow[t]{3}{*}{ Degraded } & 4 & D1 & 3 & 29 & +6 (Ash) \\
\hline & & D2 & 3 & 25 & +6 (Ash) \\
\hline & & D3 & 3 & 20 & +6 (Ash) \\
\hline \multirow[t]{3}{*}{ Semi-degraded } & 1 & SD1 & 3 & 23 & +5 (Ash) \\
\hline & & SD2 & 3 & 21 & +5 (Ash) \\
\hline & & SD3 & 3 & 20 & +5 (Ash) \\
\hline \multirow[t]{3}{*}{ Control } & 0 & $\mathrm{C} 1$ & 2 & 25 & $+7(\text { Veg }+0)^{* *}$ \\
\hline & & $\mathrm{C} 2$ & 2 & 25 & $+8(\mathrm{Veg}+\mathrm{O})$ \\
\hline & & $\mathrm{C} 3$ & 2 & 23 & $+7($ Veg+O) \\
\hline
\end{tabular}

*Site abbreviation: Degraded (D), Semi-degraded (SD) and Control (C);

$* *$ Vegetation cover (Veg), O horizon (O)

\subsection{Data collection}

\subsubsection{Soil characteristics}

We determined soil $\mathrm{pH}\left(\mathrm{H}_{2} \mathrm{O}\right)$, texture, and bulk density to a depth of $10 \mathrm{~cm}$ for each microplot. Soil $\mathrm{pH}\left(\mathrm{H}_{2} \mathrm{O}\right)$ was measured using a potentiometer with an accuracy of \pm 0.01 . Texture was analysed by sedimentation (Stokes' Law) with the Robinson pipet method (Guitián-Ojea and Carballas, 1976). Bulk density was determined by the cylindrical-core method (Blake and Hartge, 1986). Details of the average soil parameters at each site are presented in Table 2.2. The soils of the study site were described as an association of Epileptic Umbrisol and Umbric Cambisol developed on schist as parent material (WRB, 2014) and classified as loam and sandy loam.

Table 2.2 Soil surface cover and soil characteristics

\begin{tabular}{|c|c|c|c|c|c|c|c|c|}
\hline \multirow{2}{*}{ Site } & \multicolumn{5}{|c|}{ Initial surface cover (\%) } & \multirow{2}{*}{ Soil texture } & \multirow{2}{*}{ Soil pH } & \multirow{2}{*}{$\begin{array}{l}\text { Soil bulk density } \\
\qquad\left(\mathrm{g} \mathrm{cm}^{-3}\right)\end{array}$} \\
\hline & Ash & BS & $\mathbf{L}$ & $S$ & Veg & & & \\
\hline Degraded-1 & 40 & 27 & 0 & 33 & 0 & Loam & 4.32 & 1.15 \\
\hline Degraded-2 & 53 & 16 & 0 & 31 & 0 & Loam & 4.45 & 0.97 \\
\hline Degraded-3 & 46 & 30 & 1 & 23 & 0 & Loam & 4.51 & 0.82 \\
\hline Semi-degraded-1 & 58 & 1 & 27 & 14 & 0 & Sandy Loam & 4.53 & 0.90 \\
\hline Semi-degraded-2 & 52 & 2 & 21 & 25 & 0 & Sandy Loam & 4.64 & 1.11 \\
\hline Semi-degraded-3 & 47 & 8 & 36 & 9 & 0 & Loam & 4.58 & 0.75 \\
\hline Control-1 & 0 & 0 & 96 & 0 & 4 & Sandy Loam & 4.57 & 1.03 \\
\hline Control-2 & 0 & 0 & 73 & 0 & 27 & Sandy Loam & 4.58 & 1.08 \\
\hline Control-3 & 0 & 0 & 79 & 0 & 21 & Sandy Loam & 4.40 & 0.88 \\
\hline
\end{tabular}

*Bare soil (BS), Litter (L), Stone (S), Vegetation (Veg) 


\subsubsection{Soil cover}

The soil cover was assessed eight times from October 2012 to June 2014 . A $10 \times 10 \mathrm{~cm}$ gridded quadrat was laid over each plot, and the cover at each crossing point of the gridlines was determined and recorded as, stone (bedrock and fragments $>2 \mathrm{~mm}$ ), bare soil, ash, litter, or vegetation. Soil cover were included as factors affecting runoff and related sediment and OM losses.

\subsubsection{Soil moisture and soil water repellency}

Soil moisture sensors (Decagon EC5) were installed at a depth of 5-10 cm and connected to Em5b data loggers monitoring soil moisture variation in D2 and SD2 (as a random selection from the fire frequency sites). In the $C$ plots the rainfall mainly influenced the moisture of the $\mathrm{O}$ horizon and with a strong time lag the mineral soil. Therefore, we decided to use comparable data sets and only compare soil moisture in D and SD. Data were recorded at 10-min intervals from October 2012 to September 2014.

Soil water repellency (SWR) was determined by testing the molarity of ethanol droplets (Doerr, 1998; Doerr et al., 1996), and the samples were categorised into surface-tension classes from 1 (Very hydrophilic) to 7 (Extremely hydrophobic) (Doerr, 1998). Three drops of aqueous ethanol solutions of increasing concentration were applied to the soil until the concentration was reached where the drops penetrated within 5 seconds. Repellency was tested each month from December 2012 at a depth of $2.5 \mathrm{~cm}$ at three places adjacent to the micro-plots, using the same method as prior studies in the region by Keizer et al. (2008) along a vertical transect on the slopes of C1, SD3, and D2.

\subsubsection{Rainfall and runoff}

Field data and samples were collected from 4 September 2012 to 4 September 2014 at oneto two-week intervals after each rain, for a total of 70 rains. Total rainfall and rain intensity per week were measured with totaliser and automatic rainfall gauges. The totaliser gauges measured rainfall, and $\mathrm{HOBO}$ waterproof data loggers measured both rainfall and rain intensity $\left(\mathrm{I}_{30}\right)$, which is the maximum intensity recorded in $30 \mathrm{~min}$. Runoff quantity was determined by measuring the water level in the 70-L tanks. Runoff samples from each plot were collected in 1.5-L plastic bottles for determining sediment concentration. 
The erodibility of rainwater (KE; $\mathrm{J} \mathrm{m}^{-2} \mathrm{~mm}^{-1}$ ) was calculated based on local rainfall and energy-intensity relationships (Vieira et al., 2014; Morgan, 2001) as:

$K E=35.9\left(1-056 e^{-0.0341}\right)$

where I, is the typical rain intensity $\left(\mathrm{mm} \mathrm{h}^{-1}\right)$. The runoff coefficient correlates the volume of runoff and precipitation, specifying the percentage of rainfall that appears as runoff from a specific surface area. The runoff coefficient is large for areas with low infiltration and high runoff and is quite small for well-vegetated areas.

\subsubsection{Sediment and OM losses}

Sediment concentrations in the runoff samples were determined by first vigorously shaking the 1.5-L bottles and then pouring the contents over filter paper $330 \mathrm{~mm}$ in diameter with a particle-retention size of 12-15 $\mu \mathrm{m}$ (VWR International, Leuven). The filters were ovendried at $105^{\circ} \mathrm{C}$ for $24 \mathrm{~h}$. The OM contents of the eroded sediments were determined using the loss-on-ignition method (Ball, 1964). The resulting weight loss was used to compute the OM content of the mineral soil.

\subsection{Data analysis}

All statistical analyses were performed using SPSS 22.0. Kolmogorov-Smirnov (KS) tests indicated that the data for runoff and soil loss for the rains were not normally distributed, so we tested for significant differences among sites using the non-parametric Kruskal-Wallis and Mann-Whitney U-tests. Components with eigenvalues over Keiser's criterion of 1 were extracted, and differences were considered statistically significant at $p<0.05$. We also ran correlation and regression analyses on the variables. A principal component analysis (PCA) of soil cover, runoff, soil losses, rainfall and SWR was conducted to convert data of possibly correlated variables into a set of values of linearly uncorrelated variables to identify the key factors affecting runoff and soil erosion.

Data from the entire study period was analysed to assess whether (i) the three slope positions (upper, middle, and lower) and (ii) the fire frequencies ( $D, S D$, and $C$ ), caused differences in runoff, erosion, and OM losses between September 2012 and September 2014. The impacts of the five cover types immediately after the wildfire (September 2012) and two years later were also analysed. The correlation between the amount and intensity 
of rain and the observed runoff and erosion rates were separately determined for each slope by linear regression analysis. Seasonal measurements were distributed over a period of three months in this study.

\subsection{Results}

\subsubsection{Soil cover}

The initial surface cover differed significantly between sites, with D plots ( $>90 \%$ ) covered by ash, SD plots covered mainly by litter $(>40 \%)$ and ash $(>10 \%)$, and the unburnt $C$ plots totally covered by litter and shrubs, mainly $P$. tridentatum.

\subsubsection{Bulk density and change in soil cover}

The dry bulk density $(0-5 \mathrm{~cm})$ of each site was not significantly affected by fire frequency (Table 2.2) and averaged $0.98 \pm 0.18,0.92 \pm 0.18$, and $0.99 \pm 0.12 \mathrm{~g} \mathrm{~cm}^{-3}$ for the $\mathrm{D}, \mathrm{SD}$, and $C$ sites, respectively.

The vegetation cover increased in all sites during the study period. Resprouting shrubs in the $D$ sites represented 16 and $48 \%$ of the cover 10 and 21 months (June 2014) after a fire, respectively. The vegetation cover in SD sites increased from $7 \%$ in the first year after fire to $49 \%$ in the second year. The corresponding increase in the $\mathrm{C}$ sites was from 20 to $62 \%$. Stone cover increased in D from $13 \%$ in year 1 to $33 \%$ in the second year due to the ash washed away and in the SD sites from 2 to 6\% (Figure 2.3). The amount of cover did not differ significantly among the three sections of the slopes (up, middle, down) during the study period. Ash cover decreased at all sites in the burnt areas within two years, from 80 to $0 \%$ and from 43 to $13 \%$ for the D and SD sites, respectively. The ash layer decreased the most from September 2013 to January 2014, which corresponded with the period of highest rain intensity.

The depths of the ash layers in the $D$ sites were correlated $(p<0.05, r=0.51)$ with the soil losses. Litter covers in the SD sites were highly correlated $(p<0.05)$ with the soil losses. Surface cover and erosion are normally negatively correlated, but the covers (ash and litter) were not significantly correlated $(p>0.05)$ with runoff, sediment transport, or OM losses. 


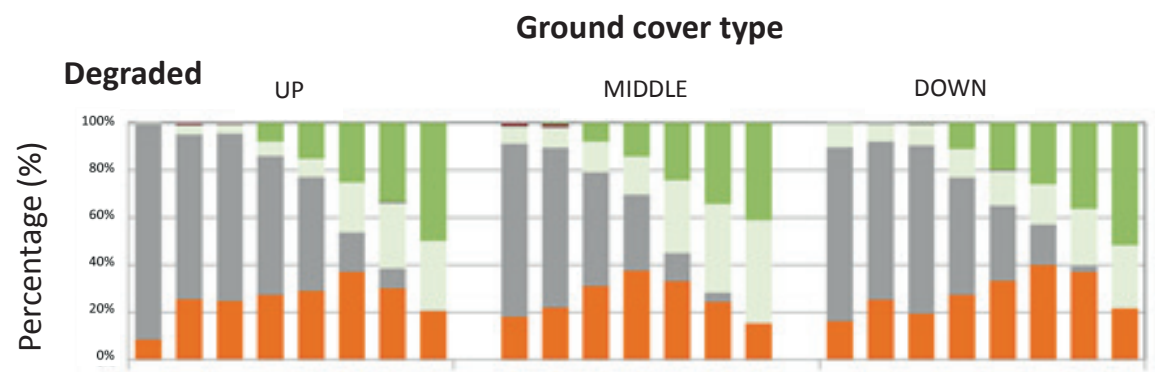

Semi-degraded
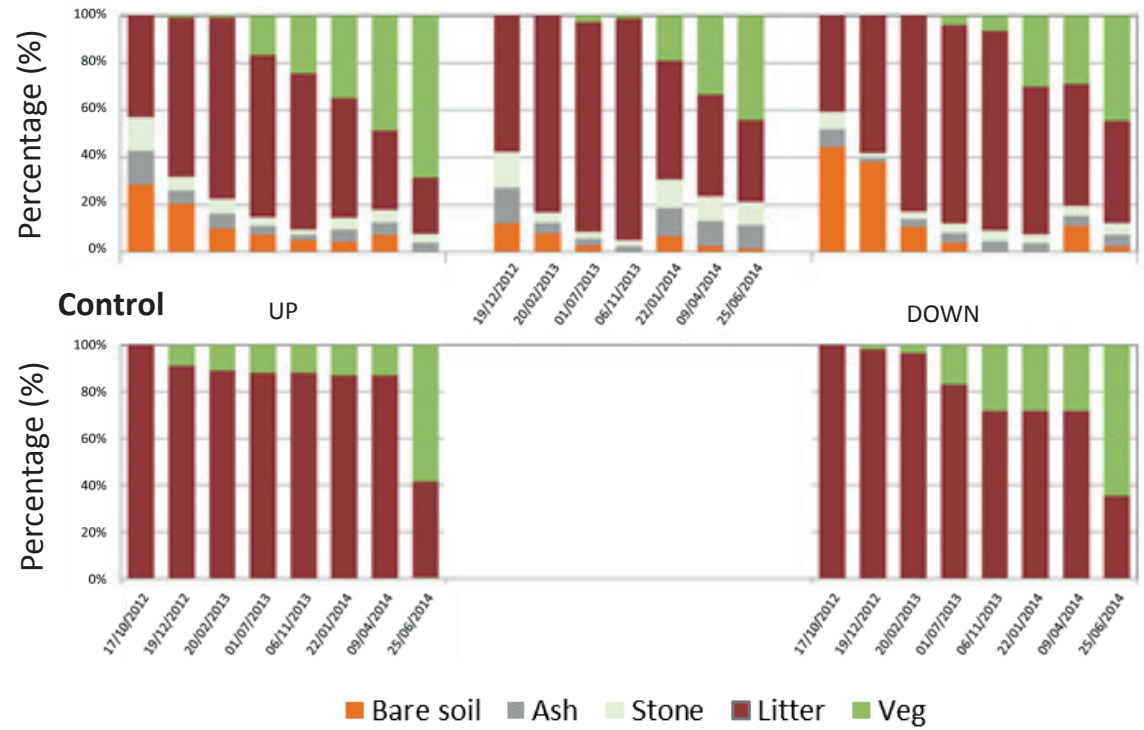

Figure 2.3 Temporal changes in ground cover (\%) during this study in the degraded, semi-degraded and control site. (No data collected for the middle section of the control site).

\subsubsection{Soil moisture and soil water repellency}

Soil moisture content differed markedly between the $D$ and SD sites. The average soil moisture content was significantly lower in the SD sites $(11.04 \pm 5.07)$ than in the D sites $(17.87 \pm 4.34)$ in the first year after the fire, from October to December 2012. The situation, however, was reversed in the dry season, with soil moisture content averaging $12.34 \pm 3.83$ in the D sites and $15.09 \pm 2.57$ in the SD sites (Figure 2.4). D2 and SD2 were randomly chosen as representatives of the $D$ and SD sites. The soil moisture contents in the $C$ sites are not presented due to the high amounts of surface covers and shrubs, which were stopped rainfall infiltration in to the soil. 

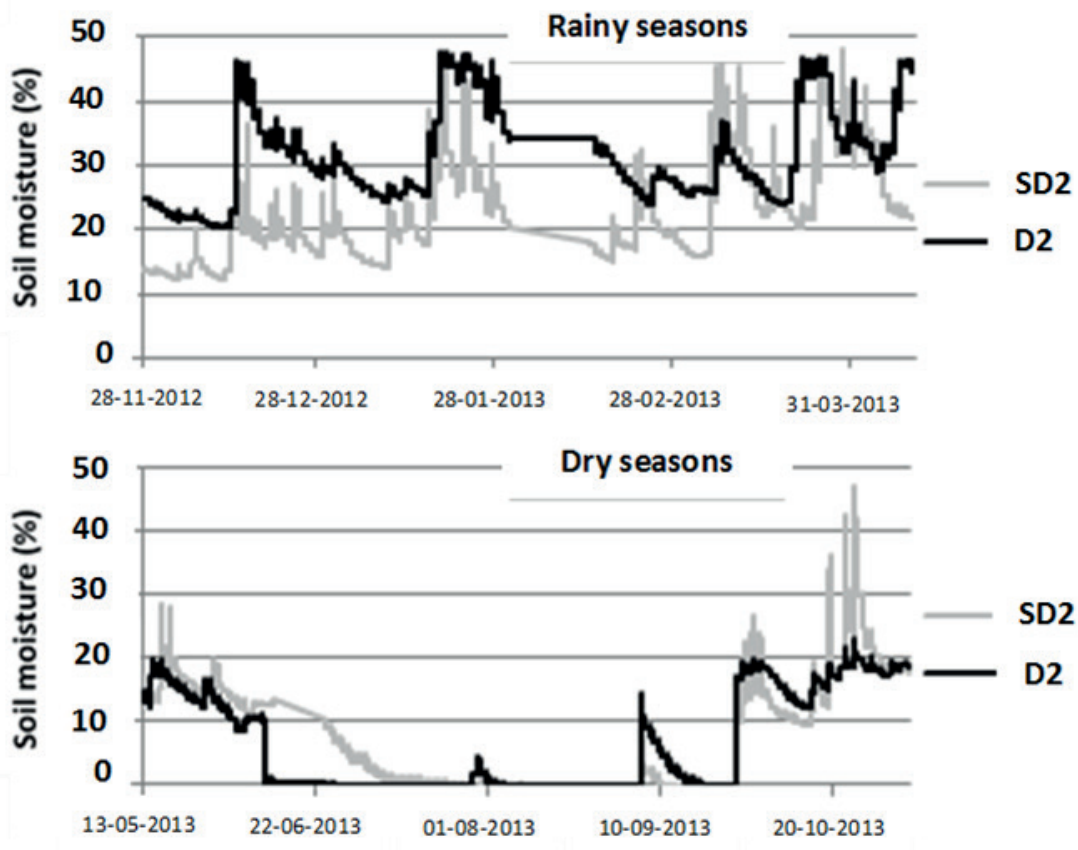

Figure 2.4 Example of soil moisture change (\%) against time in degraded (D) and semi-degraded (SD) plots.

The soils at depths of $2.5-3 \mathrm{~cm}$ were slightly more repellent in all sites. SD had a higher frequency of extreme SWR, followed by $D$ and $C$ sites. The surface SWR measurements showed high hydrophobicity in the D and SD sites in December 2012 and spring 2013, with class 6 and 5, respectively. SWR fluctuated during the study period. The water-repellency classes did not change during the second year but became more moderate in the $D$ sites and decreased to class 5 late in the second year. SWR in the SD sites increased to class 7 in summer 2013 and then decreased to class 6 in the second year after the fire. Repellency was stable over the study period in the long unburnt sites at class 5 . 
Table 2.3 Frequency distribution of repellency test by molarity of ethanol droplet (MED)

\begin{tabular}{cccc}
\hline \multirow{2}{*}{ Period } & Degraded & Degree of Hydrophobicity & \\
\cline { 2 - 4 } & Strongly hydrophobic & Very strongly hydrophobic & Strongly hydrophobic \\
\hline Aut-12 & Very hydrophobic & Very strongly hydrophobic & Strongly hydrophobic \\
Win-12 & Slightly hydrophobic & Very strongly hydrophobic & Strongly hydrophobic \\
Spr-13 & Strongly hydrophobic & Extremely hydrophobic & Strongly hydrophobic \\
Sum-13 & Moderate hydrophobic & Strongly hydrophobic & Strongly hydrophobic \\
Aut-13 & Slightly hydrophobic & Slightly hydrophobic & Strongly hydrophobic \\
Win-13 & Moderate hydrophobic & Very strongly hydrophobic & Strongly hydrophobic \\
Spr-14 & Moderate hydrophobic & Extremely hydrophobic & Strongly hydrophobic \\
Sum-14 & & &
\end{tabular}

\subsubsection{Rainfall amounts and rain intensity ( $\left.I_{30}\right)$}

A total of $2917 \mathrm{~mm}$ of rain fell during the 70 events from 4 October 2012 to 25 September 2014. Of this total, $1289 \mathrm{~mm}$ fell during the first year after the fire and $1628 \mathrm{~mm}$ during the second year (Table 2.4). Rainfall and maximum $I_{30}$ per rain are plotted in Figure 2.5. Rainfall was particularly high on eleven occasions, exceeding $100 \mathrm{~mm}$. These heavy rains fell mostly during the autumn and winter. The heavy rains in September, October, and late December 2013 had the highest rain intensities $\left(25-30 \mathrm{~mm} \mathrm{~h}^{-1}\right)$. Nearly $64 \%$ of the $1628 \mathrm{~mm}$ of rain that fell in the second year fell within this period (Figure 2.5). 


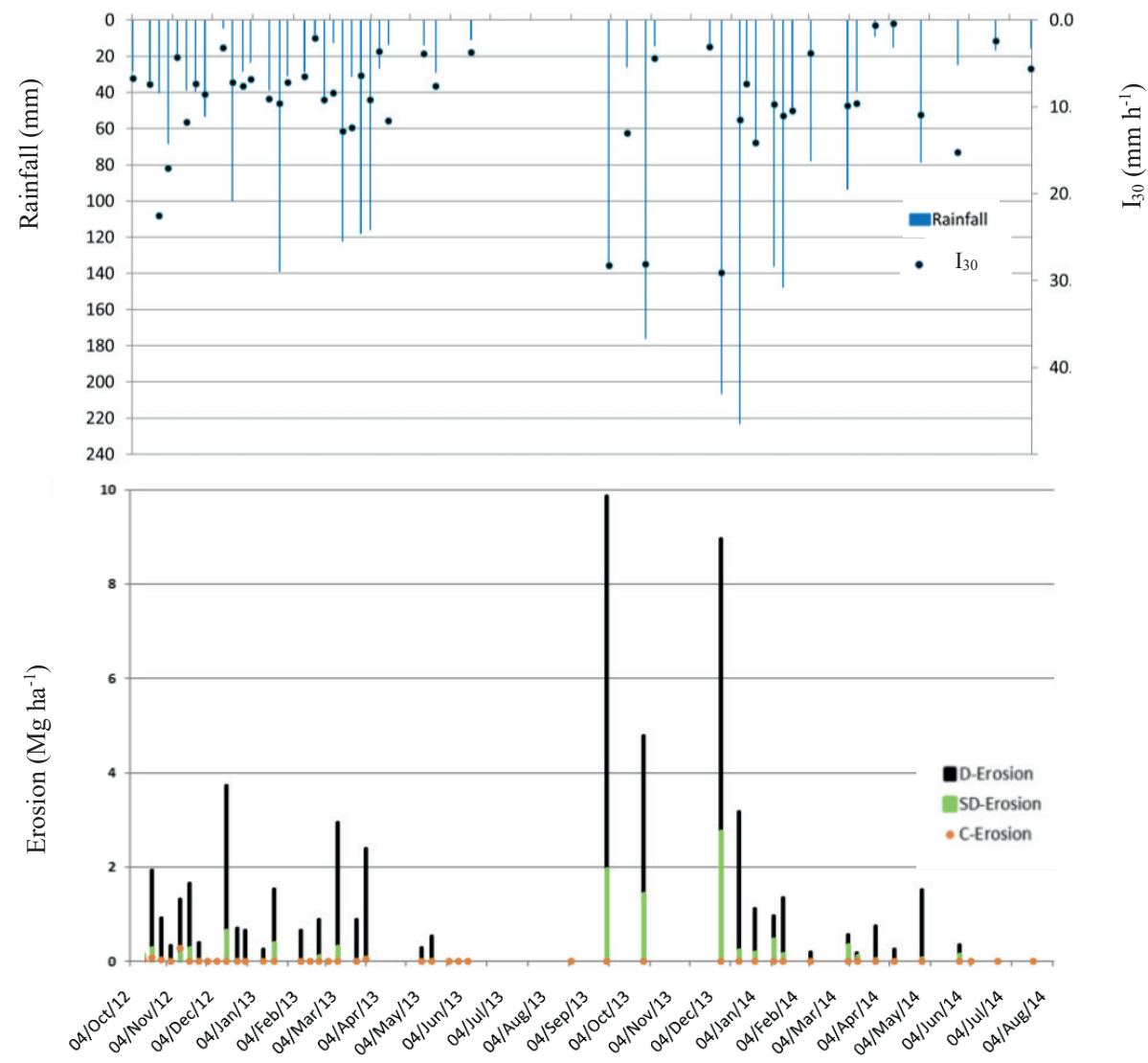

Figure 2.5 Erosion rates per event $\left(\mathrm{Mg} \mathrm{ha}^{-1}\right)$ for degraded (D), semi-degraded (SD) and control (C) site from October 2012 to August 2014.

\subsubsection{Annual runoff, soil erosion, and OM losses}

The annual runoffs for the first and second post-fire years were significantly $(p<0.05)$ and nearly four-fold higher in the D than in the SD sites (411 vs. $115 \mathrm{~mm}$ and $733 \mathrm{vs.} 197 \mathrm{~mm}$, respectively). Runoff from the $C$ sites $(51 \mathrm{~mm})$, however, was significantly lower $(p<0.05)$ than that in both the $D$ and SD sites. Runoff increased as $I_{30}$ increased in the second year, to $733 \mathrm{~mm}$ for the $D$ and $197 \mathrm{~mm}$ for the SD sites, but to only $67 \mathrm{~mm}$ in the C sites. Runoff from the $C$ slopes was again significantly lower $(p<0.05)$ than that from the D and SD slopes. Soil and $\mathrm{OM}$ losses differed significantly with fire frequency. The losses were significantly higher $(p<0.05)$ in the D sites compared to the SD and C sites for both the first and the second years after the fire (Table 2.4). 
Table 2.4 Average annual rainfall, runoff, soil erosion and OM losses. Lowercase letters indicate significant differences ( $p<0.05)$ (Mann-Whitney U-test) ( $a>b>c)$.

\begin{tabular}{|c|c|c|c|c|c|c|}
\hline & Site* & $\begin{array}{c}\text { Rainfall } \\
\text { (mm) }\end{array}$ & Runoff (mm) & $\begin{array}{c}\text { Runoff- } \\
\text { coefficient (\%) }\end{array}$ & $\begin{array}{c}\text { Soil losses } \\
\left(\mathrm{Mg} \mathrm{ha}^{-1}\right)\end{array}$ & $\begin{array}{c}\text { OM loss } \\
\left(\mathrm{Mg} \mathrm{ha}^{-1}\right)\end{array}$ \\
\hline \multirow{3}{*}{ 1st Year } & D & & $411 a$ & $25.3 a$ & $2.57 a$ & $1.29 a$ \\
\hline & SD & 1289 & $115 b$ & $6.3 b$ & $0.31 b$ & $0.14 b$ \\
\hline & $\mathrm{C}$ & & $51 c$ & $4.0 \mathrm{c}$ & $0.04 c$ & $0.03 c$ \\
\hline \multirow{3}{*}{ 2nd Year } & D & & $733 a$ & $40.3 a$ & $3.79 a$ & $2.32 a$ \\
\hline & SD & 1628 & $197 b$ & $10.0 \mathrm{~b}$ & $0.84 b$ & $0.37 b$ \\
\hline & C & & $67 c$ & $2.4 c$ & $0.00 c$ & $0.00 c$ \\
\hline
\end{tabular}

* Site abbreviation: Degraded (D), Semi-degraded (SD) and Control (C)

Runoff, soil erosion, and OM losses were all positively correlated with rain intensity. The correlation coefficients (Pearson) at the $D$ sites between runoff and $I_{30}$ were $0.62,0.60$, and 0.65 and between soil losses and $\mathrm{I}_{30}$ were $0.52,0.76$, and 0.65 for D1, D2, and D3 sites, respectively. The correlation coefficients at the SD sites between runoff and $I_{30}$ were 0.40 , 0.48 , and 0.47 and between soil losses and $I_{30}$ were $0.52,0.54$, and 0.51 for SD1, SD2, and $\mathrm{SD} 3$, respectively. Correlations for the $\mathrm{C}$ sites were not significant due to the low runoff rates.

\subsubsection{Temporal patterns in runoff and erosion}

The temporal variation in rainfall, runoff, and sediment losses were summarised by year in Table 2.4 and by season in Table 2.5. Seasonal runoff varied strongly in the $D$ sites, ranging from only $1.29 \mathrm{~mm}$ during the driest season (summer 2013) to slightly under $67 \mathrm{~mm}$ in autumn 2013 and $70.69 \mathrm{~mm}$ during winter 2013. Runoff in the D sites averaged $23.4 \mathrm{~mm}$ in spring 2013, much lower than the amounts in the autumn or winter of the second year, by 66.9 and $70.69 \mathrm{~mm}$, respectively. Runoff in the SD sites varied from $0.09 \mathrm{~mm}$ during the driest season to $20.7 \mathrm{~mm}$ in autumn 2013 and $19.4 \mathrm{~mm}$ during winter 2013. The spring average volumes in both years were 5.5-6 mm. As expected, runoff was always less in the SD than in the D sites and, not surprisingly and regardless of the season, runoff in $C$ sites was always significantly less than in either the D or SD sites.

Erosion and OM losses were highest during autumn and winter 2013 for both the D and SD sites, corresponding to the periods with the highest rain intensities of 18.67 and $14.98 \mathrm{~mm}$ $h^{-1}$, respectively (Table 2.5$)$. Seasonal variation in erosion was significantly stronger $(p<0.05)$ in the $D$ than the SD sites, except during the summer. For example, erosion volumes in autumn and winter were 0.85 and $0.89 \mathrm{Mg} \mathrm{ha}^{-1}$ in 2013 and 4.88 and $3.12 \mathrm{Mg} \mathrm{ha}^{-1}$ in 2014, respectively, in the $D$ sites in comparison to 0.12 and $0.14 \mathrm{Mg} \mathrm{ha}^{-1}$ in 2013 and 1.46 and 0.76 $\mathrm{Mg} \mathrm{ha}^{-1}$ in 2014, respectively, in the SD sites. OM losses in the first and second years were significantly higher in the $D$ than in the SD sites. Erosion and OM losses were significantly lower for the $\mathrm{C}$ sites. OM losses were higher in the second year due to the heavy rains in 
September, October, and December 2013, which had maximum rain intensities and caused more than $70 \%$ of the total soil loss.

Table 2.5 Total seasonal runoff, soil erosion and organic matter (OM) loss for degraded (D), semi-degraded $(S D)$ and control (C) sites. Lowercase letters indicate significant differences ( $p<0.05)$, ( $a>b>c)$.

\begin{tabular}{|c|c|c|c|c|c|c|c|c|}
\hline & \multirow{2}{*}{$\begin{array}{c}\text { Rainfall } \\
\text { (mm) }\end{array}$} & \multirow{2}{*}{$\begin{array}{c}\mathrm{l}_{30} \\
\left(\mathrm{~mm} \mathrm{hr} \mathrm{hr}^{-1}\right)\end{array}$} & \multicolumn{3}{|c|}{ Runoff (mm season-1) } & \multicolumn{3}{|c|}{ Runoff coef (\%) } \\
\hline & & & D & SD & C & D & SD & C \\
\hline Aut-12 & 322.2 & 11.1 & $12.26 \mathrm{a}$ & $4.60 \mathrm{~b}$ & $4.71 \mathrm{~b}$ & 28 & 11 & 10 \\
\hline Win-12 & 455.0 & 5.9 & $16.88 \mathrm{a}$ & $4.27 \mathrm{~b}$ & $0.39 c$ & 26 & 5 & 1 \\
\hline Spr-13 & 482.5 & 8.7 & $23.40 \mathrm{a}$ & $5.81 \mathrm{~b}$ & $1.60 \mathrm{~b}$ & 29 & 6 & 4 \\
\hline Sum-13 & 20.7 & 4.2 & $1.29 \mathrm{a}$ & $0.09 a$ & $0.00 \mathrm{~b}$ & 17 & 1 & 0 \\
\hline Aut-13 & 387.1 & 18.7 & 66.95 a & $20.68 b$ & $15.58 \mathrm{~b}$ & 33 & 11 & 8 \\
\hline Win-13 & 868.2 & 14.9 & 70.69 a & $19.44 \mathrm{~b}$ & $3.02 \mathrm{c}$ & 40 & 10 & 2 \\
\hline Spr-14 & 317.0 & 5.9 & 27.44 a & $5.49 \mathrm{~b}$ & $0.87 \mathrm{~b}$ & 52 & 11 & 1 \\
\hline Sum-14 & 63.9 & 6.8 & $3.51 \mathrm{a}$ & $1.11 \mathrm{a}$ & 0.08 a & 18 & 5 & 0 \\
\hline
\end{tabular}

Table 2.5 Continued.

\begin{tabular}{|c|c|c|c|c|c|c|c|c|}
\hline & \multirow{2}{*}{$\begin{array}{c}\text { Rainfall } \\
\text { (mm) }\end{array}$} & \multirow{2}{*}{$\begin{array}{c}\mathrm{l}_{30} \\
\left(\mathrm{~mm} \mathrm{hr} r^{-1}\right)\end{array}$} & \multicolumn{3}{|c|}{ Erosion $\mathrm{Mg} \mathrm{ha}^{-1}$ season $^{-1}$} & \multicolumn{3}{|c|}{ OM loss $\mathrm{Mg}$ ha-1 $^{-1}$ season ${ }^{-1}$} \\
\hline & & & D & SD & C & D & SD & C \\
\hline Aut-12 & 322.2 & 11.1 & $0.85 \mathrm{a}$ & $0.12 \mathrm{~b}$ & $0.02 \mathrm{c}$ & $0.43 a$ & $0.09 \mathrm{~b}$ & $0.02 c$ \\
\hline Win-12 & 455.0 & 5.9 & $0.89 a$ & $0.14 \mathrm{~b}$ & $0.00 \mathrm{c}$ & $0.44 a$ & $0.04 \mathrm{~b}$ & $0.00 \mathrm{c}$ \\
\hline Spr-13 & 482.5 & 8.7 & $1.23 \mathrm{a}$ & $0.08 \mathrm{~b}$ & $0.01 \mathrm{c}$ & $0.62 \mathrm{a}$ & $0.02 \mathrm{~b}$ & $0.00 \mathrm{c}$ \\
\hline Sum-13 & 20.7 & 4.2 & $0.01 \mathrm{a}$ & $0.00 \mathrm{a}$ & $0.00 \mathrm{a}$ & $0.00 \mathrm{a}$ & $0.00 \mathrm{a}$ & $0.00 \mathrm{a}$ \\
\hline Aut-13 & 387.1 & 18.7 & $4.88 \mathrm{a}$ & $1.46 \mathrm{~b}$ & $0.00 \mathrm{c}$ & $3.00 \mathrm{a}$ & $0.54 \mathrm{~b}$ & $0.00 \mathrm{c}$ \\
\hline Win-13 & 868.2 & 14.9 & $3.12 \mathrm{a}$ & $0.76 b$ & $0.00 \mathrm{c}$ & $1.92 \mathrm{a}$ & $0.28 \mathrm{~b}$ & $0.00 \mathrm{c}$ \\
\hline Spr-14 & 317.0 & 5.9 & $0.58 \mathrm{a}$ & $0.10 \mathrm{a}$ & $0.00 \mathrm{c}$ & $0.35 a$ & $0.05 a$ & $0.00 \mathrm{c}$ \\
\hline Sum-14 & 63.9 & 6.8 & $0.09 a$ & $0.04 \mathrm{a}$ & $0.00 \mathrm{a}$ & $0.05 a$ & $0.02 a$ & $0.00 \mathrm{a}$ \\
\hline
\end{tabular}

\subsubsection{Spatial variations in runoff and erosion}

Variations in runoff and soil losses in the different sections of the slopes and in the sites for the first and second years after the wildfire are shown in Figure 2.6. Runoff, soil erosion, and OM loss differed significantly in the frequently burnt sites due to both the surface cover and rain intensity. Different volumes were collected from the plots (upper, middle, and lower sections), but the analysis found no statistical differences ( $p>0.05)$ for runoff, soil erosion, or OM losses. For example, average soil losses for the plots in the middle sections were $2.57 \pm 0.35$ and $4.74 \pm 1.48 \mathrm{Mg} \mathrm{ha}^{-1}$ for the first and second years, respectively, for the $D$ sites and were $0.07 \pm 0.12$ and $0.63 \pm 0.41 \mathrm{Mg} \mathrm{ha}^{-1}$ in the first and second years, respectively, for the SD sites. D2 had the highest soil losses of $3.04 \pm 0.43 \mathrm{Mg} \mathrm{ha}^{-1}$ in the first year after the fire and $5.13 \pm 0.25 \mathrm{Mg} \mathrm{ha}^{-1}$ in the second year. D3 had a large stone below the middle section of the slope with only a few centimetres of soil, which caused an increase in runoff and soil losses (Figure 2.7). Soil cover did not change significantly from the bottoms to the tops of the slopes in the sites within the same degraded state, but the covers differed significantly between the $D, S D$, and $C$ sites. 

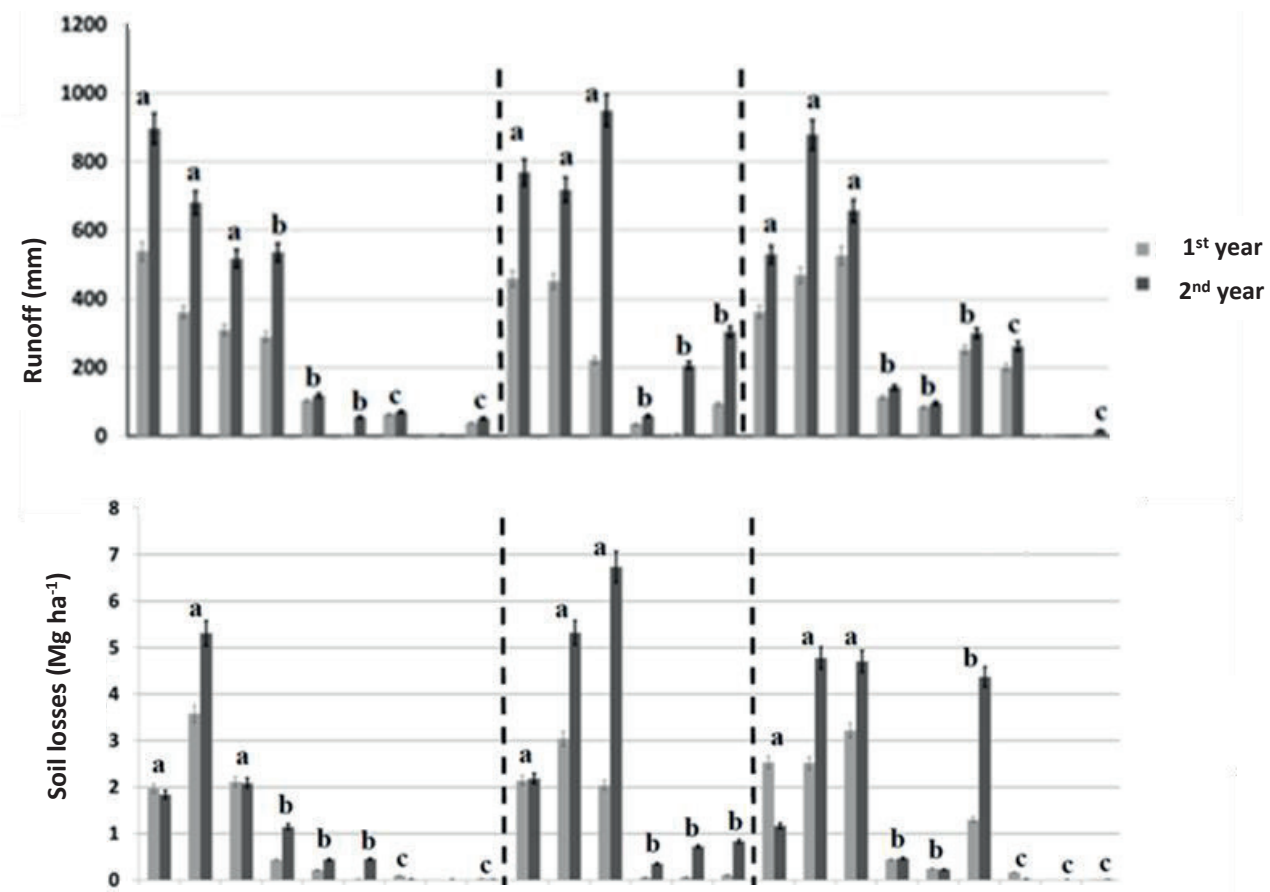

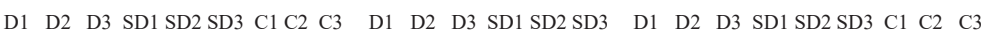

Up

Middle

Down

Figure 2.6 Runoff and soil losses per year for D, SD and Control plots and slope sections. Lowercase letters indicate significant differences $a>b>c$. (1 $1^{\text {st }}$ year: Sep $2012-A u g 2013,2^{\text {nd }}$ year: Sep $2013-A u g$ 2014)

\subsubsection{Key factors influencing runoff and soil loss}

SWR was consistently higher in the SD than in the D sites and in both cases, was negatively correlated with soil moisture content ( $r=-0.31$ and -0.42 , respectively). Rainfall, $1_{30}$, surface cover, soil moisture content, and SWR explained 77 and $79 \%$ of the variance in the data in D2 and SD2, respectively. These sites were good indicators of the conditions in the D and SD sites. The principal components analysis explained 77 and $79 \%$ of the variance in the data for D2 and SD2 respectively. The main components in D2 were $I_{30}(35 \%)$, soil cover (23\%), and soil moisture content (19\%), and the main components in SD2 were soil cover (40\%), soil moisture content (25\%), and rainfall (14\%) (Figure 2.7$)$. 
Rainfall and soil loss in the D sites were positively correlated and soil cover and soil moisture content were negatively correlated with $I_{30}$. SWR was positively correlated with soil cover, but soil cover was negatively correlated with soil moisture content. Runoff and soil losses in the SD sites were negatively correlated with both soil cover and soil moisture content. Litter was the main factor which is protecting soil against erosion in the $\mathrm{C}$ sites. Data for the $\mathrm{C}$ sites were not included in the principal component analysis figure due to the lack of erosion in these sites during the study period.
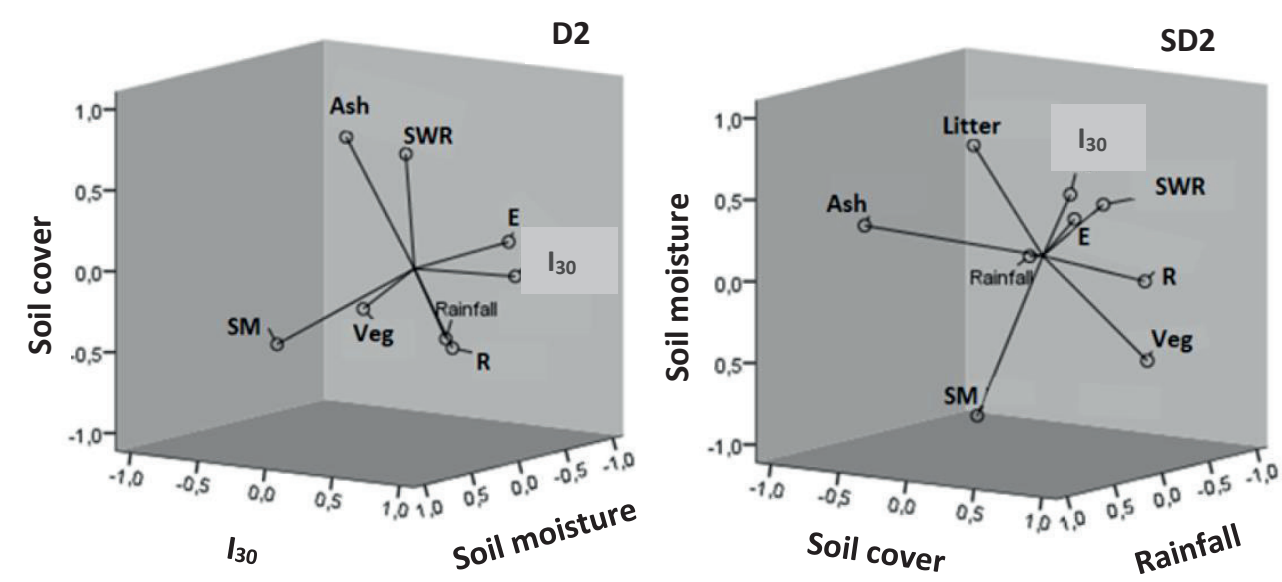

Figure 2.7 PCA plots and the main components for the Degraded-2 (D2) and Semi-degraded-2 (SD2) sites. Rainfall, rainfall intensity $\left(I_{30}\right)$, runoff $(R)$, sediment losses $(E)$, soil moisture $(S M)$, soil water repellency (SWR), soil cover (Ash, Litter, Vegetation).

\subsection{Discussion}

\subsubsection{Effect of rainfall and rain intensity on runoff and soil erosion}

Prolonged dry periods in summer and heavy rains in autumn and winter are responsible for significant annual variation in runoff and soil erosion in Mediterranean regions. Wildfires have become common in Mediterranean forests particularly in summer, and mainly due to the low surface moisture and expanding human activities (González-Pelayo et al., 2010; Cerdà and Lasanta, 2005). The characteristics of autumnal post-fire rains, especially rain intensity, can consequently have an impact on runoff trends.

Many studies have reported that the volumes of runoff and sediment loss are ultimately linked to high I $_{30}$ (Moody et al., 2013; Robichaud et al., 2013; Cannon et al., 2011; Dunkerley, 
2010; Moody et al., 2008; Robichaud et al.,2007; Mayor et al., 2007; Spigel and Robichaud, 2007). These infrequent but intense rainstorms can cause high runoffs and soil losses within short periods. Our study found the same trend, with the three high rain intensities in October, November, and December 2013 producing the highest runoff volumes and interrill sediment losses after the wildfire (Figure 2.5). These effects depended strongly on time, site properties, and changes in soil conditions over time after the fire. Rain intensity clearly had a major impact on runoff and erosion rates. Soil cover and soil moisture content also affected runoff and erosion, in agreement with the findings of other studies (Malvar et al., 2015b; Cerdà, 2005). Our results indicated that factors such as SWR and rainfall also played key roles in runoff and soil erosion.

Some researches mentioned that high rain intensity can sometimes be mitigated by high infiltration, but infiltration is not commonly high and can be quite low after a fire, especially due to the SWR layer in recently burnt areas (Malvar et al., 2015a; Dekker et al., 2000; DeBano, 1998; DeBano, 1981). Hydraulic conductivity in a burnt forest in Australia was very spatially variable due to the blocking of macropores in the soil, The amount of infiltration in recently burnt areas can be dependent mainly on the generation of surface-soil hydrophobicity (Shakesby and Doerr, 2006; Ferreira et al., 2005a). The results of the present study are consistent with those of some previous studies of the development of SWR after the 2012 fire. Our study also provides interesting insights into fire frequency and its effect on SWR and subsequent runoff and erosion. Repellency was initially the same in the D and SD sites, but this repellent layer washed away very quickly in the D sites due to the lack of surface cover and to the high rainfall and runoff. Surface cover, however, played an important role in the SD sites to maintain this repellent cover layer over time, even for one year after the fire. Our study thus demonstrated a direct effect of rain intensity on runoff and erosion even long after the fire.

\subsubsection{Risk of post-fire erosion in burnt pine plantations}

The impacts of fire on sediment yield and vegetational recovery have been well studied, but the effects of repeated fires and the impacts on maritime pine plantations, which are widespread in Portugal, have received less attention (Malkisnon et al., 2011).

Our study is comparable to that by (Prats et al., 2012), which compared mulched and unmulched stands of burnt pine and eucalyptus at a slope-plot scale in a similar area of Portugal using the same procedures and measuring techniques for SWR and soil moisture content. The plots with and without mulch were comparable to our SD plots that were covered with natural mulch and the D plots that had no mulch cover, respectively. Prat's 
research reported that the average runoffs and sediment losses did not differ significantly between the control and mulched plots in the pine site, but the control plots tended to produce less runoff and sediments. Soil erosion and OM losses differed significantly between the $D$ and SD sites in our study. Vegetation recovery relatively quick in the Mediterranean regions, while repeated fires are the reasons to reduce vegetation cover followed by a higher exposure of the soil surface, which cause the chance of higher runoff (Wittenberg and Inbar, 2009a). Repeated fires may thus increase the risk of erosion and OM losses by removing the humus and cover layers. Soil and OM losses in the D sites were quite high due to the lack of cover, high $\mathrm{I}_{30}$, and low soil moisture content, and the losses in the SD sites were lower mainly because of the soil cover.

Runoff is frequently correlated with SWR, and increased ground exposure (Moody et al., 2013; Shakesby et al., 2011; Larsen et al., 2009; Benavides-Solorio and MacDonald, 2005), reduced vegetational canopy (Stoof et al., 2012), and the absence of any surface-water storage capacity, and all can contribute to erosion. Our study found that fire frequency was also an important factor for producing SWR and lack of cover, which result in conditions much more susceptible to higher runoff and increased soil erosion and OM losses.

Some previous studies have indicated that the sediment load is the highest in the first few months after a fire (Shakesby, 2011; Mayor et al., 2007). Our study provided additional insight and conflicting results. The low sediment and OM losses in the SD sites could be explained by the much higher litter cover relative to that in the D sites, which played a large role in reducing sediment losses (Figure 2.2) (Malvar et al., 2015a; Keesstra et al., 2016; Prats et al., 2012). Our study also indicated that the pre-fire condition of a site was an important factor in sediment losses and that sediment loads can be higher in subsequent years following a fire, especially after a dry summer followed by heavy rain.

Our research is agreed with previous research about the effect of fire frequency on increasing the soil erosion. In such an environment like Mediterranean region, the rates of regeneration and restoration processes vary when the number of fires increases (Wittenberg and Inbar, 2009a). In our research, significantly more soil was lost from the D than the SD sites (Figure 2.5) in the first few months after the fire, indicating that the prefire state of an area could have an impact on the amount of sediment loss. Our study also showed that the higher amounts of soil erosion and OM losses were not only due to higher runoff but, were mainly due to rain intensity, type of soil cover, and soil moisture content. The significant differences in sediment load between the D and SD sites agreed with the findings by (Wittenberg and Inbar, 2009a) and (Malkisnon et al., 2011). 
Other studies have suggested that initial soil losses can be quite high during the first two years after a fire and then swiftly decline due to broad recovery of the vegetation (Wittenberg and Inbar, 2009a; Pausas et al., 2008), Our study supports these findings. The vegetation grew rapidly in the $D$ sites in response to climatic factors such as rate and amount of rain, probably due to the lack of cover following repeated fires. In contrast, this response was significantly lower in the SD sites, due to the presence of litter cover. Recovery, though, fluctuates at larger spatial scales due to climatic variances and may also differ locally based on slope aspect (Cerdà, 1999; Inbar et al., 1998), soil properties and conditions (Giovannini et al., 1990; Kutiel and Shaviv, 1992), climatic circumstances after a fire, and vegetational type (Mayor et al., 2007).

\subsubsection{Post-fire management and its role in runoff and soil erosion}

A review of wildfires in the Mediterranean Basin by (Pausas et al., 2008) indicated that high wildfire frequencies are the effect of two main trends: (i) the abandonment of large agricultural areas within the last sixty years, which led to more vegetational cover (Moreira et al., 2011) increased human activities due to population growth, which contributed to the risk of fire ignitions (Shakesby, 2011). In fact, many species of vegetation have developed responses to fire (Malkisnon et al., 2011; Pausas et al., 2008; Naveh, 1974). These developments have arisen with local long-term fire management systems. Updates to the classifications of fire management may thus have various effects on vegetational cover other than the local geomorphic routes (Malkisnon et al., 2011).

This study investigated the common theory that post-fire rains can be a major factor in increasing the amount of erosion in burnt Mediterranean areas. The warmer seasons and drier conditions, especially in summer, predicted by global climate change may increase the rate of wildfires and the risk of post-fire soil degradation (Shakesby, 2011). These variations will increase the vulnerability of Mediterranean drylands to post-fire hazards (Mayor et al., 2007). The results of our study provide additional insights into fire and these vulnerabilities that can help for making decisions on landscape management to decrease the risk of fire and to rehabilitate post-fire conditions. Mayor et al. 2007 have stated that Mediterranean environments are generally well known as areas resilient to fire. Several circumstances, e.g. post-fire drought, south-facing slopes, fire severity, and vegetational type, however, may excessively stress the ecosystems and decrease plant recovery and increase soil degradation, with subsequently higher risks of runoff and spilling over in downstream. Runoff, soil erosion, and OM losses increased over time in this study, especially during the autumn and winter of the second year after the wildfire. Hydrological behaviour and 
especially changes in the surface conditions of a burnt catchment can quickly revert to the state of unburnt areas.

A key uncertainty in this study was the severity of the wildfires that occurred in the different sites and probably also in the control sites before 1975. More information about the severity of earlier fires would likely allow more conclusions to be drawn from the data for soil moisture and SWR.

\subsection{Conclusions}

This study of the effect of fire frequency on runoff, soil erosion, and OM losses at the microplot scale in north-central Portugal provided the following conclusions:

- Fire affected runoff and soil losses after erosive rainstorms shortly after a fire but also after droughts in subsequent years, which reduced vegetational recovery and rendered the catchment prone to periods of highly erosive rains;

- Repeated wildfires strongly increased the runoff coefficient and the risk of spilling over in downstream regions, likely due to on-going changes in soil properties and lack of vegetational cover;

- OM loss was extremely high (almost half of the soil losses) in the $4 x$ burnt sites due to the transport of ash in the runoff;

- Litter cover and rain intensity $\left(I_{30}\right)$ had the strongest effects on runoff, soil erosion, and OM losses.

Increased understanding of the post-fire dynamics in areas which were experiencing frequent wildfire can contribute to the development of effective pre- and post-fire management to protect, repair, and promote the recovery of affected landscapes. 


\section{Acknowledgements}

This research was supported and carried out in the framework of the CASCADE project (FP7 - ENV.2011.2.1.4-2/283068), which was funded by the European Union. The University of Aveiro, CESAM team is acknowledged for providing a nice work environment and access to relevant facilities. The authors also gratefully acknowledge Astrid Mous, Ayşe Betül Baytürk, Ariët Kieskamp, Daniela Varandas, Liliana Santos, Ana-Isabel Machado and Martinho Martins for their help with the fieldwork and laboratory analyses, Demie Moore for inputs to improve an earlier version of this manuscript, and SAR-UAF Netherlands for their kind overall support. 


\title{
3. Effects of fire occurrence and recurrence on nitrogen and phosphorus losses by overland flow in maritime pine plantations in north- central Portugal
}

\begin{abstract}
Wildfires have increased in Portugal in the recent decades, raising concerns about the long-term negative effects of fire recurrence on the environment. We studied the impacts of recurrent fires on the nitrogen $(N)$ and phosphorus $(P)$ content of mineral soil in the first year after a fire. Total nitrogen (TN) and phosphorus (TP) losses by runoff were also evaluated within the two years after a fire. Nine sites in a maritime pine forest were selected following a large wildfire in September 2012 that affected roughly 3000 ha of the Viseu municipality. Three sites had been burnt four times in the past 40 years (4x), three sites had been burnt once in September 2012 (1x), and three control sites had not been burnt (0x). Runoff was collected in 9 micro-plots $\left(0.25 \mathrm{~m}^{2}\right)$ at each site after rain events from September 2012 to September 2014. Soil N and P content were significantly higher in both burnt sites relatively to the control sites. Nitrogen as well as phosphorus losses via runoff were significantly higher at the $4 \mathrm{x}$ burnt sites than at both the $1 \mathrm{x}$ burnt and unburnt sites. Nutrient loss was particularly high after heavy rains. Vegetation and litter cover played an important role in reducing runoff and the associated $N$ and $P$ transport at the $4 \mathrm{x}$ burnt sites, since a decrease in both variables was observed with the increase in vegetation cover after fire.
\end{abstract}

Based on:

Hosseini, M., Geissen, V., González-Pelayo, O., Serpa, D., Machado, A.I., Ritsema, C.J. and Keizer, J.J., 2017. Effects of fire occurrence and recurrence on nitrogen and phosphorus losses by overland flow in maritime pine plantations in north-central Portugal. Geoderma, 289, pp.97-106. 


\subsection{Introduction}

Fire is an important ecological factor that has affected the Mediterranean landscape in the past and continues to influence it in the present (Pausas et al., 2008). Fire affects soils in different ways depending on various factors such as intensity, severity, fire duration and residence time of temperatures above 100C (González-Pelayo et al., 2015; Caon et al., 2014; Inbar et al., 1998; DeBano et al., 1979). These effects cause changes in the soil physical properties, for example by decreasing soil porosity, increasing bulk density (Granged et al., 2011b) and decreasing soil water retention and infiltration (Hosseini et al., 2016; Badía-Villas et al., 2014; Moody et al., 2013; González-Pelayo et al., 2010), but also on its chemical and biological properties, by changing soil pH and the nutrient cycles (Hosseini et al., 2016; Stoof et al., 2015; Inbar et al., 2014; Inbar et al., 1998; Raison, 1979). Mediterranean ecosystems are deeply affected by fire, so studying their impacts on the soil properties such as porosity, particle detachment from the surface, loss of organic matter and nutrients, water repellence and altered aggregate stability, are important (Shakesby, 2011; Shakesby and Doerr, 2006). Wettability, aggregate stability, infiltration and soil moisture are quite important physical parameters altered by fire (Jordán et al., 2011; Giovannini et al., 1990). Water repellency through depth can be affected (decrease or increase) by fire intensity (Aznar et al., 2016). Burnt vegetation and soil organic matter by fires, produce accumulations of hydrophobic substances on the soil surface that reduce wettability and infiltration while increasing runoff (Wittenberg et al., 2014; Imeson et al., 1992). Increased runoff, ash and soil erosion leads to the loss of nutrients transported as suspended sediment or solubilised in runoff (Badía et al., 2014; Badia and Marti, 2008; Badia et al., 2008). Type of soil and vegetation, slope, lithology, physiography, and other factor like human intervention can influence both the magnitude of fire impacts and the ecosystems' recovery (Shakesby, 2011; Certini, 2005).

Uncontrolled wildfires cause large environmental damages, especially in the Mediterranean region (San-Miguel-Ayanz et al., 2012) and Portugal has been one of the most affected countries in southern Europe (Prats et al., 2014; Shakesby, 2011; Ferreira et al., 2005b). With the increased frequency of fire, the cumulative loss of nutrients, particularly nitrogen $(N)$ and phosphorus $(P)$, has led to soil nutrient deficit in fire affected areas (Eugenio and Lloret, 2007; Eugenio and Lloret, 2004). The effects of fire frequency on nutrient availability and losses have not been widely studied (Malkisnon et al., 2011), whereas the impacts of individual fires on nutrient losses have been reasonably well described at least in Portugal (Ferreira et al., 2016a; Ferreira et al., 2016b; Ferreira et al., 2005b; Thomas et al., 2000a; Thomas et al., 2000b Thomas et al., 1999). $\mathrm{N}$ and $\mathrm{P}$ are important elements in the growth of plants and are the two most important nutrients often limiting crop production (Jin-yan and Jing, 2003; Caon et al., 2014). Therefore, studying the effects of fire on N and P transport, is of great importance for assessing the effects of wildfires on soil nutrient losses and also on 
the quality status of downstream aquatic habitats (Ferreira et al., 2016b). In addition to above changes in the physical and chemical properties of soil, fires can dramatically affect nutrient cycling (DeBano et al., 1998). The soil O horizon and upper $\mathrm{cm}$ of the A horizon are typically affected by fire and suffer the largest changes in nutrient contents (Caon et al., 2014; Novara et al., 2011). Fire decreases nutrient contents, although the inorganic forms of some elements, which are produced by plants can increase and temporarily increase soil fertility (Duguy et al., 2007). Some studies have demonstrated a connection between fire severity and recurrence and the availability of nutrients in the topsoil (Badía et al., 2014; Caon et al., 2014). Nutrients, water holding capacity, organic carbon, aggregate stability, and hydrophobicity are just a few soil properties that can be significantly altered with fire exposure, compromising the health of the entire ecosystem (Certini, 2005). The severity of a wildfire can play an important role in how severely soil properties can be altered. Severe fires can generally remove organic carbon and decrease nitrogen and phosphorus availability (Certini, 2005). Most studies have evaluated the impact of single fires on soil nutrients rather than the potentially more significant impact of long-term fire regimes (Ferreira et al., 2016a; Ferreira et al., 2016b; Machado et al., 2015; Badía et al., 2014). High fire frequencies can be a reason for coating of the soil surface, decrease of water infiltration and soil aggregation and increase of nutrient losses by runoff (Richards et al., 2012). Fires can also lead to large losses of nutrients from the combustion of timber, large debris, and organic matter on the soil surface, which leads to losses by volatilisation (Neary et al., 1999); Factors like the destruction of organic matter (Knoepp et al., 2005), consumption of vegetation and litter, reduced infiltration capacity and increased runoff (Cerda, 2009; Ferreira et al., 2005b) and erosion (Knoepp et al., 2005; Thomas et al., 1999) are principal causes of nutrient losses after fire. Soil erosion and nutrient losses have been reported to be considerably higher after the first rainfall events (Ferreira et al., 2015). The results for an individual fire, however, may not be the same for an area affected by recurrent fires (Hosseini et al., 2016), which may have long-term cumulative effects on some ecosystem properties, such as nutrient cycling and productivity (Carter and Darwin Foster, 2004; Eugenio and Lloret, 2007). Effect of fire recurrence on nutrient export by runoff has received little research attention, especially in fire prone regions. Studying the availability and losses of nutrients in areas with a high fire frequency is thus important for a realistic evaluation of the impacts of fires on soil fertility.

The aim of this study is to provide better understanding of the effects of fire occurrence and recurrence on post-fire $\mathrm{N}$ and $\mathrm{P}$ losses by overland flow in maritime pine plantations in north-central Portugal. In order to achieve this goal, total (i.e. dissolved plus particulate forms) nitrogen and phosphorus losses by overland flow were quantified for a recently burnt maritime pine plantation in Portugal. Specific objectives were to: i) measure total $\mathrm{N}$ and $\mathrm{P}$ losses from burnt and unburnt sites and, ii) compare $\mathrm{N}$ and $\mathrm{P}$ losses by runoff from burnt 
plots with contrasting fire histories: i.e. unburnt, 1 time $(1 \mathrm{x})$ burnt and 4 times $(4 \mathrm{x})$ burnt. These losses were furthermore related to the nitrogen and phosphorus stocks of the topsoil, for a better understanding of $\mathrm{N}$ and $\mathrm{P}$ cycles after fire. Our research hypothesis is that recurrent fires induce large changes on hydrological and erosive processes, as well as on nutrient exports.

\subsection{Materials and methods}

\subsubsection{Study area and study sites}

The study area is located in north-central Portugal and is part of the Vouga River Basin which drains into the Ria de Aveiro coastal lagoon (Fig. 3.1). The climate is classified in Köppen's system as a humid meso-thermal temperate climate Csb, with a prolonged dry and warm summer. A national information source, Sistema Nacional de Informação de Recursos Hídricos (SNIRH, 2014), reported an annual rainfall ranging from 1200 to $>2000 \mathrm{~mm} \mathrm{y}^{-1}$ and mean monthly temperatures ranging from $9{ }^{\circ} \mathrm{C}$ in January to $23^{\circ} \mathrm{C}$ in July. The terrain has steep slopes of $20^{\circ}$ to $30^{\circ}$. The bedrock is schist, and the soils are mainly Humic Cambisols, Epileptic Umbrisols and, to a smaller extent, Umbric Leptosols. The soils are generally shallow, less than $30 \mathrm{~cm}$ deep, and are susceptible to degradation by soil erosion and land use.

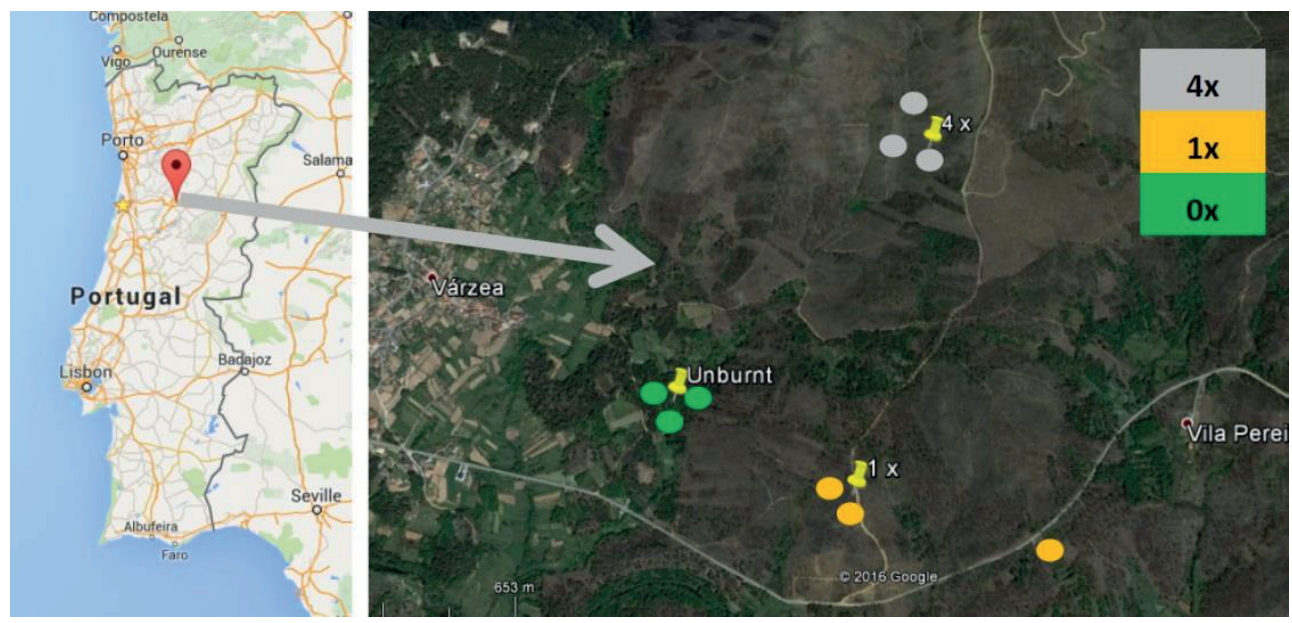

Figure 3.1 Locations of study area in the Viseu municipality, Portugal. Site abbreviation: $4 \times$ burnt, $1 \times$ burnt and unburnt. 


\subsubsection{Experimental set-up}

The experiment was carried out immediately after fire and conducted in an area of Pinus pinaster, which was burnt by a wildfire in September 2012. Based on our observation in the field, a moderate severity fire had affected the area, since ashes were black, the litter layer and understory vegetation was almost consumed by fire, and tree crowns were only partially scorched (Maia et al., 2012a; Keeley, 2009; Shakesby and Doerr, 2006). Within this area, a total of nine slopes (Fig. 3.1) were selected for this study. Three slopes had burnt four times (4x) since 1975 (1978, 1985, 2005, and 2012) and three slopes had burnt once (1x) over the same period (2012) (Fig. 3.1). Furthermore, three slopes with maritime pine stands that had remained unburnt (0x) since 1975 but were otherwise comparable to the six burnt sites were selected in the immediate vicinity (Fig. 3.1). Each slope was divided into two strips running from the base to the top of the slope section. One of these strips was used for repeated collection of ash and soil samples and another for monitoring overland flow at the micro-plot scale. Three micro-plots of approximately $0.25 \mathrm{~m}^{2}$ were established on the bottom, middle and top section of each slope (Table 3.1; Fig. 3.2). The micro-plots were installed on spots where shrubs had been absent at the time of the 2012-fire, as indicated by the absence of remaining burnt-scorched twigs (Hosseini et al., 2016). Metal plates were inserted into the soil upslope of the micro-plots to divert run-on from upslope areas. The outlet of each micro-plot was connected to a 70-L tank with a garden hose to collect the overland flow (Hosseini et al., 2016).

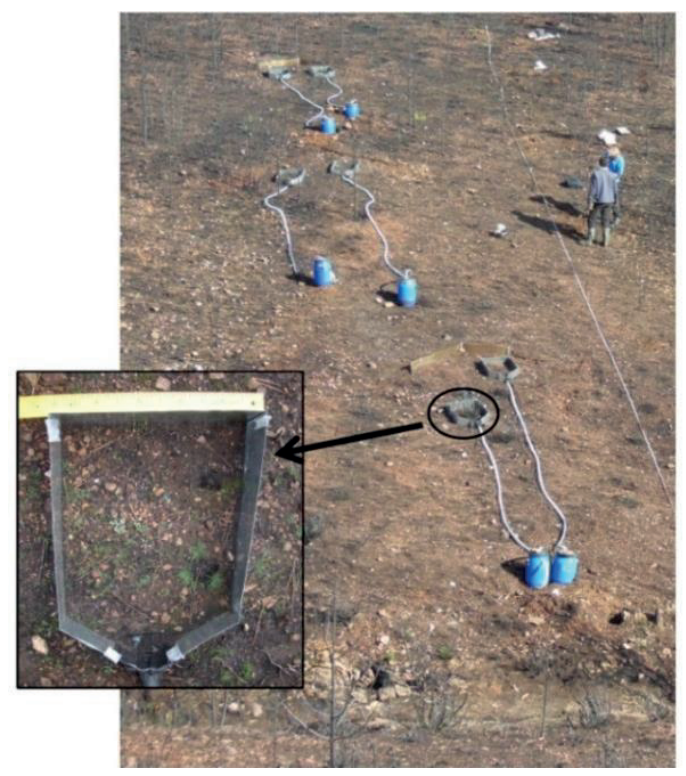

Figure 3.2 Experimental set-up. 


\subsection{Data collection}

\subsubsection{Soil sampling}

Soil samples were collected in May as well as September 2013 at three randomly chosen locations immediately next to the micro-plots at each slope. A soil sampling core was used to collect the upper $5 \mathrm{~cm}$ of the mineral soil by removing any remaining ashes and litter. Samples were then stored in a cool box and transported to the lab for analysis.

\subsubsection{Soil analysis}

The content of available $\mathrm{P}$ and Kjeldahl $\mathrm{N}$ of the soil samples were analysed respectively, by the method of (Bray and Kurtz, 1945) and Kjeldahl method (Bremner, 1965). Soil texture was analysed by sedimentation (Stokes' Law) with the Robinson pipet method (Guitián-Ojea and Carballas, 1976), and soil bulk density was determined by the cylindrical core method (Blake and Hartge, 1986). The bulk density of the soil was analysed for a same depth $(0-5 \mathrm{~cm})$ as considered for texture. Soil $\mathrm{pH}\left(\mathrm{H}_{2} \mathrm{O}\right)$ was determined in a soil:water solution (1:5) for three samples from each study horizon and analysed as described by Ross and Ketterings (1995). Results regarding soil properties (Table 3.1) were shown in a previous work (Hosseini et al., 2016).

Table 3.1 Characteristics of the study sites. Soil data concerns to the 0-5 cm layer. Source: Hosseini et al. (2016).

\begin{tabular}{|c|c|c|c|c|c|c|c|}
\hline $\begin{array}{l}\text { Burnt } \\
\text { Site }\end{array}$ & Slope & $\begin{array}{c}\text { Mean slope } \\
\text { angle }\left({ }^{\circ}\right)\end{array}$ & $\begin{array}{l}\text { Soil bulk } \\
\text { density } \\
\left(\mathrm{g} \mathrm{cm}^{-3}\right)\end{array}$ & Soil pH & Soil texture & $\begin{array}{c}\text { Soil OM } \\
\text { (\%) }\end{array}$ & $\begin{array}{c}\text { Ash/litter } \\
\text { layer } \\
\text { (mm) }\end{array}$ \\
\hline \multirow[t]{3}{*}{$4 x$} & $4 x-1$ & 29 & 1.15 & 4.3 & Loam & 23 & $<10$ (Ash) \\
\hline & $4 x-2$ & 25 & 0.97 & 4.5 & Loam & 16 & $<10$ (Ash) \\
\hline & $4 x-3$ & 20 & 0.82 & 4.5 & Loam & 19 & $<10$ (Ash) \\
\hline \multirow[t]{3}{*}{$1 x$} & $1 x-1$ & 23 & 0.90 & 4.5 & Sandy loam & 17 & 10 (Ash) \\
\hline & $1 x-2$ & 21 & 1.11 & 4.6 & Sandy loam & 16 & 10 (Ash) \\
\hline & $1 x-3$ & 20 & 0.75 & 4.6 & Loam & 24 & 10 (Ash) \\
\hline \multirow[t]{3}{*}{$0 x$} & $0 x-1$ & 25 & 1.03 & 4.6 & Sandy loam & 13 & 70 (Lit.) \\
\hline & $0 x-2$ & 25 & 1.08 & 4.6 & Sandy loam & 11 & 80 (Lit.) \\
\hline & $0 x-3$ & 23 & 0.88 & 4.4 & Sandy loam & 17 & 70 (Lit.) \\
\hline
\end{tabular}




\subsubsection{Soil cover}

Soil cover was measured 8 times from October 2012 to June 2014 (Hosseini et al., 2016). A $10 \times 10 \mathrm{~cm}$ gridded square was put over each micro-plot, and the cover at each crossing point of the gridlines was verified as stone (bedrock and coarse fragments $>2 \mathrm{~mm}$ ), bare soil, ash, litter, or vegetation cover as analysed by previous research done by (Hosseini et al., 2016).

\subsubsection{Rainfall and runoff}

The rainfall and runoff amounts were measured and runoff samples collected between 4 September 2012 (shortly after the fire) and 4 September 2014 (end of the monitoring period) at intervals of one to two weeks, depending on rainfall. Total rainfall and rain intensity per measurement period were measured using various pairs of storage and automatic rainfall gauges. The storage gauges following an in-house design were mainly used to validate the automatic rainfall data, obtained using tipping-bucket pronamic professional gauges with a $0.2 \mathrm{~mm}$ resolution and linked to measured just the rainfall. The $\mathrm{pH}$ and electrical conductivity (EC) of the runoff samples were measured by a Hanna Instruments potentiometer HI991301 (accuracy of \pm 0.01 ).

\subsubsection{Laboratory analysis of runoff samples}

The concentration of Total Suspended Solids (TSS) in runoff samples was quantified gravimetrically by filtering $50 \mathrm{~mL}$ of water through a glass-fibre filter with particle retention of $1.5 \mu \mathrm{m}$, followed by drying to a constant weight at $105^{\circ} \mathrm{C}$. This was carried out according to the method D 2540 - Total Suspended Solids (APHA, 1999).

\subsubsection{Nutrient transport by runoff}

Total nitrogen and total phosphorus (i.e. dissolved plus particulate $\mathrm{N}$ and $\mathrm{P}$ forms) in runoff samples were analysed using a flow injection FIAstar ${ }^{\mathrm{TM}} 5000$ analyser (FOSS-Tecator). Runoff subsamples $(50 \mathrm{~mL}$ ) were used for analysing total $\mathrm{N}(\mathrm{TN})$ and total $\mathrm{P}(\mathrm{TP})$. Prior to the analysis, all subsamples were subjected to an oxidative digestion using

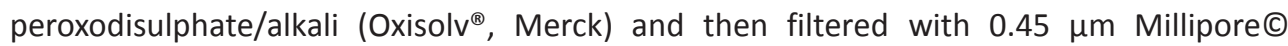
membrane filters. 
TN and TP losses by runoff per micro-plot were computed for each measurement period as:

$$
\left(m_{i}\right)=\left(\frac{\left(C_{i}\right) \times(E)}{A}\right)
$$

Where $m_{i}$ is the nutrient loss in the runoff $\left(\mathrm{mg} \mathrm{m}^{-2}\right), C_{i}$ is the nutrient concentration in the runoff ( $\left.\mathrm{mg} \mathrm{L}^{-1}\right)$; $\mathrm{E}$ is the total runoff $(\mathrm{L})$, and $A$ is the micro-plot area $\left(\mathrm{m}^{2}\right)$.

\subsection{Data analysis}

All statistical analyses were performed using IBM SPSS 22.0 Statistics software. Data on nutrient in soil and (TN and TP) losses by runoff, were tested for normality with the Kolmogorov-Smirnov test. The effects of slope position, fire frequency and time on TN and TP losses by runoff were tested using a ANOVA repeated measures. Following the ANOVA, a Tukey's HSD Post-hoc test was used to identify significant differences among sites and treatments for each sampling event. Whenever the data failed the normality test, a nonparametric Mann-Whitney $U$ test was applied to identify significant differences amongst treatments. All tests were deemed statistically significant at $(p<0.05)$. A principal component analysis (PCA) is mainly used to summarise the information contained in a large number of variables into a smaller set of new merged dimensions, with a minimum loss of information. In this research PCA was conducted for $4 \mathrm{x}$ and $1 \mathrm{x}$ burnt sites for runoff, rainfall, $\mathrm{N}$ and $\mathrm{P}$ losses, soil cover, and rainfall intensity $\left(I_{30}\right)$. Components with eigenvalues higher than Keiser's criterion of 1 were extracted.

\subsection{Results}

\subsubsection{Soil cover}

The vegetation cover increased in all sites during the study period. Vegetation cover in the $4 \mathrm{x}$ burnt sites represented $16 \%$ and $48 \%$ of the cover respectively, 10 and 21 months (June 2014) after the fire. The vegetation cover in $1 x$ burnt sites increased from $7 \%$ in the first year after fire to $49 \%$ in the second year. The corresponding increase in the $0 x$ burnt sites was from 20 to $62 \%$ (Hosseini et al., 2016). 


\subsubsection{Rainfall and runoff distribution}

A total of $2917 \mathrm{~mm}$ of rain fell in 70 read-outs, from 4 October 2012 to 25 September 2014. Of this total, $1289 \mathrm{~mm}$ fell during the first year after the fire, and $1628 \mathrm{~mm}$ fell during the second year. Total rainfall and its maximum intensity over 30 minutes ( $\left.1_{30}\right)$ as well as the average runoff volumes per fire recurrence are plotted together in Fig. 3.3. Rainfall totals were particularly high for eleven occasions, exceeding $100 \mathrm{~mm}$. These heavy rains occurred mainly during the autumn and winter season. Maximum rainfall intensities ( $I_{30}: 25-30 \mathrm{~mm}$ $\mathrm{h}^{-1}$ ) were highest in September, October, and December 2013. Nearly 64\% of the $1628 \mathrm{~mm}$ of rain in the second year fell within this period. The annual runoff amounts for the first and second post-fire years differed significantly $(F=3.361, p<0.05)$ and were nearly four- and eight- fold higher in the $4 \mathrm{x}$ burnt sites than at the $1 \mathrm{x}$ and $0 \mathrm{x}$ burnt sites respectively.

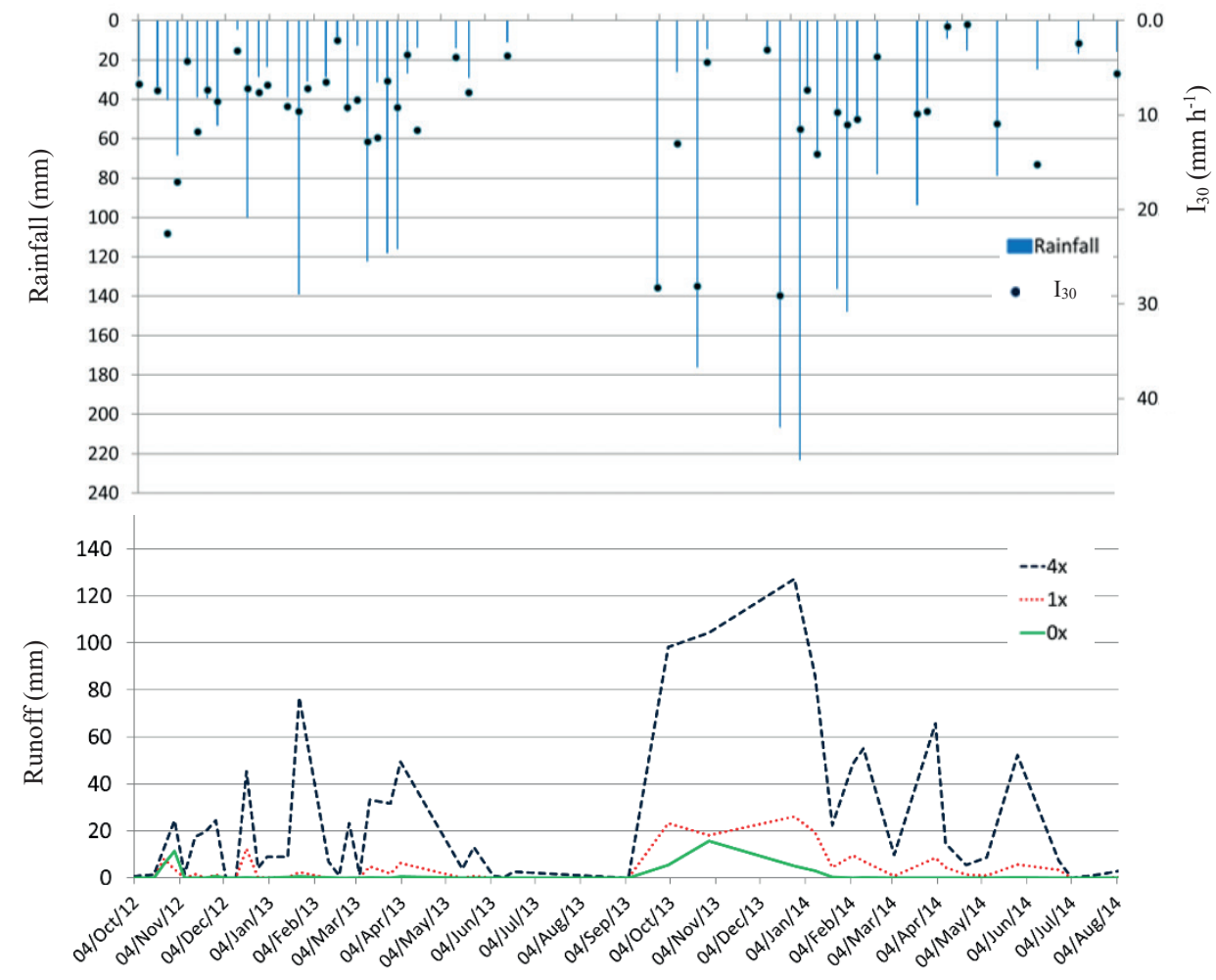

Figure 3.3 Rainfall and runoff amounts. Site abbreviation: $4 \times, 1 \times$ and $0 \times$ burnt sites. 


\subsubsection{Soil nitrogen and phosphorus contents}

In May 2013, Kjeldahl N contents in the topsoil were significantly higher $(F=4.262, p<0.05)$ at the $1 x$ burnt sites than at the $4 x$ and 0x burnt sites. In September 2013, on the other hand, differences between burnt sites were not significant but slightly higher values were found at the $1 \mathrm{x}$ burnt than $4 \mathrm{x}$ burnt sites. As regards to available $\mathrm{P}$ contents, significantly higher ( $\mathrm{F}$ $=4.623, \mathrm{p}<0.05$ ) $\mathrm{N}$ contents were found at the $4 \mathrm{x}$ burnt sites than $1 \mathrm{x}$ and $0 \mathrm{x}$ burnt sites (Table 3.2) on both sampling dates. In all treatments Kjeldahl $N$ and available $P$ contents were significantly higher in May than in September $2013(F=4.325, p<0.05)$. Average nutrient content in the topsoil $(0-5 \mathrm{~cm})$ are presented in Table 3.2 and depicted in Fig. 3.4.

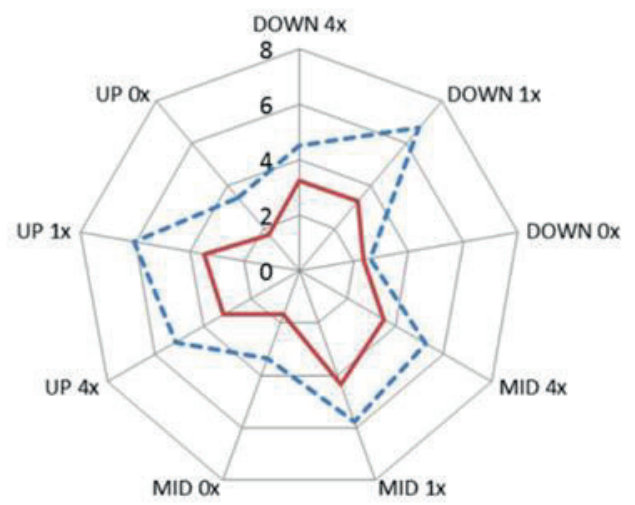

a. $\mathrm{N}$ concentration in topsoil (mg g-1)

$$
---M a y / 13
$$



b. $P$ concentration in topsoil $\left(\mathrm{mg} \mathrm{g}^{-1}\right)$

Figure 3.4 Soil $N$ and $P$ concentrations within the first year after fire. Site abbreviation: $4 x, 1 \times$ and $0 x$ burnt sites. 
The nutrient content in topsoil did not differ significantly $(F=0.361, p>0.05)$ between the locations of the micro-plots on each slope from top to bottom. Kjeldahl $\mathrm{N}$ contents at the $4 \mathrm{x}$ burnt sites averaged (4.5 \pm 1.50$),(5.3 \pm 1.93)$, and $(5.1 \pm 1.41) \mathrm{mg} \mathrm{g}^{-1}$, and for $1 \mathrm{x}$ burnt sites were $(6.7 \pm 1.68),(5.8 \pm 0.61)$ and $(6.1 \pm 0.52) \mathrm{mg} \mathrm{g}^{-1}$ and for unburnt sites were $(2.6 \pm 0.34)$, $(3.4 \pm 1.35)$ and $(3.4 \pm 1.24)$ in the micro-plots at the bottom, middle, and top parts of the slope, respectively, in May 2013 (Fig. 3.4a). The available P concentrations also varied between the two sampling campaigns (Fig. 3.4b). Available P concentrations at the $4 \mathrm{x}$ burnt sites averaged $(0.028 \pm 0.008),(0.026 \pm 0.004)$, and $(0.027 \pm 0.003) \mathrm{mg} \mathrm{g}^{-1}$ in $1 x$ burnt sites were $(0.007 \pm 0.006),(0.015 \pm 0.004)$ and $(0.012 \pm 0.005)$ and for unburnt sites were $(0.003 \pm 0.002)$, $(0.003 \pm 0.001)$ and $(0.002 \pm 0.001)$ in the micro-plots at the bottom, middle and top sections of the slope, respectively, in May 2013 but had decreased in 4x and 1x burnt sites at the bottom, middle, and top parts of the slope in September 2013. Available P concentrations at unburnt sites increased to $(0.004 \pm 0.002),(0.003 \pm 0.001)$ and $(0.005 \pm 0.003)$ respectively from bottom, middle, and top parts of the slope, by September 2013.

Table 3.2 Average nutrient content in topsoil within the first year after fire for the $4 \times$ burnt, $1 \times$ burnt and $0 \times$ burnt sites. Lowercase letters indicate significant differences between treatments $(p<0.05)$.

\begin{tabular}{c|cc|cc|}
\cline { 2 - 5 } Burnt Site & \multicolumn{2}{|c|}{$\mathbf{N}\left(\mathbf{m g ~ g}^{-1}\right)$} & \multicolumn{2}{c|}{$\mathbf{P}\left(\mathbf{m g ~ g}^{-1}\right)$} \\
\hline $4 x$ & $5.0 \pm 0.33^{b}$ & $3.3 \pm 0.17^{a}$ & $0.027 \pm 0.008^{a}$ & $0.013 \pm 0.0001^{a}$ \\
$1 x$ & $6.2 \pm 0.40^{a}$ & $3.7 \pm 0.47^{a}$ & $0.011 \pm 0.003^{b}$ & $0.002 \pm 0.0002^{b}$ \\
0x & $3.1 \pm 0.38^{c}$ & $1.9 \pm 0.32^{b}$ & $0.002 \pm 0.004^{c}$ & $0.004 \pm 0.0002^{c}$ \\
\hline
\end{tabular}

Table 3.3 Average $\mathrm{pH}$ and electrical conductivity (EC) of runoff samples within the first and second years after fire (Hosseini et al., 2016) for the $4 \times$ burnt, $1 \times$ burnt and $0 \times$ burnt sites.

\begin{tabular}{c|cc|cc|}
\cline { 2 - 5 } Burnt Site & \multicolumn{2}{|c|}{$\mathbf{p H}$} & \multicolumn{2}{c|}{$\mathrm{EC}\left(\boldsymbol{\mu S} \mathbf{~ c m}^{-1}\right)$} \\
$\mathbf{1}^{\text {st }}$ Year & $\mathbf{2}^{\text {nd }}$ Year & $\mathbf{1}^{\text {st }}$ Year & 2 $^{\text {nd }}$ Year \\
\hline 4x & $5.7 \pm 0.56$ & $5.4 \pm 0.34$ & $15.2 \pm 8.63$ & $20.2 \pm 12.21$ \\
1x & $5.8 \pm 0.45$ & $5.3 \pm 0.38$ & $22.7 \pm 9.20$ & $23.1 \pm 11.64$ \\
0x & $5.4 \pm 0.70$ & $5.1 \pm 0.46$ & $19.0 \pm 13.75$ & $21.0 \pm 15.01$ \\
\hline
\end{tabular}

\subsection{4 pH, EC of overland flow, and suspended solid losses}

The $\mathrm{pH}$ of runoff samples was steady over time in burnt and unburnt sites. EC $\left(\mu \mathrm{cm}^{-1}\right)$ didn't change significantly $(F=2.241, p>0.05)$ between sites in the $1^{\text {st }}$ and $2^{\text {nd }}$ year of monitoring (Table 3.3).

The amount of TSS in runoff was significantly higher $(F=5.281, p<0.05)$ at the $4 x$ burnt than the $1 x$ and $0 x$ burnt sites (Fig. 3.5). Total TSS losses within the two years after the fire were, on average, $335.3 \pm 7.43 \mathrm{~g} \mathrm{~m}^{-2}$ at the $4 \mathrm{x}$ burnt sites and $42.9 \pm 1.02 \mathrm{~g} \mathrm{~m}^{-2}$ at the $1 \mathrm{x}$ burnt 
sites. Total TSS losses were significantly lower at the unburnt sites $9.8 \pm 0.46 \mathrm{mg} \mathrm{m}^{-2}$. TSS losses were also more seasonally variable at the $4 \mathrm{x}$ burnt sites than at the $1 \mathrm{x}$ and $0 \mathrm{x}$ burnt sites. Highest sediment losses in both years were found during the autumn and winter months. Total TSS amounts at the $4 x$ burnt sites during the autumn and winter season were, on average, $106.7 \mathrm{~g} \mathrm{~m}^{-2}$ in 2013 and $152.5 \mathrm{~g} \mathrm{~m}^{-2}$ in 2014. By comparison, at the $1 \mathrm{x}$ and $0 \mathrm{x}$ burnt sites, TSS losses amounted respectively to, $15.0 \mathrm{~g} \mathrm{~m}^{-2}$ and $5.0 \mathrm{~g} \mathrm{~m}^{-2}$ in 2013 and to 16.9 and $3.7 \mathrm{~g} \mathrm{~m}^{-2}$ in 2014.

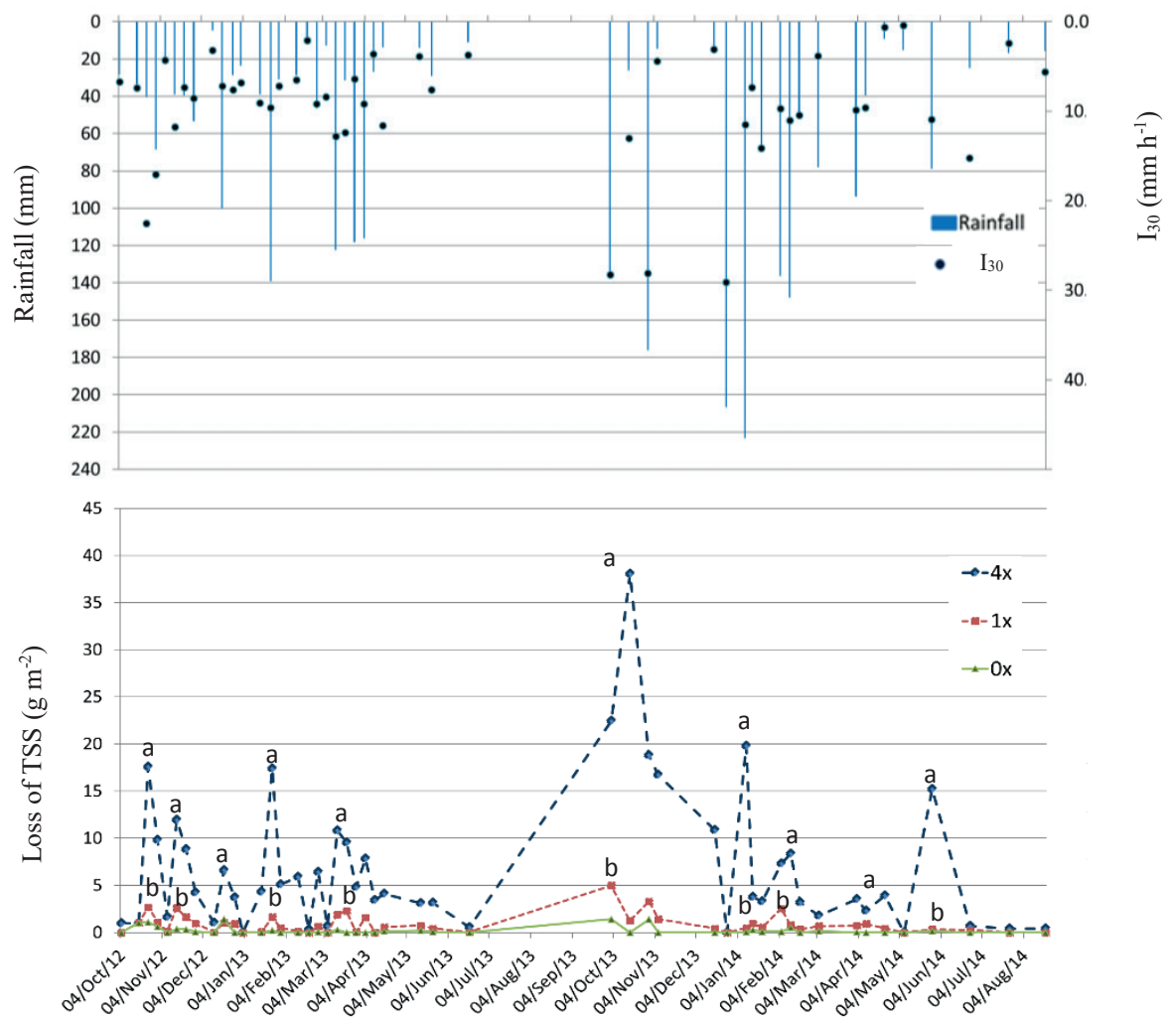

Figure 3.5 Loss of total suspended solids (TSS) by overland flow in the two years after fire for the $4 x, 1 \times$ and $0 \times$ burnt sites. Lowercase letters indicate significant differences among sites $(p<0.05),(a>b>c)$. 


\subsubsection{Nitrogen and phosphorus losses by overland flow}

Annual rainfall, runoff and sediment losses as well as $\mathrm{N}$ and $\mathrm{P}$ exports for each study site are presented in Table 3.4. $\mathrm{N}$ and $\mathrm{P}$ losses via runoff were significantly different $(\mathrm{p}<0.05)$ between treatments and years. Higher $\mathrm{N}$ and $\mathrm{P}$ losses were found at the second than in the first year after fire $(F=3.921, p<0.05)$. Several nutrient peaks after fire, occurred in the autumn and winter 2013 associated to the high $\mathrm{I}_{30}$ values at all the study sites.

\subsubsection{Nitrogen losses}

The first rainfall event after the fire caused the highest $N$ losses by runoff (Fig. 3.6). Nonetheless, several peaks in $\mathrm{N}$ exports occurred by intensive rainfall events within the second year after fire. In our study, the loss of TN was mainly affected by rainfall and runoff. $\mathrm{N}$ losses were significantly higher $(\mathrm{F}=4.261, p<0.05)$ at the $4 \mathrm{x}$ burnt than $1 \mathrm{x}$ and $0 \mathrm{x}$ burnt sites. The sum of $\mathrm{N}$ losses by runoff in autumn and winter were $726.4 \mathrm{mg} \mathrm{m}^{-2}$ in 2013 and $1563.9 \mathrm{mg} \mathrm{m}^{-2}$ in 2014 at the $4 x$ burnt sites in comparison to 115.4 and $20.8 \mathrm{mg} \mathrm{m}^{-2}$ in 2013, and 430.8 and $70.4 \mathrm{mg} \mathrm{m}^{-2}$ at the $1 \mathrm{x}$ and $0 \mathrm{x}$ burnt sites, respectively.

Table 3.4 Annual rainfall, runoff and sediment losses (from Hosseini et al., 2016) and $N$ and $P$ exports by overland flow for the $4 \times$ burnt, $1 \times$ burnt and $0 \times$ burnt sites. Lowercase letters indicate significant differences between treatments $(p<0.05)$. Uppercase letters indicate that significant differences were found for the different variables between sampling years.

\begin{tabular}{ccccccc}
\hline \multirow{2}{*}{ Year } & $\begin{array}{c}\text { Burnt } \\
\text { Site }\end{array}$ & $\begin{array}{c}\text { Rainfall } \\
(\mathbf{m m})\end{array}$ & $\begin{array}{c}\text { Runoff } \\
(\mathbf{m m})\end{array}$ & $\begin{array}{c}\text { Sediment losses } \\
\left(\mathbf{M g ~ h a}^{-1}\right)\end{array}$ & $\begin{array}{c}\text { N export } \\
\left(\mathbf{m g ~ m}^{-2}\right)\end{array}$ & $\begin{array}{c}\text { P export } \\
\left(\mathbf{m g ~ m}^{-2}\right)\end{array}$ \\
\hline \multirow{2}{*}{$1^{\text {st }}$ Year $^{\mathrm{A}}$} & $4 \mathrm{x}$ & & $411^{\mathrm{a}}$ & $2.57^{\mathrm{a}}$ & $917.3 \pm 35.0^{\mathrm{a}}$ & $473.9^{\mathrm{a}} \pm 24.3^{\mathrm{a}}$ \\
& $1 \mathrm{x}$ & \multirow{2}{*}{1289} & $115^{\mathrm{b}}$ & $0.31^{\mathrm{b}}$ & $177.7 \pm 6.0^{\mathrm{b}}$ & $213.8 \pm 13.5^{\mathrm{b}}$ \\
& $0 \mathrm{x}$ & & $51^{\mathrm{c}}$ & $0.04^{\mathrm{c}}$ & $22.1 \pm 1.5^{\mathrm{c}}$ & $53.3 \pm 20.7^{\mathrm{c}}$ \\
& $4 \mathrm{x}$ & & $733^{\mathrm{a}}$ & $3.79^{\mathrm{a}}$ & $1861.8 \pm 32.1^{\mathrm{a}}$ & $1033.6 \pm 46.1^{\mathrm{a}}$ \\
$2^{\text {nd }}$ Year $^{\mathrm{B}}$ & $1 \mathrm{x}$ & \multirow{2}{*}{1628} & $197^{\mathrm{b}}$ & $0.84^{\mathrm{b}}$ & $524.4 \pm 22.1^{\mathrm{b}}$ & $441.4 \pm 23.9^{\mathrm{b}}$ \\
& $0 \mathrm{x}$ & & $67^{\mathrm{c}}$ & $0.00^{\mathrm{c}}$ & $86.5 \pm 7.8^{\mathrm{c}}$ & $46.0 \pm 3.7^{\mathrm{c}}$ \\
\hline
\end{tabular}



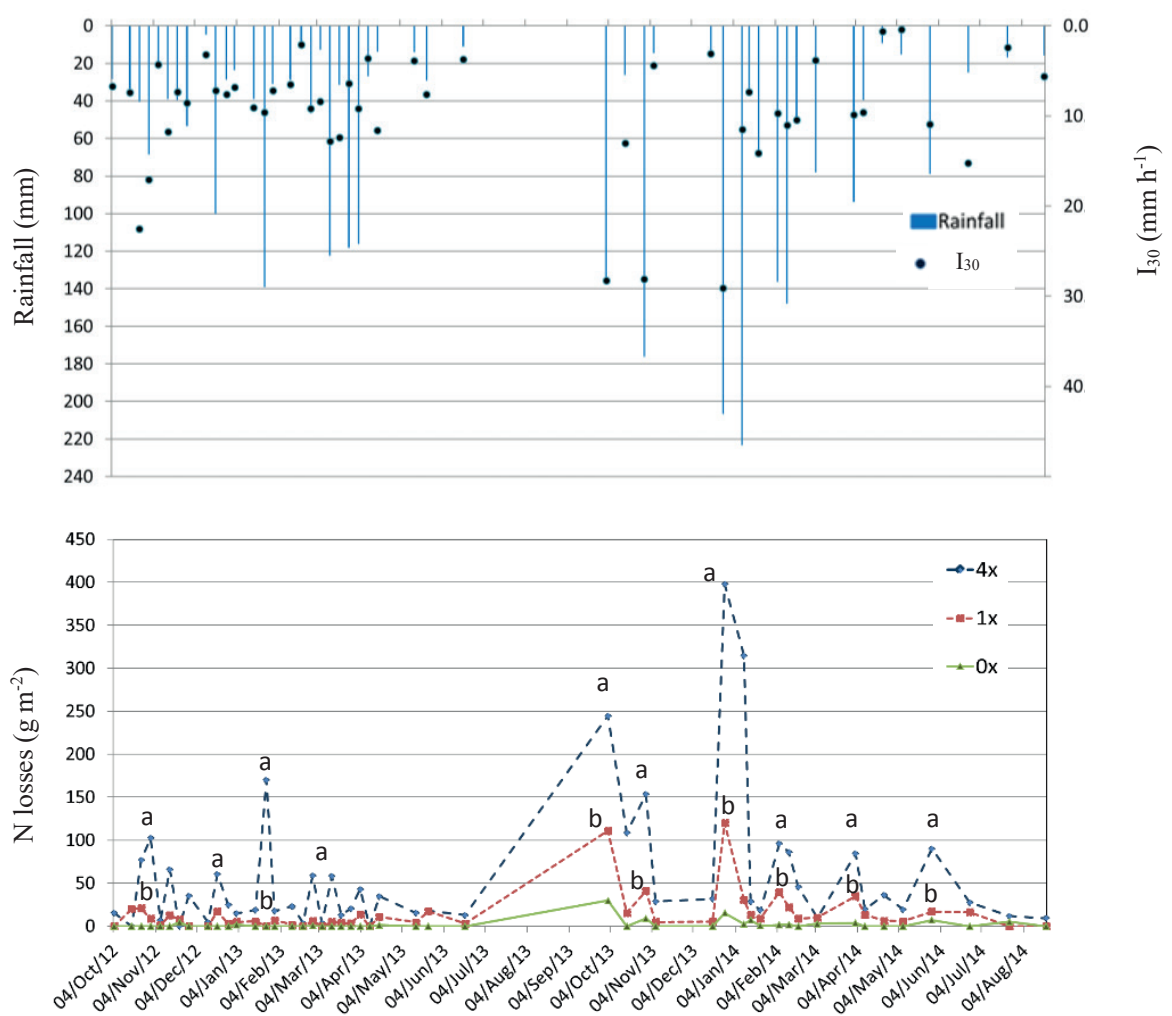

Figure 3.6 Nitrogen losses by overland flow in the two years after fire for the $4 \times, 1 \times$ and $0 \times$ burnt sites. Lowercase letters indicate significant differences between the treatments per rainfall event $(p<0.05),(a>b>c)$.

\subsubsection{Phosphorus losses}

The amount of $P$ losses by runoff started with the first rain after the fire but, several peak in $P$ losses occurred during time as a result of intensive rainfall events (Fig. 3.7). P losses were significantly higher $(F=3.620, p<0.05)$ at the $4 x$ burnt than $1 x$ and $0 x$ burnt sites. The sum of $P$ losses by runoff in autumn and winter were $404.1 \mathrm{mg} \mathrm{m}^{-2}$ in 2013 and $891.6 \mathrm{mg} \mathrm{m}^{-2}$ in 2014 at the $4 x$ burnt sites in comparison to 172.6 and $52.1 \mathrm{mg} \mathrm{m}^{-2}$ in 2013 and 384.3 and $33.2 \mathrm{mg} \mathrm{m}^{-2}$ in 2014 at the $1 \mathrm{x}$ and $0 \mathrm{x}$ burnt sites, respectively. $\mathrm{P}$ losses were significantly higher $(F=3.741, p<0.05)$ in the more frequently burnt area and increased during autumn and winter 2013 at both the $4 x$ and $1 x$ burnt sites, corresponding to the periods with the highest rain intensities of 18.7 and $14.9 \mathrm{~mm} \mathrm{~h}^{-1}$, respectively. 

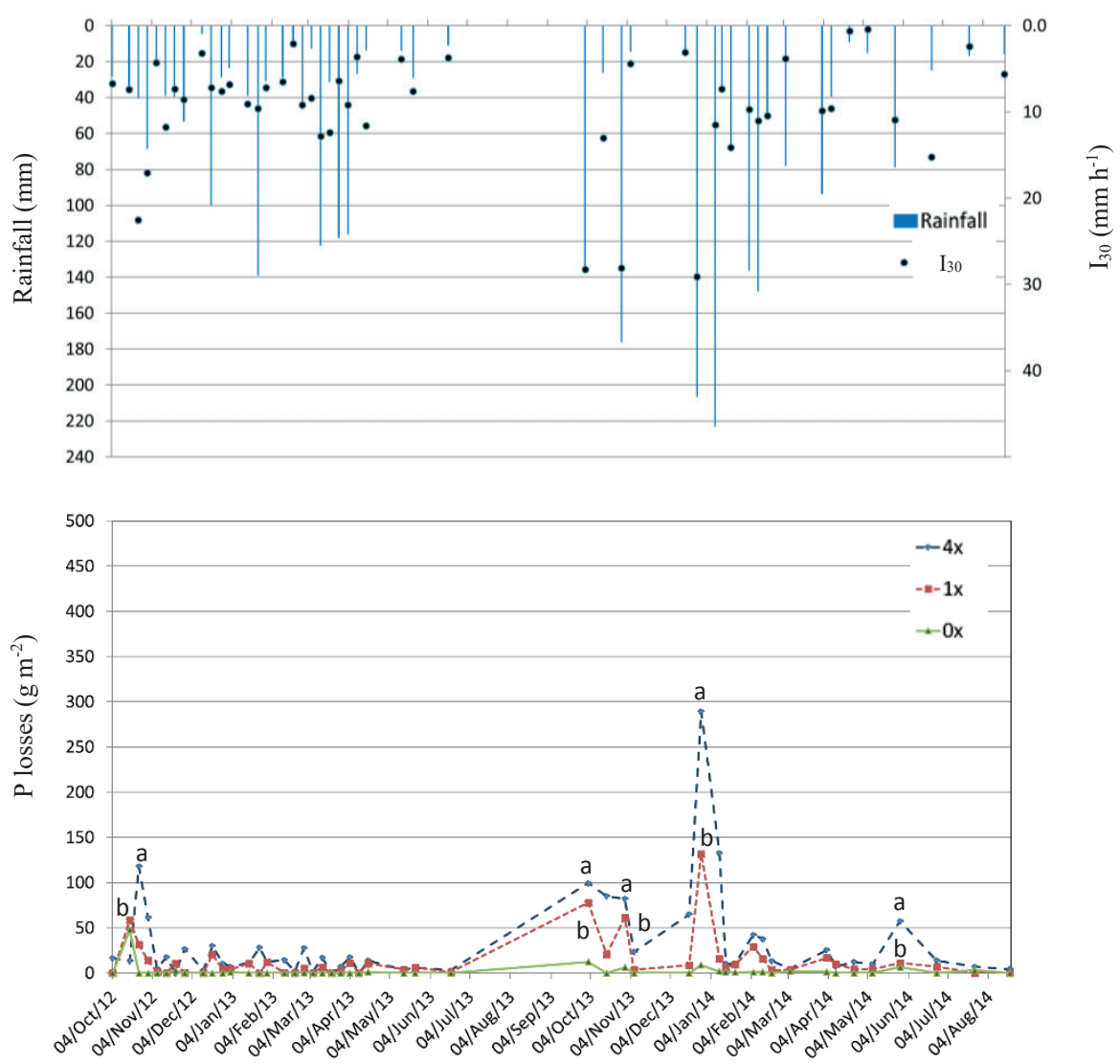

Figure 3.7 $P$ losses by overland flow during 24 months after fire for the $4 \times, 1 \times$ and $0 \times$ burnt sites. Lowercase letters indicate significant differences between the treatments per rainfall event ( $p$ $<0.05),(a>b>c)$. 

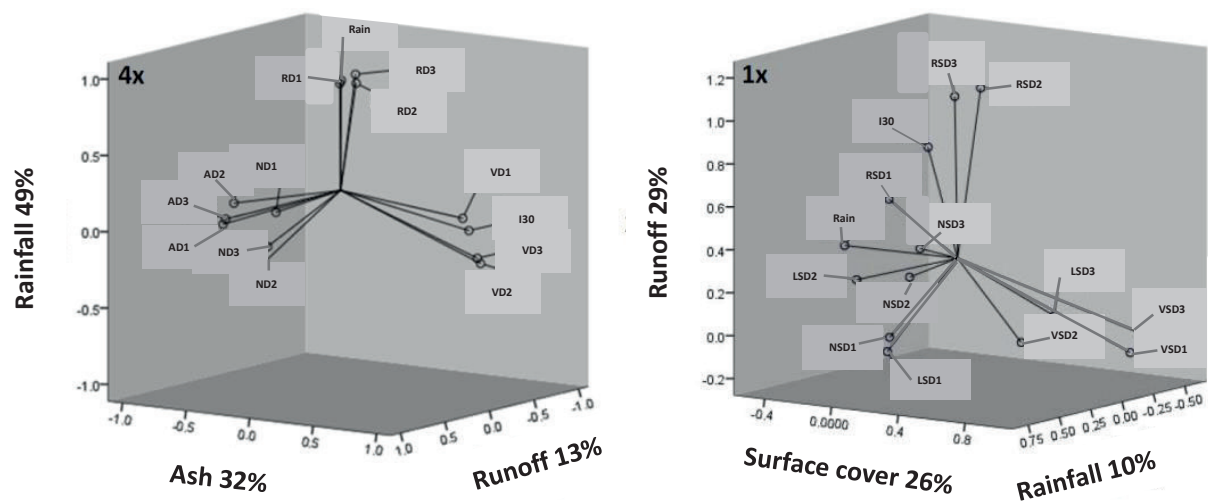

Figure 3.8 Three principal components extracted from the variables for $N$ losses: runoff $(R) ; N$ loss $(N)$; ash (A); litter (L) and vegetation (V) for the $4 \times$ and $1 \times$ burnt sites (1,2,3: No. of plots).
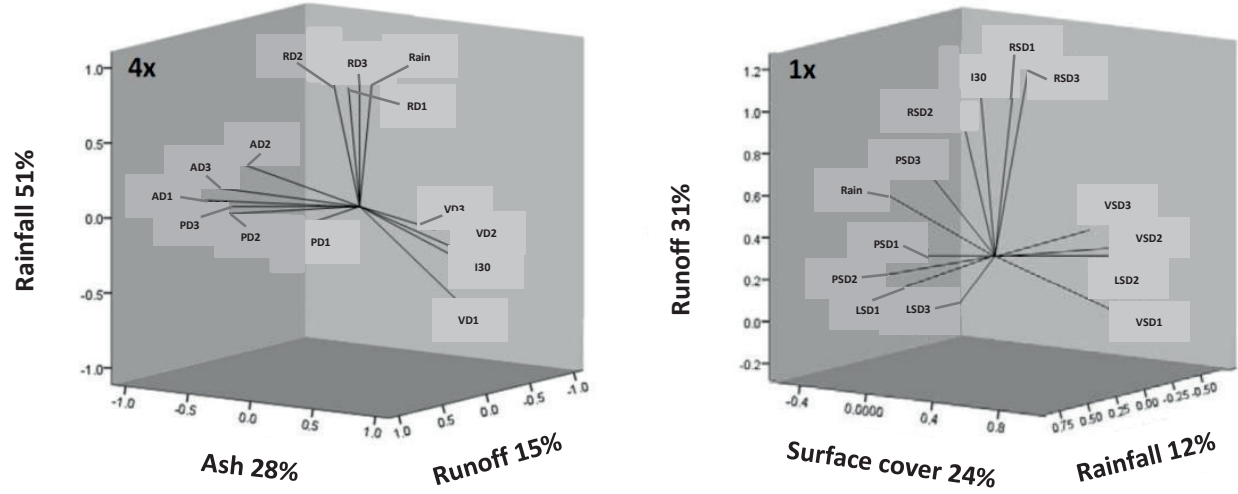

Figure 3.9 Three principal components extracted from the variables for $P$ losses: runoff $(R)$; $P$ loss $(P)$; ash (A); litter (L) and vegetation (V) for the $4 \times$ and $1 \times$ burnt sites (1,2,3: No. of plots).

3.5.6 Relation between environmental variables and nitrogen and phosphorus exports

A principal component analysis (PCAs) for the burnt sites, with rainfall, runoff, soil cover and ash as main factors, explained $94 \%$ and $65 \%$ of the variance of nitrogen (Fig. 3.8) losses and, $93 \%$ and $70 \%$ of the variance of phosphorus losses (Fig. 3.9) for respectively, the $4 x$ and $1 x$ burnt sites. The losses of TN and TP were highly correlated $(r \geq 0.83)$ with the amount of rainfall as well as runoff $(r \geq 0.78)$. There was not however a significant correlation with surface cover. Data for the 0x burnt sites were not included in the PCA analysis due to the very low runoff amounts and nutrient losses in these sites during the study period. 


\subsection{Discussion}

\subsubsection{Nitrogen and phosphorus contents in the topsoil}

In this study, soil $\mathrm{N}$ and $\mathrm{P}$ concentrations were significantly higher $(\mathrm{p}<0.05)$ at the burnt sites $(1 \mathrm{x}$ and $4 \mathrm{x})$ than at the unburnt site (0x) during the first year after fire (Table 3.2). Comparing the two burnt sites, higher $\mathrm{N}$ concentrations were observed at the $1 \mathrm{x}$ burnt than at the $4 \mathrm{x}$ burnt sites in both sampling dates, which suggests that fire recurrence is likely to promote nitrogen loss in Mediterranean soils (Caon et al., 2014; Esteves et al., 2012). As regards to $P$, and unlike it was expected, significantly higher concentrations were observed at the $4 x$ than at the $1 x$ burnt site. This is in line with the findings of other authors Badía and Martí (2003) who reported that available $P$ in burnt soils is proportional to the ash availability (Table 3.1) because of the high available $P$ contents in ashes. On the other hand, the higher amount of clays in the $4 \mathrm{x}$ burnt sites associated to the low soil $\mathrm{pH}$ could also explain these findings, since clay particles tend to increase the P sorption capacity of soils (Tiessen et al., 1994). In both sites, a decrease in soil $\mathrm{N}$ and $\mathrm{P}$ contents was observed within the first year after fire, most likely as a result of $\mathrm{N}$ and $\mathrm{P}$ losses by runoff and erosion (Ferreira et al., 2016a; Ferreira et al., 2016b). This decrease, however, was considerably higher for $P$ than for $N$, particularly at the $1 \mathrm{x}$ burnt site reinforcing the idea that other processes, such as $\mathrm{P}$ adsorption and leaching after intensive rainfall, might have influenced the contents of available $P$ at this site. As regards to slope position of each plot, no significant differences ( $p>0.05$ ) were found between soil samples collected at the top, middle and bottom of all slopes, which points out to a reduced variability within slopes.

\subsubsection{Nutrient losses by overland flow}

Total runoff increased with rainfall intensity and consequently affected nutrient losses by overland flow. As presented in Table 3.4, runoff increased from the first to the second year after fire at both the $4 x$ burnt (from $411 \mathrm{~mm}$ to $733 \mathrm{~mm}$ ) and the $1 \mathrm{x}$ burnt sites (from 115 $\mathrm{mm}$ to $197 \mathrm{~mm}$ ) (Hosseini et al., 2016). Total annual $\mathrm{N}$ and P losses were significantly higher at the burnt than at the unburnt sites (Table 3.4), as would be expected since wildfires typically remove or substantially reduce the soil protective litter and vegetation layers (Hosseini et al., 2016; Vega et al., 2015; Prats et al., 2012; Shakesby, 2011). Comparing the two burnt sites, significantly higher $N$ and $P$ exports were found at the $4 x$ than at the $1 x$ burnt site (Fig. 3.6 and Fig. 3.7), most likely because the needle cast layer from the scorched tree crowns at the $1 \mathrm{x}$-burnt was able to effectively reduce runoff generation and soil erosion (Table 3.4), as also found in other works carried out in the study region (Ferreira et al., 2016a; Ferreira et al., 2016b; Hosseini et al., 2016; Martins et al., 2013; Prats et al., 2013; 
Prats et al., 2012). A needle cover acts mainly by increasing water storage, infiltration chance and resistance to the flow while decreasing splash erosion (Martins et al., 2013; Prats et al., 2013; Prats et al., 2012; Thomas et al., 2000a; Thomas et al., 2000b), thus reducing runoff and the associated sediment and nutrient losses (Ferreira et al., 2016a; Ferreira et al., 2016b; Ferreira et al., 2015; Machado et al., 2015). At the $4 x$ burnt sites, the lack of a vegetation and litter layer immediately after the fire (average 40-53\%; Hosseini et al. (2016)), associated to the decrease in the thickness of the ash layer after rainfall (Keesstra et al., 2016; Prosdocimi et al., 2016a; Cerdà et al., 2015) and the slow recovery of vegetation (Hosseini et al., 2016) was likely to have increased post-fire runoff and the associated sediment and nutrient losses (Table 3.4; Fig. 3.6 and Fig. 3.7). Inter-annual differences in nutrient exports were generally found for all the study sites as a result of differences in rainfall amounts and intensities between the two hydrological years (Table 3.4; Fig. 3.6 and Fig. 3.7). At the two burnt sites, $\mathrm{N}$ and $\mathrm{P}$ losses were significantly higher in the second than in first year after fire, as a response to the higher rainfall amounts and intensities occurring in the latter year (Fig. 3.6 and Fig. 3.7), which generated higher runoff and sediment losses than in the first year (Table 3.4). These results were further reflected in the EC $\left(\mu \mathrm{cm}^{-1}\right)$ of runoff samples since slightly higher annual values were found for the second year after fire especially at the $4 \mathrm{x}$ burnt sites (Table 3.3), as would be expected since this parameter is an indicator of ions availability (e.g. nitrates and phosphates) in water (Heiniger et al., 2003). At the unburnt site, $\mathrm{N}$ losses were also higher in the second year but no significant differences were found for $\mathrm{P}$ losses between the two hydrological years, possibly due to the complex biogeochemical process involving this nutrient (Murphy et al., 2006; Certini, 2005; Kutiel and Shaviv, 1992).

Differences in TN and TP exports over time were also found between unburnt and burnt sites (Fig. 3.6 and Fig. 3.7). At the unburnt site, nutrient exports were maintained low over time, most likely due to the existence of a permanent soil cover (Cerdan et al., 2010). At the two burnt sites ( $4 \mathrm{x}$ and $1 \mathrm{x}$ ), on the other hand, a peak in $\mathrm{N}$ and $\mathrm{P}$ exports was observed immediately after the first significant post-fire rainfall event, possibly due to the transport of the easily-erodible nutrient-enriched ash layer (Caon et al., 2014; Pereira et al., 2012; Murphy et al., 2006). After this initial peak, peaks in $\mathrm{N}$ and $\mathrm{P}$ exports were mainly observed during the autumn and winter seasons associated to major rainfall events (Fig. 3.6 and Fig. 3.7), as would be expected since these are the events generating the highest runoff amounts and sediment losses. The highest peaks, however, were found in the autumn and winter of 2014 ( $2^{\text {nd }}$ year) mainly as a result of the higher rainfall amounts and intensities registered in this period (Figs. 6 and 7), which promoted runoff generation and sediment losses (Figs. 3). Between-site differences in nutrient exports were maintained over time, i.e. for every moment in time, the highest nutrient exports were found at the $4 \mathrm{x}$ burnt sites, followed by the $1 \mathrm{x}$ burnt sites and the unburnt sites. The slow recovery of litter and vegetation at the $4 \mathrm{x}$ 
burnt site was likely to have promoted overland flow and the associated sediment and nutrient losses (Malvar et al., 2015a; Doerr, 1998) due to the absence of a soil protective layer. These findings suggest that fire recurrence is likely to promote a loss in soil fertility, making more difficult for affected area to recover between fires. Such findings are in line with other studies carried out at micro-plot scale in the study region (Prats et al., 2014), but contradict those of other authors which found post-fire runoff and erosion to be dependent on slope position (Malvar et al., 2015b).

An uncertainty in this study was the severity of the wildfires that arised in the different sites, and probably also in the control sites before 1975. This aspect deserves attention in future studies also. Furthermore, quick post-fire management practices should be applied to burnt areas with high runoff and erosion risk and slow plant recovery potentials (Hosseini et al., 2016) to minimize the risk of further soil fertility losses.

\subsection{Conclusions}

The present study evaluated the effects of wildfire occurrence and recurrence on nutrient losses by overland flow. The main findings of the present study were that:

- Wildfires induced marked changes on hydrological processes, as well as on nutrient cycles, which contribute to strong degradation of ecosystems;

- Repeated wildfires seem to have compromised the recovery of vegetation and the reestablishment of the litter layer, leading to higher $\mathrm{N}$ and $\mathrm{P}$ losses by runoff than single wildfires;

- The presence of a pine needle cover from scorched crowns at the $1 \mathrm{x}$ burnt sites reduced $\mathrm{N}$ and $\mathrm{P}$ losses by overland flow. These results emphasize the importance of a protective soil layer to reduce post-fire nutrient losses and, eventually, for actions against soil fertility loss;

- High concentrations of suspended solids and nutrients in runoff water might affect the water quality of downstream aquatic systems, which preferably should be prevented by targeted post-fire land management;

- Studies at longer time scales than considered in this study are needed to assess the implications of fire frequency and intensity on Mediterranean ecosystems. 
Acknowledgements

This research was supported and carried out in the framework of the CASCADE project (FP7 - ENV.2011.2.1.4-2/283068), which was funded by the European Union. The University of Aveiro, CESAM team is acknowledged for providing a nice work environment and access to relevant facilities. The authors also gratefully acknowledge Astrid Mous, Ayşe Betül Baytürk, Ariët Kieskamp, Daniela Varandas, Liliana Santos, Ana-Isabel Machado and Martinho Martins for their help with the fieldwork and laboratory analyses, Demie Moore for inputs to improve an earlier version of this manuscript, and SAR-UAF Netherlands for their kind overall support. 


\section{The short-term effectiveness of surfactant seed coating and mulching treatment in reducing post-fire runoff and erosion}

Over the last few decades, there has been a rise in the incidence of wildfires in Portugal which can have negative effects on environmental efficiency in the long run. Wildfires are a common phenomenon in Portugal, with an average of 130,000 hectares of land burned every year. The loss of vegetation and the increase in soil water repellency resulting from these fires, in turn, increases runoff and erosion. Wildfires physically degrade land by promoting runoff and erosion. This leads to an increase in suspended solids in aquatic ecosystems which may negatively impact aquatic habitat quality. The frequency of wildfires is likely to increase due to climate change. There are still significant knowledge gaps in post-fire erosion research. Therefore, in this study, a field soil erosion assessment at micro-plot scale was conducted in order to assess runoff, erosion and mitigation methods aimed at reducing runoff and erosion in a former maritime pine forest. In the field experiment, the effects of four mitigation methods were assessed which included the use of i) grass seeds (Fescue), ii) grass seeds with a surfactant coat, iii) pine seeds (maritime pine) and iv) pine seeds with pine needle mulch. In a randomized block design with plots measuring $0.25 \mathrm{~m}^{2}$, the runoff and erosion was measured at weekly intervals and compared to control plots, located on bare soil. Total rainfall and maximum rainfall intensity ( $\left.I_{30}\right)$ data were recorded using automatic and totalizer rainfall gauges. The outcome of this study shows that in plots with needle mulch, the erosion rates were some of the lowest recorded since the needles protected the soil from erosion. We also found that the use of surfactant-coated (SC) grass seeds would result in the lowest runoff measurements since they enhanced infiltration. Demonstrated surfactant-coating technology can improve soil hydrologic properties as well as seedling emergence and growth in rangeland soils impacted by wildfire.

Based on:

Hosseini, M., Pelayo, O.G., Vasques, A., Ritsema, C.J., Geissen, V. and Keizer, J.J. 2017. The short-term effectiveness of surfactant seed coating and mulching treatment in reducing post-fire runoff and erosion. Geoderma, 307, pp.231-237. 


\subsection{Introduction}

Fire can cause significant changes in the configuration of forests ecosystems, acting as an essential ecological factor in the distribution of biomes, especially in the Mediterranean area (Fernandez-Manso et al., 2016). Performing management actions in areas affected by fires is essential for forest recovery. Any management practices used are dependent upon several factors such as a fire's size, recurrence, intensity and severity as well as an area's topography, climate and soil type (Vlassova and Pérez-Cabello, 2016). Wildfires are a common occurrence in Mediterranean regions. In Portugal, between 1980 and 2016, an average of 130,000 hectares of forest burned every year (ICNF, 2016; Prats et al., 2012; Giglio et al., 2006). The last few decades, the frequency of wildfires has increased due to lightening, desertification, deforestation, persistent droughts, urban growth, resource exploitation, fresh water reduction, and global warming, just to name a few (Westerling et al., 2006). Furthermore, the current practice of planting highly flammable trees like pines and eucalyptus increases the frequency of fires (Almeida et al., 2016; Shakesby et al., 1996). Although fires play an important role in the regulation and development of Mediterranean forest ecosystems by inhibiting or setting back succession, they can also increase surface runoff and erosion and thus contribute to the physical degradation of the land (Shakesby, 2011). In burned areas formerly covered by maritime pine (Pinus pinaster), each millimetre of runoff can result in approximately $0.25 \mathrm{~g} \mathrm{~m}^{-2}$ of sediment loss (Martins et al., 2013; Prats et al., 2012). Apart from the loss of vegetation, which is also controlled by factors like fire frequency, severity and post-fire changes in soil properties (Shakesby, 2011). Systems of human origin such as pine and eucalyptus plantations are more prone to erosion than areas with native vegetation due to the higher percentage of bare soil in these areas (Pausas et al., 2008; Wilkinson et al., 2006). Furthermore, erosion is linked to the loss of plant nutrients (e.g. N and P) (Hosseini et al., 2017). This contributes to decreased soil fertility (Stoof et al., 2012) while at the same time contributing to increased nutrient concentrations in aquatic systems such as rivers (Wilkinson et al., 2006).

Although the generation of runoff and erosion that occurs after forest fires is well studied (Stoof et al., 2012; Shakesby, 2011; Shakesby and Doerr, 2006; Certini, 2005), there is a lack of comprehensive knowledge regarding off-site effects as well as a lack of understanding in how to mitigate them (Prats et al., 2012). Since the lack of vegetation cover is a key factor in enhanced runoff and erosion rates, a commonly applied mitigating treatment is mulching (Prats et al., 2016a and b; Prats et al., 2012). Mulching is the process of applying mulch that could consist log slash, bark or pine needles to soil (Prats et al., 2012; Shakesby, 2011). It prevents soil erosion by creating a cover that protects the soil (Díaz-Raviña et al., 2012; Prats et al., 2012). 
One mitigation method includes sowing grass or pine seeds, which contributes to vegetation recovery and therefore indirectly reduces runoff and erosion. Seeds with a surfactantcoating might be even more promising since surfactants reduce the surface tension of water and hence function as wetting agents, resulting in an enhanced infiltration of water. The root-zone water reserves are improved in water repellent soils when using surfactant-coated seeds which in turn promote vegetation growth thus increasing the protective cover (Madsen et al., 2012). The use of surfactants alone has been found to reduce soil-water repellency hence enhancing infiltration (Moore et al., 2010; Leighton Boyce et al., 2007). According to previous studies that were conducted in the same area, mulching has rarely been used in post-fire land management even though it has shown to be very effective in directly reducing runoff and erosion in Portugal (Prats et al., 2016b; Prats et al., 2014; Prats et al., 2012). Further research on the benefits of these mitigation methods is necessary. It is also important to develop and test methods that would indirectly reduce runoff and soil erosion such as the use of surfactant-coated seeds.

The objective of this research was to learn more about post-fire management techniques with the aim of decreasing soil erosion and runoff which could in turn help guarantee the preservation of forest ecology and the reduction of forest fires. In this research, runoff and erosion occurring after repeated wildfires in a maritime pine forest were studied and different mitigation methods were assessed. We selected a study site that had burned four times in the last 30 years. An erosion assessment at micro plot scale was performed to test the effectiveness of four mitigation methods in reducing runoff and erosion. This assessment included: i) sowing pine seeds, ii) sowing pine seeds combined with mulching with pine needles, iii) sowing grass seeds and iv) sowing surfactant-coated seeds. It was expected that the runoff from plots with surfactant-coated seeds would be lower. Reduced sediment transport was expected to occur in the mulched plots since different types of mulching have shown to be highly effective in reducing soil erosion (Prats et al., 2012; Pannkuk and Robichaud, 2003; Shakesby et al., 1996). 


\subsection{Materials and methods}

\subsubsection{Study site characterization}

The study area is located in north-central Portugal and is part of the Vouga River Basin which drains into the Ria de Aveiro coastal lagoon area. According to Köppen's system, the climate can be classified as a temperate climate (Csb) as well as a humid mesothermal climate with a prolonged dry and warm summer. National information resource (SNIRH, 2014) reported that annual rainfall ranges from 1200 to over $2000 \mathrm{~mm}$ per year and the mean monthly temperatures range from $9^{\circ} \mathrm{C}$ in January to $23^{\circ} \mathrm{C}$ in July. The terrain has a relief with steep slopes of around $20-30^{\circ}$. The bedrock is Schist and the soils are mainly humic Cambisols and epileptic Umbrisols and, to a smaller extent, umbric Leptosols. Overall, soils are shallow, being less than $30 \mathrm{~cm}$ deep, and are susceptible to degradation by soil erosion, land use and vegetation (Figure 4.1).

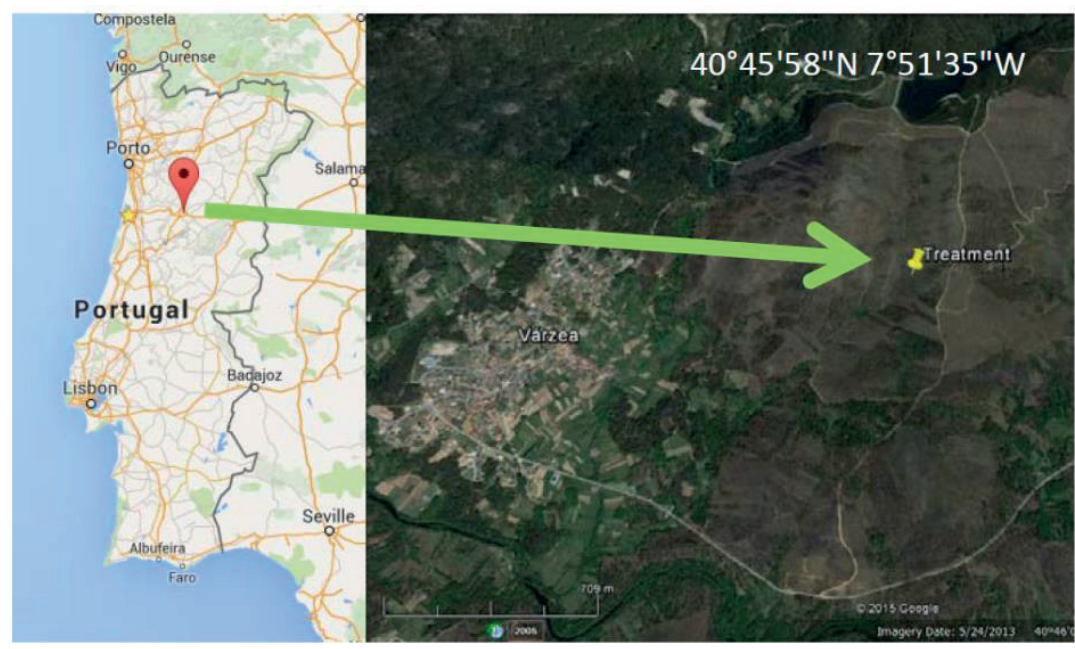

Figure 4.1 Locations of study sites in Viseu municipality, Portugal.

\subsubsection{Experimental set-up}

The experimental design of this study is focused around a forest area that has burned four times since 1975 (in 1978, 1985, 2005, 2012). Micro-plots of approximately $0.25 \mathrm{~m}^{2}$ (Figure 4.2) were set up on the site. Iron plates were installed at the uppermost points of these plots to protect the experiment area from upslope run-off. Initial characteristics of the research area are presented in Table 4.1. Every plot was connected to a hose which diverted any 
surface runoff to a $70 \mathrm{~L}$ tank. The 15 plots were used to test four different erosion mitigation methods that were developed with the aim of reducing runoff and erosion: $(n=3)$ : i) grass seeds, ii) grass seeds with a surfactant coating, iii) pine seeds and iv) pine seeds with pine needle mulch (Table 4.2). In addition, three control plots were made on bare soil (Figure 4.2). The treatments were applied in October 2013. Seed coating was performed according to Madsen and Petersen, 2010. The surfactant chemical used was ACA-1820, which is a nonionic, alkyl-terminated, EO/PO alkyl-terminated block copolymer from Aquatrols Corporation of America (Paulsboro, NJ, USA). In this research, we used the native grass species tall Fescue (Festuca arundinacea) and Agrostis which comprised the main grass cover in the field. For the pine seeds, we used the native species maritime pine (Pinus pinaster).

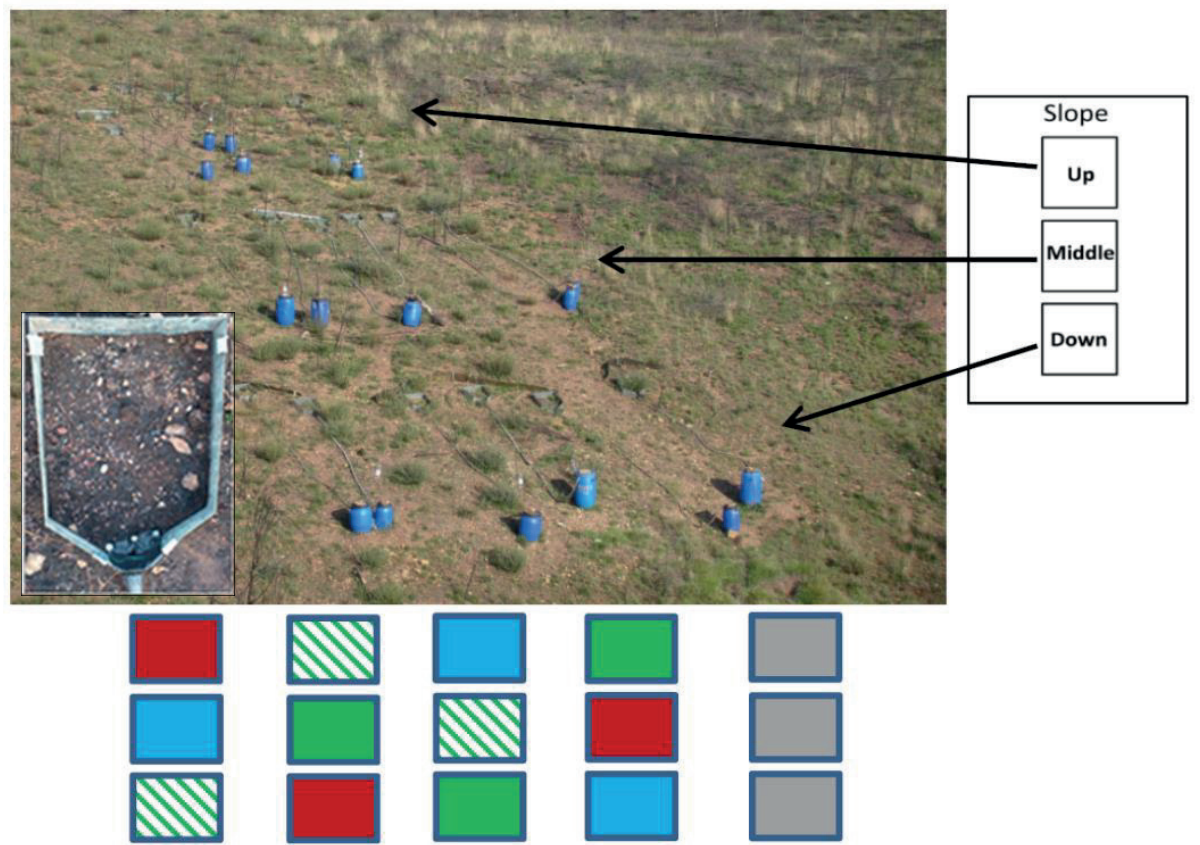

Figure 4.2 Experimental plots, connected to pipes and blue tanks. The distribution of the treatments according to a randomized block design is shown on the right with control plots (grey), grass seed plots (green), grass seeds + surfactant coating 20\% (green with patterns), pine seed plots (blue) and pine seeds + pine needle (red).

Table 4.1 Site charactristics.

\begin{tabular}{ccccccccc}
\hline Treatment Slope & \multicolumn{4}{c}{ Initial surface cover $(\%)^{*}$} & Top soil texture & Top soil pH & $\begin{array}{c}\text { Top soil bulk } \\
\text { density }\left(\mathrm{g} \mathrm{cm}^{-3}\right)\end{array}$ \\
\hline \multirow{2}{*}{4 4x burnt } & Ash & BS & L & S & Veg & Loam & $4.5 \pm 0.05$ & $0.82 \pm 0.09$ \\
\cline { 2 - 5 } & 46 & 30 & 1 & 23 & 0 & & & \\
\hline
\end{tabular}

*BS: Bare soil, L: Litter, S: Stone, Veg: Vegetation 
Table 4.2 Treatments applied in this study.

\begin{tabular}{cccc}
\hline Treatment number & Treatment & Amount & No. of plots \\
\hline T1 & Grass seed & $3200 \mathrm{gr}$ & 3 \\
T2 & Grass seeds + surfactant coating 20\% & $3200 \mathrm{gr}$ & 3 \\
T3 & Pine seed & $25^{*}$ & 3 \\
T4 & Pine seeds + pine needle & $25^{*}$ & 3 \\
T5 & Control (bare soil) & - & 3 \\
\hline
\end{tabular}

* 25 is the number of pine seeds used in this treatment (one seed for each $0.01 \mathrm{~m}^{2}$ )

\subsubsection{Data collection}

\subsubsection{Rainfall and runoff characteristic}

The field data and samples were collected from the $4^{\text {th }}$ of September 2013 to the $4^{\text {th }}$ of September 2014 at one to two-week intervals after each rainfall occurrence. Total rainfall and rain intensity per week were measured with totalizer and automatic rainfall gauges. Totalizer rain gauges were used to measure rainfall and $\mathrm{HOBO}$ waterproof data loggers were used to measure rainfall and rain intensity $1_{30}$, which is defined as the amount of rain falling during a 30 minute period. Every plot was connected to a hose that diverted the surface runoff to a $70 \mathrm{~L}$ tank. $\mathrm{pH}$ and $\mathrm{EC}\left(\mathrm{H}_{2} \mathrm{O}\right)$ of runoff were measured by a potentiometer (accuracy of \pm 0.01 ) (Hosseini et al., 2016).

\subsubsection{Soil cover}

The plots were assessed from October 2013 to June 2014 . A $10 \times 10 \mathrm{~cm}$ gridded quadrat was laid over each plot and the cover at each crossing point of the gridlines was determined and recorded as stone cover (bedrock and fragments $>2 \mathrm{~mm}$ ), bare soil, ash, litter, Festuca, Agrostis and other vegetation. These cover types were included as factors affecting runoff and erosion.

\subsubsection{Organic matter losses by runoff}

Sediment concentrations in the runoff samples were determined by first vigorously shaking the $1.5 \mathrm{~L}$ bottles and then pouring the contents over filter paper that was $330 \mathrm{~mm}$ in diameter with a particle-retention size of 12-15 $\mu \mathrm{m}$ (VWR International, Leuven). The filters were oven-dried at $105{ }^{\circ} \mathrm{C}$ for 24 hours. The organic matter (OM) content of the eroded sediments was determined using the loss-on-ignition method (Ball, 1964). The resulting weight loss was used to compute the OM content of the mineral soil (Hosseini et al., 2016). 


\subsection{Data analysis}

All statistical analyses were performed using IBM SPSS 22.0 statistics software. The data were tested for normality based on the Kolmogorov-Smirnov test. We used the one way ANOVA for normally distributed data and the Mann-Whitney $U$ test for non-homogenous variances to identify significant differences among the plots. All tests were deemed statistically significant at a probability value of 0.05 . Pearson correlation analyses of the variables were also performed, six of the highest rainfall events were chosen to statistically compare and analyse the treatment results. A principal component analysis (PCA) was mainly used to compress the information contained in a large number of variables into a smaller set of new merged dimensions with a minimum loss of information. In this research, PCA was conducted for 4 times burnt site for runoff, rainfall, soil cover, seed coating and rainfall intensity $\left(\mathrm{I}_{30}\right)$.

\subsection{Results}

\subsubsection{Rainfall and $I_{30}$ distribution}

A total amount of $1632 \mathrm{~mm}$ of rain fell between October 2, 2013 and October 22, 2014. Rainfall was particularly high on six occasions, exceeding $100 \mathrm{~mm}$. These heavy rains occurred mostly during the autumn and winter. The heavy rains in September, October, and late December 2013 had the highest rain intensities (25-30 $\mathrm{mm} \mathrm{h}^{-1}$ ) (Hosseini et al., 2016).

\subsubsection{Soil cover}

The treatment using a $20 \%$ surfactant coating had a tendency to have more Festuca than the control treatment without surfactant (Fig 4.3). The cover of Agrostis was greater in the plots with Festuca (T1) than in the treatment plots with $20 \%$ surfactant coated seeds (T2) and similar to the cover observed in the bare plots (T5). This could be due to differences in the initial selection of the plots. The total cover was lower in the bare soil plots than in the other treatments but this was mainly due to the cover of Festuca that was exclusive to the other plots. The average heights of the pines located in the plots with the treatment of pine seeds and pine seeds with needle are given in Figure 4.4. 


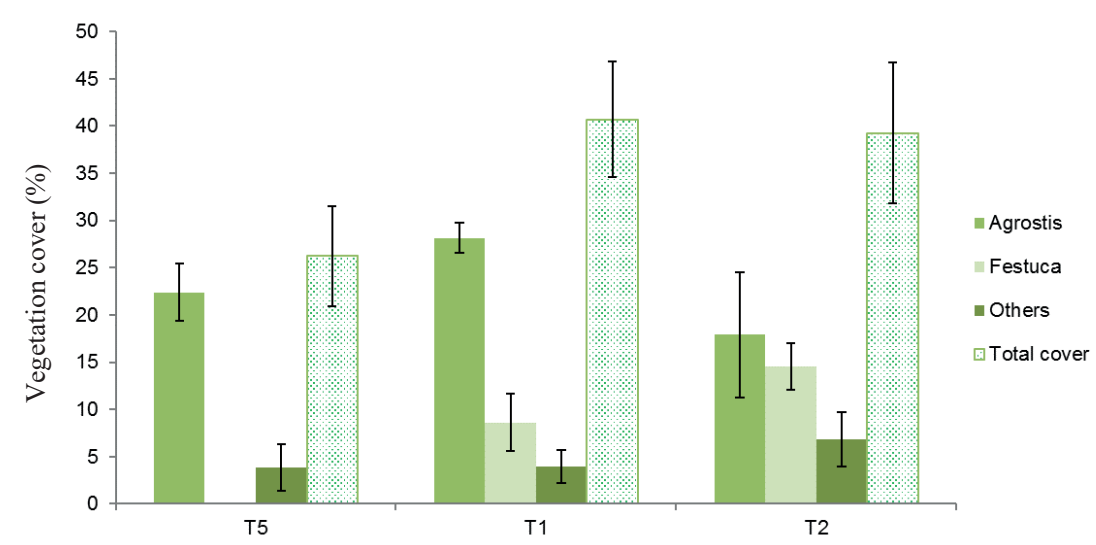

Figure 4.3 Average vegetation cover in plots T1 (Grass seed), T2 (Grass seeds + surfactant coating 20\%), T5 (Control), measured from October 2013 to June 2014.

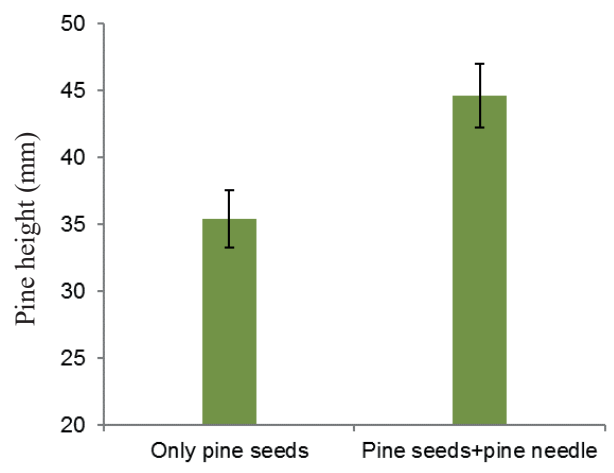

Figure 4.4 Average pine height in T3 (pine seeds) and T4 (pine seeds + pine needle) plots, measured from October 2013 to June 2014.

\subsubsection{Runoff distribution}

Plots with grass seeds which were $20 \%$ covered with a surfactant coating produced a significantly lower $(p<0.05)$ total runoff compared to the plots using grass seeds without the surfactant coating (Fig 4.5): $206 \pm 48 \mathrm{~mm}$ and $642 \pm 149 \mathrm{~mm}$, respectively. The plots with pine seeds with pine needle showed significantly reduced $(p<0.05)$ runoff compared to the control treatment, which significantly decreased the total erosion (Fig 4.6). During the research period, total runoff was measured as $426 \pm 118 \mathrm{~L} \mathrm{~m}^{-2}$ for plots with pine seeds plus needle, $720 \pm 201 \mathrm{~L} \mathrm{~m}^{-2}$ for plots with bare soil and $764 \pm 231 \mathrm{~L} \mathrm{~m}^{-2}$ for plots with pine seed alone. 

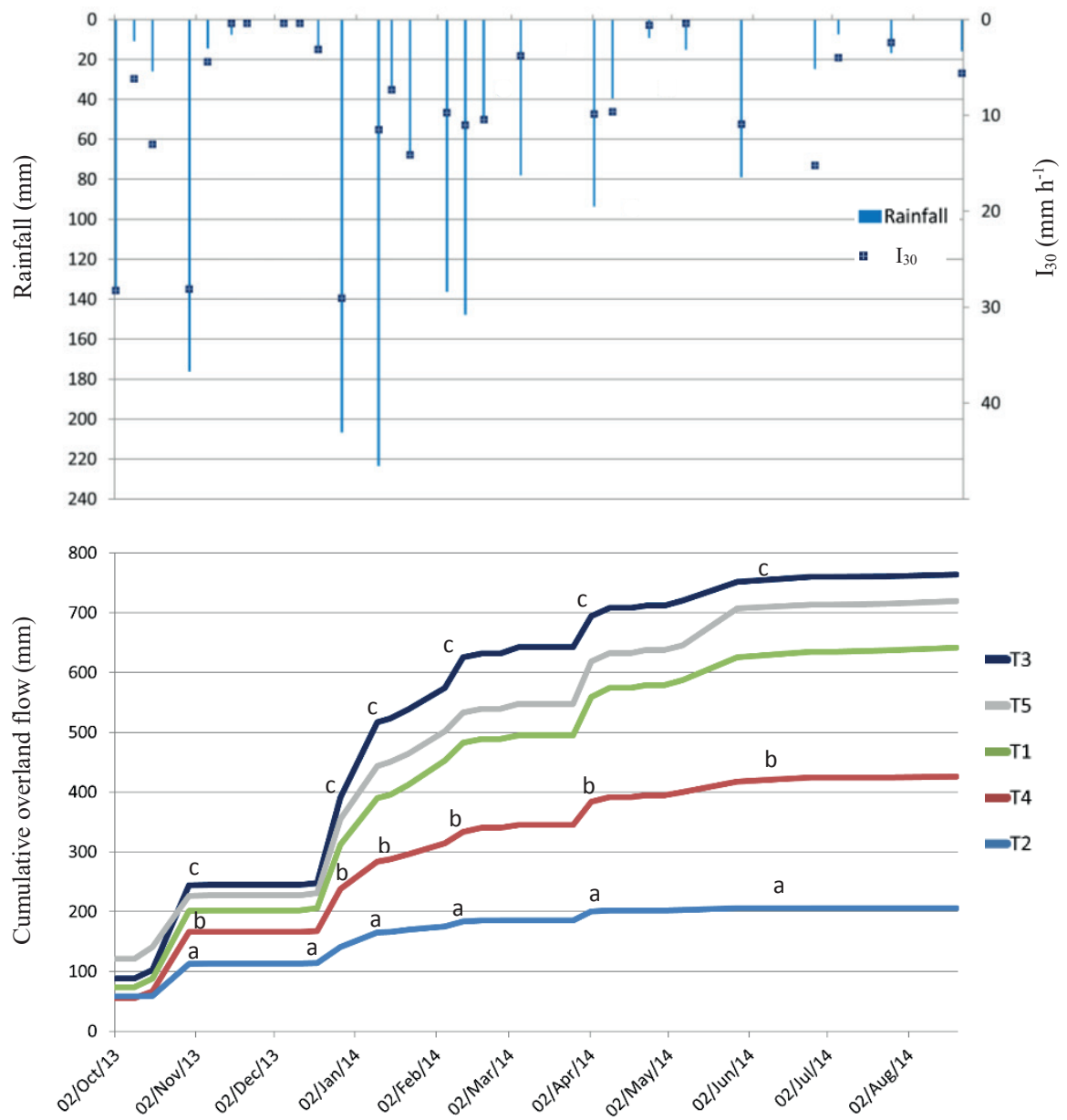

Figure 4.5 Rainfall and cumulative overland flow for treated plots T1 (grass seed), T2 (grass seeds + surfactant coat 20\%), T3 (pine seed), T4 (Pine seeds + pine needle) and T5 (control). Different lowercase letters indicate significant differences among treatments $(p<0.05),(a>b>c)$. Treatment $T 2$ performs best and T3 and T5 worst. 

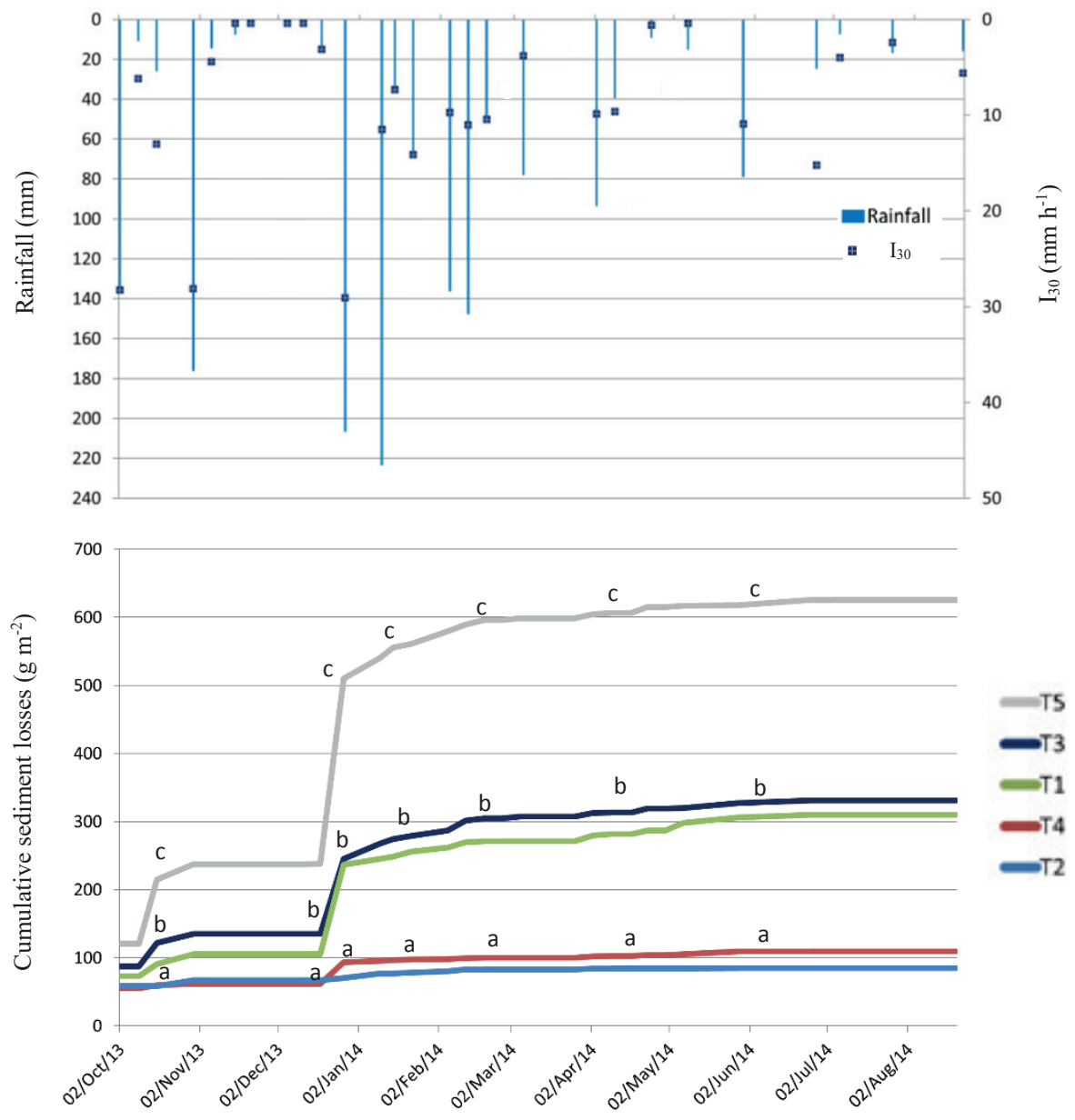

Figure 4.6 Rainfall and cumulative sediment losses for treated plots T1 (grass seed), T2 (grass seeds + surfactant coat 20\%), T3 (pine seed), T4 (Pine seeds + pine needle) and T5 (control). Different lowercase letters indicate significant differences among sites $(p<0.05),(a>b>c)$. Treatment $T 2$ performs best and $T 3$ and $T 5$ worst.

\subsubsection{Sediment and OM losses}

After a fire, the surface of most of the plots consisted of bare soil with a thick layer of ash and exhibiting an altered structure. The different treatments had a significant effect on the sediment yield (Fig 4.6). The seed coating and pine needle mulching treatment yielded 
significantly less sediment than the grass and pine seeding treatment $(p<0.05)$ and the untreated burned soils $(p<0.05)$. There were no significant differences between surfactant seed coating and mulching treatment $(p=0.38)$.

The magnitude of the OM losses by runoff varied widely among treatments after rain events (Fig 4.7). Generally, the significant OM losses occurred in the bare soil plots $(p<05)$. The OM losses in the T3 and T1 plots were significantly smaller than the losses seen in the bare soil plots and significantly higher $(p<0.05)$ than T2 and T4. The greatest OM losses were measured right from the start of the experiment until spring 2014 after which losses ceases.



Figure 4.7 Rainfall and cumulative organic matter losses by runoff for treated plots T1 (grass seed), T2 (grass seeds + surfactant coat 20\%), T3 (pine seed), T4 (Pine seeds + pine needle) and T5 (control). Different lowercase letters indicate significant differences among sites $(p<0.05)$, $(a>b>c)$. T4 and T2 performs best and T5 worst. 


\subsubsection{Relation of various parameters that affect runoff and erosion}

The principal component analysis (PCAs) of burnt sites was carried out using the principal components: surfactant coating, rainfall, and surface cover by $84 \%, 65 \%$ and $60 \%$, respectively. The main components extracted from the variables for treatment plots are presented in (Fig 4.8). The runoff and sediment losses showed a strong positive correlation to the amount of rainfall, which was also positively correlated to the $1_{30}$. However, there was also a significant correlation between mulching and surface cover with decreasing runoff and sediment losses.

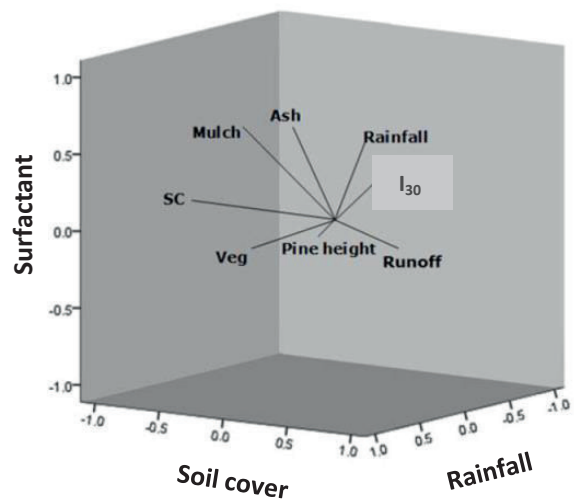

Figure 4.8 Three principal components extracted from the variables for treatment: Rainfall, rainfall intensity (I30); runoff; ash; vegetation (Veg); pine mulch; surfactant coating (SC); pine height.

\subsection{Discussion}

\subsubsection{Treatment with seeds}

Wildfires can enhance soil water repellency (Malvar et al., 2015a; Shakesby and Doerr, 2006). The use of surfactants has been found to decrease the soil water repellency and therefore increase the soil's ability to absorb water (Madsen et al., 2013b; Ritsema et al., 2008). Applying surfactants by using surfactant-coated seeds has been studied by Madsen et al., 2012. Researchers showed that the use of surfactant-coated seeds reduced the runoff of plots planted Blue-bunched Wheatgrass (Pseudoegneria spicata) by $59 \%$, compared to control plots. In the present study, there was also a reduction in runoff in the plots treated with surfactant-coated seeds. Although it was clear that these plots experienced less runoff, the question arises as to whether this runoff reduction was caused by the surfactant coat itself, the increased germination due to the surfactant coat, or by both. Results from Madsen 
et al., 2012 using Blue-bunched Wheatgrass showed an increased germination rate of approximately three times. However, in the same study, the use of surfactant-coated Crested Wheatgrass seeds (Agropyron cristatum) resulted in the same seedling density as seeds without a surfactant coating (Madsen et al., 2012). Germination rates depended on the moisture requirements of each species and whether the surfactant coating could influence the germination rate or not (Madsen et al., 2013a; Madsen et al., 2012). It is possible that the germination rate of Tall Fescue used in our study is affected by the surfactant coating since the Tall Fescue cover was higher than the cover in plots with non-treated seeds. However, it is not likely that this possibly enhanced germination rate affected the reduced runoff since the total vegetation cover was approximately the same ( $41 \%$ for non-treated seeds and $39 \%$ for surfactant-coated seeds). It could also be that the reduction of runoff was mainly caused by the surfactant itself. But we are not sure how long the surfactant was effective. Also, we can't say if the germination rate would be different between non-treated and surfactant-coated seeds in the long term. The application of untreated seeds, either grass or pine, did not result in significantly lower total runoff and erosion values as compared to the treatment with $20 \%$ surfactant-coated seeds and pine seeds combined with mulching with pine needles within the present experiment. This is in line with findings of MacDonald and Larsen (2009) who indicate that the most effective methods to reduce erosion rates were the ones that immediately covered the soil. The use of Slender wheatgrass (Elymus trachycaulus) or Mountain brome (Bromus marginatus) did not result in lower erosion rates while mulch treatments like straw mulch and hydro mulch did (MacDonald and Larsen, 2009).

\subsubsection{Treatment with pine needle}

The affected reduction of total erosion values by pine needle mulch is also shown by Pannkuk and Robichaud (2003). Although they used a different design than the current study in the fact that they performed laboratory experiments with simulated rainfall on granitic soil and used different species, it is clear that needles significantly reduced erosion with a $94 \%$ reduction with the use of Ponderosa pine needles and a $74 \%$ reduction with the use of Douglas fir needles (Pannkuk and Robichaud, 2003). The value for sediment erosion in our research showed that erosion was reduced by $88 \%$ because the needles provided a protective carpet over the soil, intercepting the rain and thus preventing transport of sediment away from the plot (Prosdocimi et al., 2016b). Compared to other mulching techniques, using chopped Eucalypt bark reduced erosion by $89 \%$ (Prats et al., 2012) and using Eucalypt logging slash reduced erosion by $91 \%$ (Shakesby et al., 1996). The effectiveness of pine needle mulch is comparable to these findings (Prosdocimi et al., 2016b). 
Although the values for total runoff were lower in the plots with grass seeds than the total runoff in the control plots (Krebs et al. 2010), the difference was not significant. It was expected that the needles would enhance the runoff because the interception of the water by the needles should have prevented the water from infiltrating the soil (Prosdocimi et al., 2016a; Sadeghi et al., 2015). This was not demonstrated in the present study.

\subsection{Conclusion}

The present study evaluated four different treatments to minimize runoff and erosion after wildfire. Results indicated that:

- Treatment T2 (grass seeds + surfactant coating 20\%), and T4 (Pine seeds + pine needle) performs best to decrease overland flow, sediment transport and OM losses and T3 (pine seed) and T5 (control) worst;

- Surfactant coating seeds (SC) technology increased rootzone water reserves for seedling emergence substantially, as well as cover and biomass production;

- SC technology may provide a promising approach to cope with water scarcity issues and at the same time increase plant performance.

Acknowledgements

This research was supported and carried out in the framework of the CASCADE project (FP7 - ENV.2011.2.1.4-2/283068), which was funded by the European Union. Aquatrols Corporation of America and the University of Aveiro, CESAM team are highly acknowledged for providing access to relevant materials and facilities. The authors also gratefully acknowledge Astrid Mous, Ayşe Betül Baytürk, Ariët Kieskamp, Daniela Varandas, Liliana Santos, Ana-Isabel Machado and Martinho Martins for their help with the fieldwork and laboratory analyses, Demie Moore for inputs to improve an earlier version of this manuscript, and SAR-UAF Netherlands for their kind overall support. 


\section{Developing generalized parameters for post- fire erosion risk assessment using the revised Morgan-Morgan-Finney model: a test for north-central Portuguese pine stands}

Models can be useful for predicting the hydrological impacts of natural phenomenon such as wildfires and to help implement effective post-fire land management options. In this research, the revised Morgan-Morgan-Finney (MMF) model was used to simulate runoff and soil erosion in recently burned maritime pine plantations with contrasting fire regimes, in a wet Mediterranean region of north-central Portugal. The MMF model was adapted for burnt areas by implementing seasonal changes in model parameters in order to accommodate seasonal patterns in runoff and soil erosion, attributed to changes in soil water repellency and vegetation recovery. The model was then evaluated by applying it for a total of 18 experimental micro-plots $\left(0.25 \mathrm{~m}^{2}\right)$ at 9 once burned and 9 four times burned slopes, using both previously published and newly calibrated parameters, with observed data used to evaluate the robustness and wider applicability of each parameterization. The prediction of erosion was more accurate than that of runoff, with an overall Nash-Sutcliffe efficiency of 0.54. Slope angle and the soils' effective hydrological depth (which depends on vegetation and/or crop cover) were found to be the main parameters improving model outcomes, and different parameters were needed to differentiate between the two contrasting fire regimes. This case study showed that most existing benchmark parameters can be used to apply MMF in burned pine forest areas with moderate severity fires to support post-fire management, but indicated that further efforts should focus on mapping soil depth and vegetation cover to improve these assessments.

Based on:

Hosseini, M., Nunes, J.P., González-Pelayo, O., Keizer, J.J., Ritsema, C.J., and Geissen, V., 2018. Developing generalized parameters for post-fire erosion risk assessment using the revised Morgan-Morgan-Finney model: a test for north-central Portuguese pine stands. Catena, 165, pp.358-368. 


\subsection{Introduction}

Fire is a key component of the Earth system. It is a major and frequent disturbance in forest ecosystems, especially in Mediterranean regions due to their dry, hot summers followed by frequent and high-intensity rain in the autumn immediately after the wildfire season (Shakesby, 2011). Post-fire erosion is an important societal concern because of the potential impacts on soils and water resources. Increases in soil erosion rates are frequently observed following wildfires (Fernández et al., 2010; Shakesby and Doerr, 2006). Increases in wildfire frequency and burned area are commonly expected under probable future climate scenarios for the Mediterranean region (Fernández et al., 2010), further stressing the need for adequate post-fire vegetation and soil management strategies.

The heating of the soils by fire can change its physical, chemical and biological characteristics, such as water repellency, behaviour and stability of aggregates (Shakesby and Doerr, 2006), soil organic matter quantity and quality (Wittenberg et al., 2014; Shakesby, 2011), nutrient availability (Ferreira et al., 2016a and b), and composition of soil microbial and invertebrate communities (Certini, 2005). Besides soils, vegetation is typically consumed to a smaller or larger degree, depending on fire severity (Díaz-Delgado et al., 2003). Post-fire circumstances can be favourable for vegetation regrowth, due to increased nutrient and water availability while facing less competition (Cerdà and Doerr, 2005). Nonetheless, vegetation cover is typically reduced during the post-fire period, leading to decreased rainfall interception and overland flow resistance (Esteves et al., 2012; Ferreira et al., 2008). Fire-induced changes in soil and vegetation properties can substantially influence post fire hydrological and erosion processes (Shakesby, 2011). Mayor et al. (2007), for example, found increased peak discharges at the catchment-scale occurred especially during the first year after a wildfire. Compared to single fires, recurrent fires may affect soil properties, and reduce or, at least, slow down vegetation recovery, leading to higher runoff and erosion rates, high concentrations of suspended solids and nutrients in runoff can reduce the quality of downstream aquatic systems (Hosseini et al., 2016).

Accurate predictions of post fire erosion rates are needed to estimate the potential impacts of wildfires on on-site ecosystem services such as biomass productivity as well as on downstream aquatic habitats and organisms, and, at the same time, to assess the potential benefits of post fire rehabilitation treatments (Larsen and MacDonald, 2007). However, models can only use approximate descriptions of the system under study, and moreover contain parameters, initial and boundary conditions which are unknown (Moody et al., 2013). Modelling efforts for burned areas, including erosion predictions after fire, have been a research goal of several studies (van Eck et al., 2016; Langhans et al., 2016; Vieira et al., 2014; Fernández et al., 2010; Moody et al., 2008; Larsen and MacDonald, 2007; Benavides- 
Solorio and MacDonald, 2005). Erosion prediction approaches are well developed for postfire conditions in the U.S., where they are applied operationally (e.g. Robichaud et al., 2007, 2016). However, other regions can have different dominant erosion processes (Moody et al., 2013), and therefore require adapted models. Mediterranean burnt areas have particular conditions, such as a strongly seasonal soil water repellency which is not caused by fire, very shallow soils, or the absence of generalized riling in burnt areas (Shakesby, 2011). In particular, soil water repellency has been pointed as an important limitation in the application of erosion models for burnt conditions in the Mediterranean (Vieira et al., 2014; Esteves et al., 2012). Therefore, there is still a need to improve process representation for Mediterranean burned areas, including the determination of appropriate model parameters which can be used for general application as post-fire management tools.

The present study focused on testing soil parameters to predict the impact of recurrent wildfires on runoff and erosion using the revised Morgan-Morgan-Finney (MMF) model (Morgan, 2001), and on understanding which parameters can be generalized for use in different sites, and which ones require local information, in particular related with soil physical properties. The revised MMF was applied to predict runoff and associated sediment losses at the micro-plot scale $\left(0.25 \mathrm{~m}^{2}\right)$ in burned pine plantations in north-central Portugal with contrasting fire histories of single vs. recurrent wildfires. Model performance with sitespecific parameters was compared with that using the parameters derived by Vieira et al. (2014). Small plots such as the present ones have been helpful to get further insights in the connectivity of sediment and water transport (Baartman et al., 2013), and to calibrate the patch-scale components of watershed models (Nunes et al., 2009), and are especially useful in areas where the generation of runoff is fast (Cerdà, 1999). Small plots can allow building a precise model, easy to run, consistent and with little input demand; such models can, when combined with runoff and sediment transport routines, predict water and sediment yield in small and medium-sized catchments (López-Vicente et al., 2013, 2015; Morgan, 2001). The present work involved: i) testing the MMF parameterization developed by Vieira et al. (2014) for this site, in order to assess the robustness of the authors' model application outside its calibration and validation region; and ii) assessing which MMF parameters are more sensitive to regional differences, by calibrating a new parameter set for this study site. 


\subsection{Materials and methods}

\subsubsection{Study area and sites}

The data collection was conducted in an area of Pinus pinaster that was burnt by a wildfire in September 2012 and, based on existing burnt area maps, had partially burnt three more times since 1975, i.e. in 1978, 1985 and 2005. Since ashes were black, the litter layer and understory vegetation were the most affected by fire, and tree crowns were only partially destroyed (Keeley, 2009; Shakesby and Doerr, 2006). The study area was mainly surrounded and covered by stands of P. pinaster, which is a highly flammable tree species with a rotation cycle of 40 years, and with Pterospartum tridentatum as the predominant shrub species (Maia et al., 2012b, 2014; Moreira et al., 2013). The study area is located in north-central Portugal, and is part of the Vouga River Basin which drains into the Ria de Aveiro coastal lagoon (Fig. 5.1). According to Köppen's system, the climate can be classified as temperate $\mathrm{Csb}$, i.e. as humid meso-thermal with a prolonged dry and warm summer, or humid Mediterranean climate. Annual rainfall averages 1690 year $^{-1}$, ranging from 1200 to more than $2000 \mathrm{~mm}$; and mean monthly temperatures range from $9^{\circ} \mathrm{C}$ in January to $23^{\circ} \mathrm{C}$ in July (SNIRH, 2014). The terrain has a relief with steep slopes of around $20-30^{\circ}$. The bedrock consists of schists and the soils are mainly humic Cambisols and epileptic Umbrisols and, to a smaller extent, umbric Leptosols. As elsewhere in the region, soils are shallow, less than $30 \mathrm{~cm}$ deep, and are susceptible to degradation by soil erosion and land use. This area is subjected to recurrent wildfires, and a study by Hosseini et al. (2016) has shown that areas with a more frequent fire history usually show more runoff and erosion in subsequent fires. 


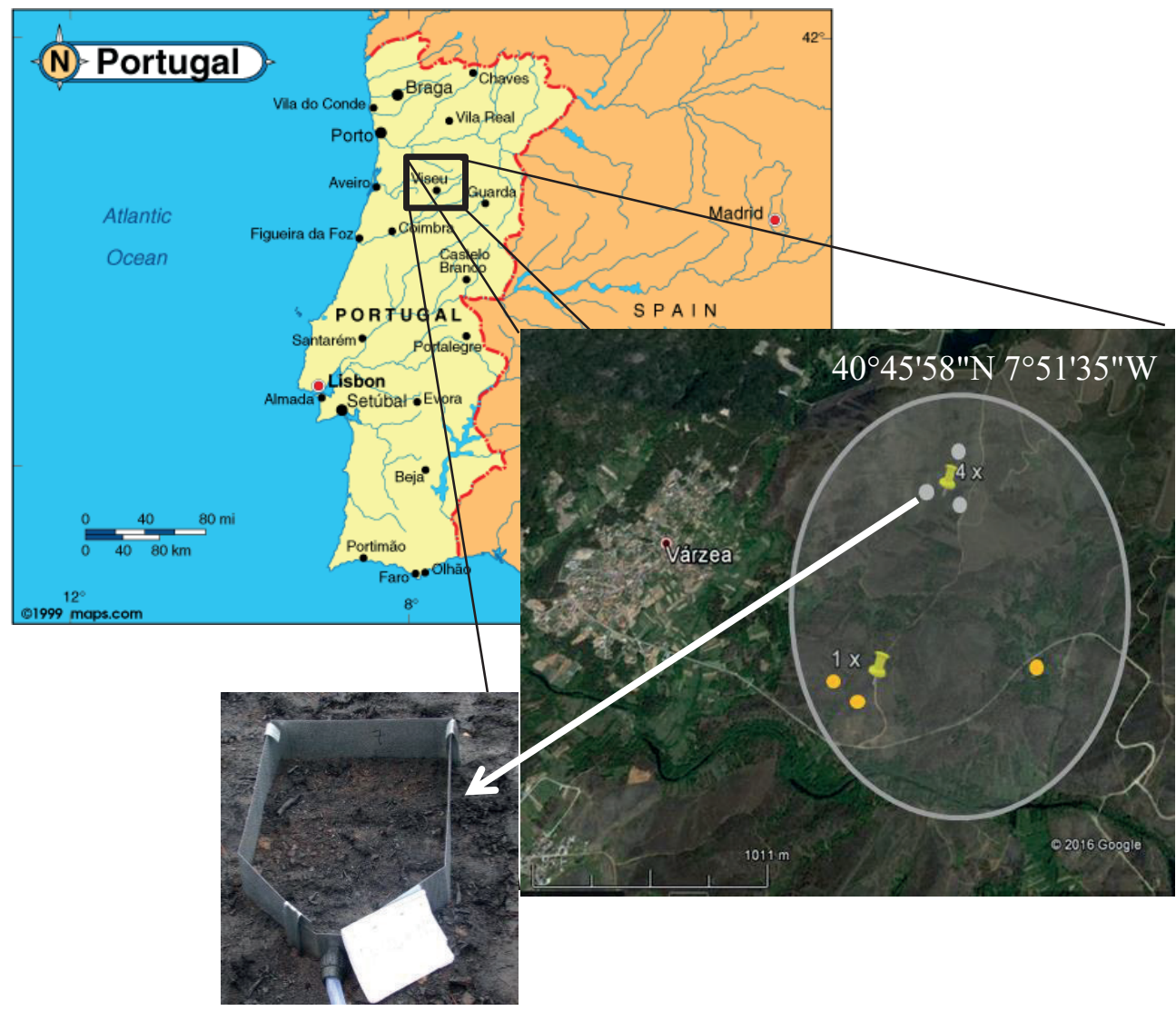

Figure 5.1 Locations of the study area, sites and plots, Viseu municipality, north-central Portugal, Site abbreviation: $4 x$ burnt ( $4 x$ ), $1 x$ burnt (1x).

\subsubsection{Data Collection}

Six maritime pine plantations with similar slope angles and aspects were selected, three of which having burned 4 times and the other three having burned once since 1975. Runoff and eroded sediments were collected from $0.25 \mathrm{~m}^{2}$ micro-plots at the lower, middle, and upper sections of the $4 x$ and $1 x$ burnt slopes, using the same design as prior studies in the region (Malvar et al., 2015b; Martins et al., 2013). The plots were bounded by iron plates; runoff was collected into a hose connected to a $70 \mathrm{~L}$ tank. Rainfall was measured with several storage gauges as well as with automatic, tipping-bucket rainfall gauges, linked to HOBO data event loggers. They were installed across the study area before the occurrence of 
rainfall. Soil moisture sensors were also installed at a depth of $5-10 \mathrm{~cm}$. The micro-plots were installed immediately after the fire, on spots where shrubs had been absent as indicated by the absence of remaining burned-scorched twigs (Hosseini et al., 2016). The experimental set-up is schematized in Fig. 5.2.

Rainfall and runoff data were collected from $4^{\text {th }}$ of September 2012 until $4^{\text {th }}$ of September 2013 at one to two weekly intervals, depending on rainfall occurrence. Rainfall and runoff volume were measured respectively in the storage gauges and $70 \mathrm{~L}$ tanks; a homogenized sample of tank water was collected and taken to the laboratory for sediment determination. The ground cover of the plots was assessed between October 2012 and June 2014 at eight occasions, at roughly two to three monthly intervals. A $10 \times 10 \mathrm{~cm}$ gridded quadrat was laid over each plot, and the cover at each crossing point of the gridlines was determined and recorded as; stone cover (bedrock and fragments $>2 \mathrm{~mm}$ ), bare soil, ash, litter, grass and other vegetation. Further details are provided in Hosseini et al. (2016). The authors also analysed this data to conclude that runoff generation and erosion was larger at the $4 \mathrm{x}$ burnt sites; the latter included an important part of organic matter due to exported ash. Runoff and erosion were driven by soil cover and rainfall amount, including after a period of drought which indicated the importance of soil water repellency.

Daily potential evapotranspiration $\left(E_{0}\right)$ was calculated from temperature records of the nearby Viseu meteorological station, using the Hargreaves method (Hargreaves and Samani, 1985). Actual evapotranspiration ( $\left.E_{t}\right)$ was calculated separately as evaporation from interception, and soil evaporation combined with plant transpiration. For interception, vegetation cover data were used to estimate Leaf Area Index (LAI) as well as canopy storage capacity, using the methods proposed by Deguchi et al. (2006) and Hoyningen-Huene (1981), respectively. Interception (and evaporation) was then calculated using the revised Gash model (Gash et al., 1995). Soil evaporation and plant transpiration were calculated from $E_{0}$, daily rainfall data and continuous soil moisture data using the soil water balance equation and the approach proposed by Nunes et al. (2015), which assumes negligible runoff in days with soil moisture deficit.

\subsubsection{Revised Morgan-Morgan-Finney model}

The revised MMF model (Morgan, 2001) was selected since it has proved simple to use and able to give reasonable estimates of annual runoff and erosion (Vieira et al., 2014). MMF is originally designed as an annual step runoff and erosion model, although Vieira et al. (2014) have shown it works better with a seasonal time step for burnt areas. Fig. 5.3 shows a simplified flow chart of MMF. Runoff is assumed to occur when daily rainfall $\left(R_{0}\right)$ exceeds 
soil water storage capacity $\left(R_{c}\right)$, with an exponential rainfall distribution assumed. Sediment detachment is calculated as the sum of raindrop splash (F), calculated from kinetic energy and canopy cover; and runoff detachment $(\mathrm{H})$, calculated from runoff, slope, vegetation cover and soil resistance. Sediment transport capacity by runoff (TC) is calculated from runoff volume, slope and vegetation cover. Erosion (E) equals the lower value between sediment detachment and transport amounts. The equations for sediment detachment and transport by runoff do not distinguish between interill and rill erosion, but the model was tested by Morgan (2001) in agricultural areas where rilling occurs.

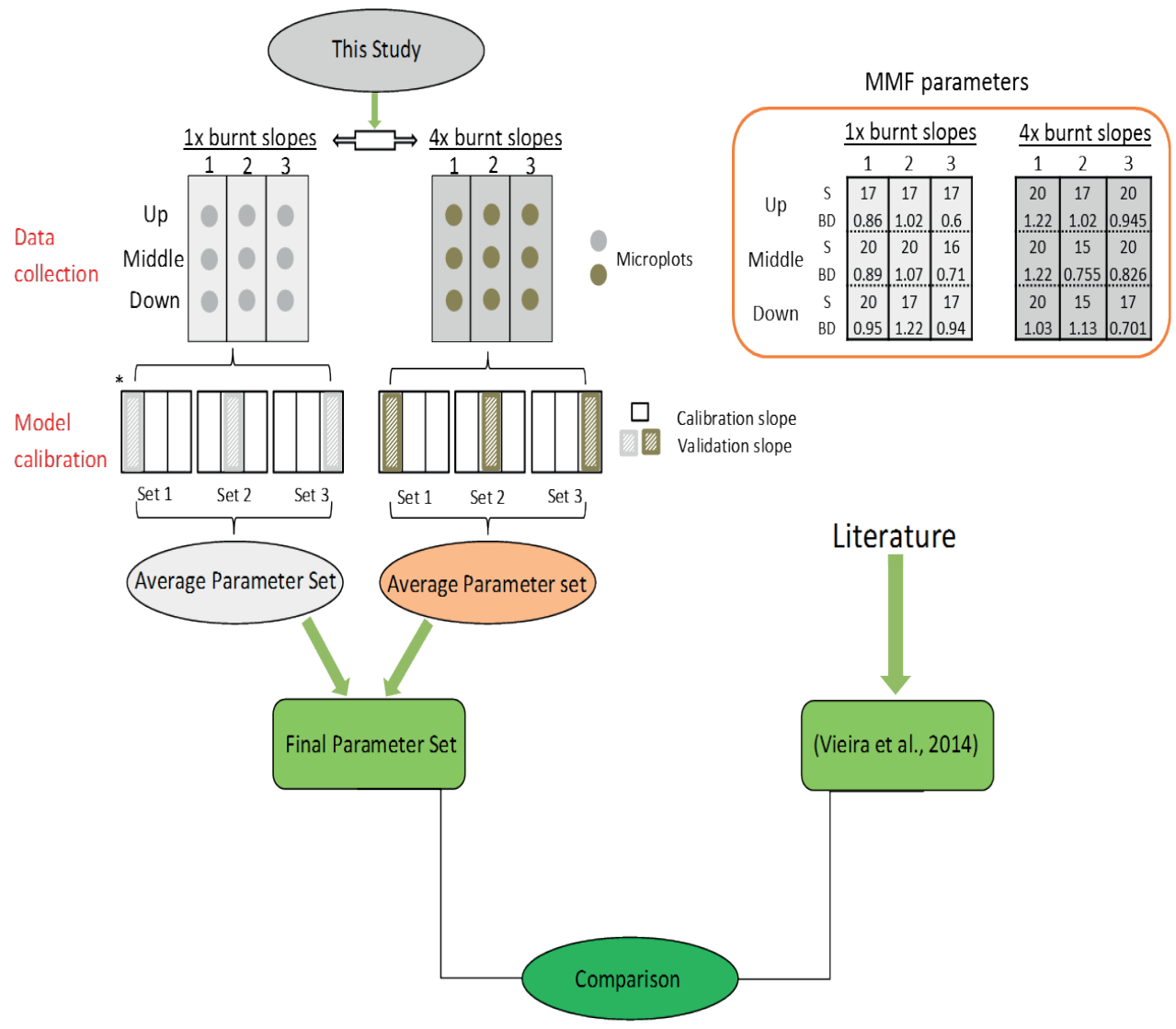

Figure 5.2 Field data collection structure and model calibration-validation procedure.

* Calibration-validation exercise was performed three times per fire recurrence. Each time, two slopes were used for calibration and a third one for validation. MMF parameters are summarized in Table 5.1.

The model was applied to the micro-plots for the entire first year after the September 2012 fire. Table 5.1 shows input parameters and determination methods that were used in this research, and Fig. 5.2 shows the structure of model application, calibration and validation. 
The model was applied with a seasonal time-step, to account for seasonal variations in soil water repellency, following Vieira et al. (2014). The effects of repellency on soil wetting were simulated by limiting water holding capacity in highly repellent seasons, following the approaches of Vieira et al. (2014) and Nunes et al. (2015). This was achieved by changing the soil effective hydrological depth (EHD), which represents not only soil depth but also properties such as interception by vegetation and litter, crusting, and an impermeable layer (Morgan, 2001). For the same purpose, Vieira et al. (2014) modified field capacity (MS), which is a conceptually very similar approach.

Table 5.1 Morgan-Morgan-Finney model factors, input parameters and information/data sources

\begin{tabular}{|c|c|c|}
\hline Factor & Parameter* & Information/data source \\
\hline \multirow[t]{3}{*}{ Rainfall } & $\mathrm{R}\left(\mathrm{mm} \mathrm{yr} \mathrm{r}^{-1}\right)^{* *}$ & measured in the study area ((Hosseini et al., 2016) \\
\hline & $\mathrm{Rn}^{* *}$ & \\
\hline & $\mathrm{I}\left(\mathrm{mm} \mathrm{h}^{-1}\right)^{* *}$ & \\
\hline \multirow[t]{4}{*}{ Soil } & MS $(\%)^{* *}$ & measured at the study sites (Hosseini et al., 2016) \\
\hline & $\mathrm{BD}\left(\mathrm{g} \mathrm{cm}^{-3}\right)$ & measured at the study sites (Hosseini et al., 2016) \\
\hline & $\operatorname{EHD}(m)^{* *}$ & derived from (Morgan, 2001) \\
\hline & $\mathrm{K}\left(\mathrm{g} \mathrm{J}^{-1}\right)$ & $\begin{array}{l}\text { based on measured soil texture class ((Hosseini et al., 2016), following } \\
\qquad \text { (Morgan, 2001) }\end{array}$ \\
\hline Landform & $S\left({ }^{\circ}\right)$ & measured for individual plots (Hosseini et al., 2016) \\
\hline \multirow[t]{7}{*}{ Land cover } & $A^{* *}$ & this work \\
\hline & $\mathrm{E}_{\mathrm{t}} / \mathrm{E}_{0} * *$ & this work \\
\hline & $\mathrm{C}^{* *}$ & $\begin{array}{l}\text { estimated using the RUSLE methodology (Renard et al., 1997; Vieira et al., } \\
\text { 2014) }\end{array}$ \\
\hline & $\mathrm{P} * *$ & derived from (Vieira et al., 2014) \\
\hline & $\mathrm{CC}(\%)^{* *}$ & measured for individual plots (Hosseini et al., 2016) \\
\hline & $\mathrm{GC}(\%)^{* *}$ & this work \\
\hline & $\mathrm{PH}(\mathrm{m})^{* *}$ & measured for individual plots (Hosseini et al., 2016) \\
\hline \multicolumn{3}{|c|}{$\begin{array}{l}\text { * Rainfall volume per year (R), Number of rain days }\left(\mathrm{R}_{\mathrm{n}}\right) \text {, Rainfall intensity }(\mathrm{I}) \text {, Soil moisture }(\mathrm{MS}) \text {, Bulk density }(\mathrm{BD}) \text {, } \\
\text { Effective hydrological depth }(\mathrm{EHD}) \text {, Erodibility of soil }(\mathrm{K}) \text {, Slope steepness }(\mathrm{S}) \text {, Interception }(\mathrm{A}) \text {, Actual } \\
\text { evapotranspiration }\left(\mathrm{E}_{\mathrm{t}}\right) \text {, Potential evapotranspiration }\left(\mathrm{E}_{0}\right) \text {, Crop cover management factor (C and P), Percentage } \\
\text { canopy cover }(\mathrm{CC}) \text {, Ground cover }(\mathrm{GC}) \text {, Plant height }(\mathrm{PH}) \text {. }\end{array}$} \\
\hline Paran & h season. & \\
\hline
\end{tabular}

Seasonal variations were estimated for EHD, ground cover (GC, taken from vegetation cover) and evapotranspiration $\left(E_{t} / E_{0}\right)$. MS was approximated by the maximum soil moisture content recorded during the first year of the study (Vieira et al., 2014). The remaining MMF parameters followed those calculated by Vieira et al. (2014). In this work, the name of the $C$ and P factors described by Vieira et al. (2014) were changed, as they originally applied to agricultural areas; these are now respectively the soil surface erosion factor, and the ground cover protection factor (equalling 100-GC).

MMF was calibrated using a split-sample approach, i.e., model parameters were adjusted so predictions would conform with part of the dataset, and then the model was validated by 
running it with calibrated parameters for a different part (Janssen and Heuberger, 1995; Moriasi et al., 2007). In this case, the split-sample calibration-validation exercise was performed three times per fire recurrence: for each analysis, two slopes were used for calibration and a third one for validation (Fig. 5.2). This led to 3 parameter sets per fire recurrence, which were averaged to create a final parameter set. Model calibration and validation were done separately for the $4 x$ and $1 x$ burnt plots within each three months (seasonally), to take into account different vegetation and soil properties for sites with different fire histories.

Finally, MMF was also applied using the parameters estimated by Vieira et al. (2014) for the same study area. This was done to assess i) the decrease in model performance when using generic parameters developed for other sites, and ii) to discover which generic parameters from Vieira et al. (2014) could be used unchanged, and which required modifications. Model performance was assessed with ordinarily used assessment indicators (Moriasi et al., 2007). The Nash-Sutcliffe coefficient of efficiency NS (Nash and Sutcliffe, 1970) describes the accuracy of the model prediction, and ranges from $-\infty$ to 1 ; negative values specify that the mean value of observation is a better predictor than the output from the model; values larger than 0.5 are widely considered to identify adequate model performance (Quinton, 1997); and values above 0.7 should not be expected due to imperfect knowledge on erosion modelling (Morgan, 2001; Nearing et al., 1999). The root mean squared error (RMSE) represents the sample standard deviation of the differences between predicted and observed values; this study used the ratio of RMSE to the standard deviation of the samples RSR (Moriasi et al., 2007), with an optimal value close to 0 and values above 0.7 indicating poor model performance. The percent bias (PBIAS) is a measure of accuracy, indicating the average deviation between simulations and observations. Finally, the Pearson coefficient $\left(r^{2}\right)$ is a measure of the relative model performance, i.e. its capacity to simulate relative differences between data points. Using these four indicators, model predictions were evaluated in two manners: as seasonal figures (every three months), and as total figures over the entire simulation period. 


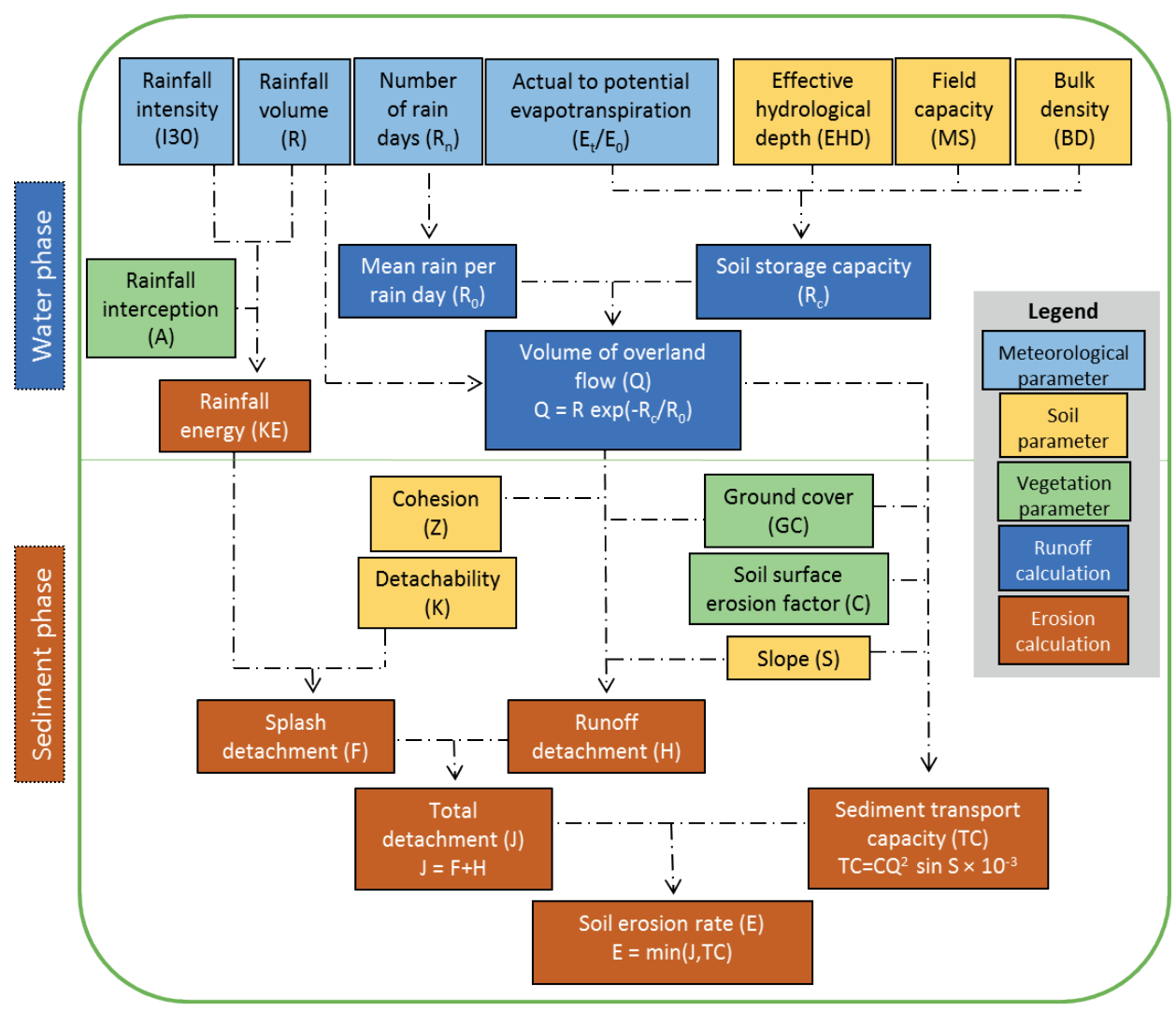

Figure 5.3 Simplified flow chart of the revised Morgan-Morgan-Finney model adapted from Vieira et al. (2014). 


\subsection{Results}

\subsubsection{Seasonal parameters}

Fig. 5.4 shows the seasonal patterns (every three months) of rainfall ( $R$ ) and the number of rain days $\left(R_{n}\right)$. Fig. 5.5 shows the seasonal patterns of three selected parameters: $E_{t} / E_{0}$ and vegetation cover (CC), which were measured or calculated from data; and effective hydrological depth (EHD), which was calibrated. The seasonal variation of $E_{t} / E_{0}$ led to a reduction in available water for runoff during the dry season and an increase during the wet season. GC was very similar for both sites, showing little vegetation recovery during the first half year after the fire with cover increasing after the spring 2013 observations. GC showed small differences between plots for the $4 x$ burnt site, with a maximum between 24 and 26\%; while for the $1 x$ burnt site, GC showed a maximum of $27 \%$ for the left-side plots (slope 1 in Fig. 5.2), and between 20 and $21 \%$ for the others.

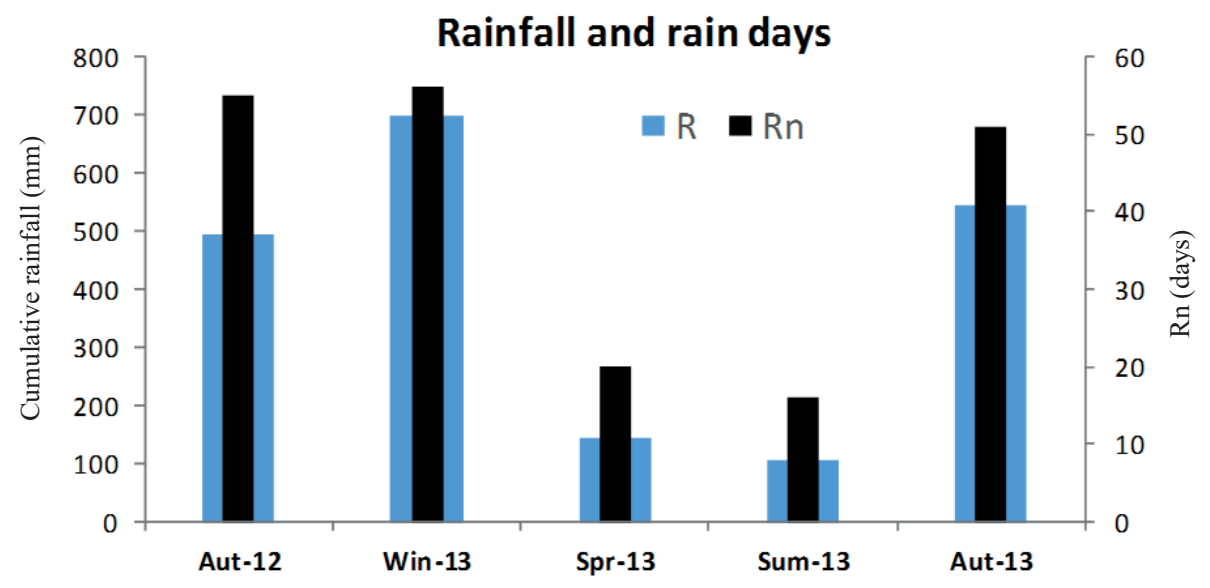

Figure 5.4 Cumulative rainfall $(R)$ and amount of rain days $(R n)$ per season. 

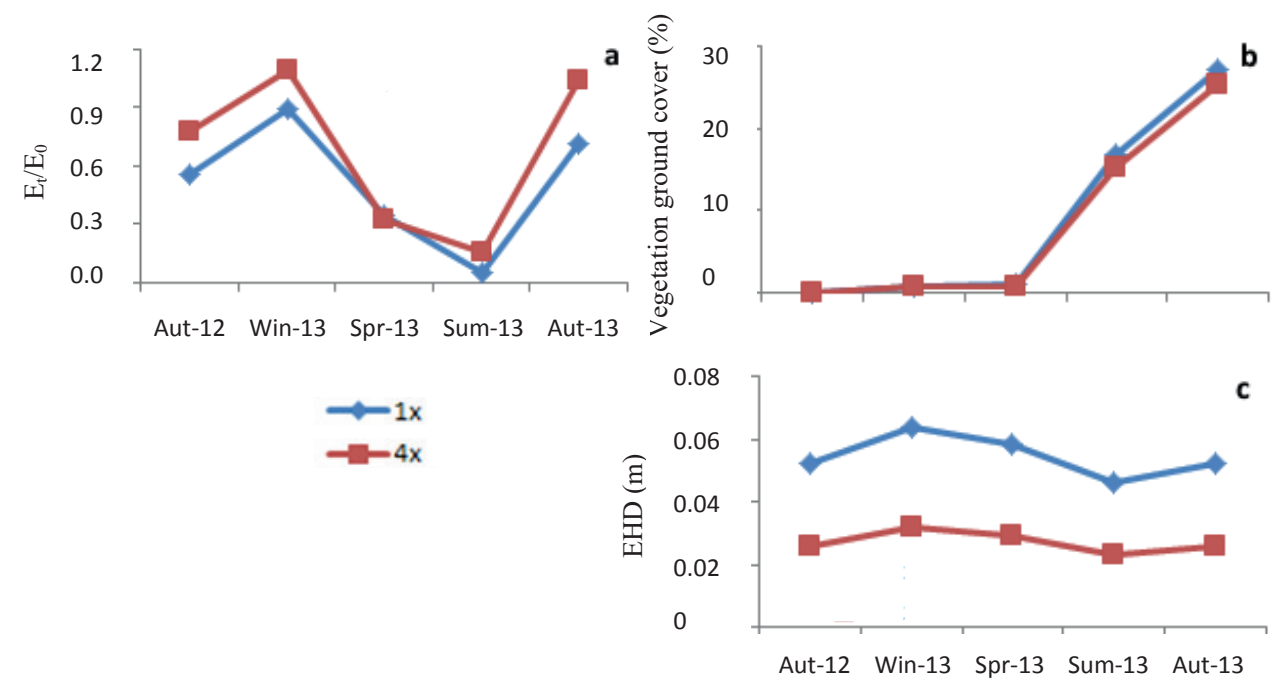

Figure 5.5 Seasonal variations in MMF parameters for the $4 \times$ and $1 \times$ burnt sites used during calibration: (a) evapotranspiration $\left(E_{t} / E_{0}\right)$, (b) vegetation ground cover $(G C, \%)$ and $(c)$ effective hydrological depth of soil (EHD, $m)$.

Calibration led to very different values for EHD between the $4 x$ and $1 x$ burnt sites. Furthermore, following Vieira et al. (2014) different EHD values were used for the different season to simulate phenomena such as changes in soil water repellency (leading to lower EHD in the drier than wetter months) and recovery of vegetation interception storage capacity. The calibration procedure showed that both sites could be simulated with similar parameter sets, but varying EHD; this indicated that the most important difference between both sites, at least concerning hydrological and erosion response, was in soil repated properties.

Table 5.2 MMF model performance in predicting annual runoff and erosion rates at the $1 x$ and $4 x$ burnt sites.

\begin{tabular}{|c|c|c|c|c|c|c|c|c|}
\hline & & \multirow[b]{2}{*}{ Satisfactory } & \multicolumn{3}{|c|}{ This work } & \multicolumn{3}{|c|}{$\begin{array}{l}\text { Based on parameters by } \\
\text { Vieira et al. (2014) }\end{array}$} \\
\hline & & & $1 x$ burnt & $4 x$ burnt & $1 x+4 x$ & 1x burnt & $4 x$ burnt & $1 x+4 x$ \\
\hline \multirow[t]{4}{*}{ Runoff } & $\mathrm{r}^{2 *}$ & $>0.5$ & 0.03 & 0.02 & 0.03 & 0.04 & 0.02 & 0.04 \\
\hline & PBIAS & Runoff $\pm 25 \%$ & $12.8 \%$ & $8.4 \%$ & $10.8 \%$ & $-34.9 \%$ & $-10.8 \%$ & $-24.4 \%$ \\
\hline & RSR & $<0.7$ & 1.78 & 1.11 & 1.17 & 2.84 & 1.13 & 1.42 \\
\hline & NSE & $>0.5$ & -1.71 & -0.36 & -0.33 & -1.82 & -0.37 & -0.55 \\
\hline \multirow[t]{4}{*}{ Erosion } & $r^{2}$ & $>0.5$ & 0.32 & 0.44 & 0.55 & 0.39 & 0.48 & 0.35 \\
\hline & PBIAS & Erosion $\pm 55 \%$ & $-0.8 \%$ & $-0.6 \%$ & $-0.8 \%$ & $-57.0 \%$ & $-30.3 \%$ & $-47.6 \%$ \\
\hline & RSR & $<0.7$ & 0.79 & 0.79 & 0.66 & 1.54 & 1.01 & 1.20 \\
\hline & NSE & $>0.5$ & 0.30 & 0.29 & 0.54 & 0.37 & 0.46 & 0.33 \\
\hline
\end{tabular}

* Coefficient of determination ( $r^{2}$ ), Percent bias (PBIAS), RMSE to sample StDev ratio (RSR), Nash-Sutcliffe coefficient of efficiency (NSE). 


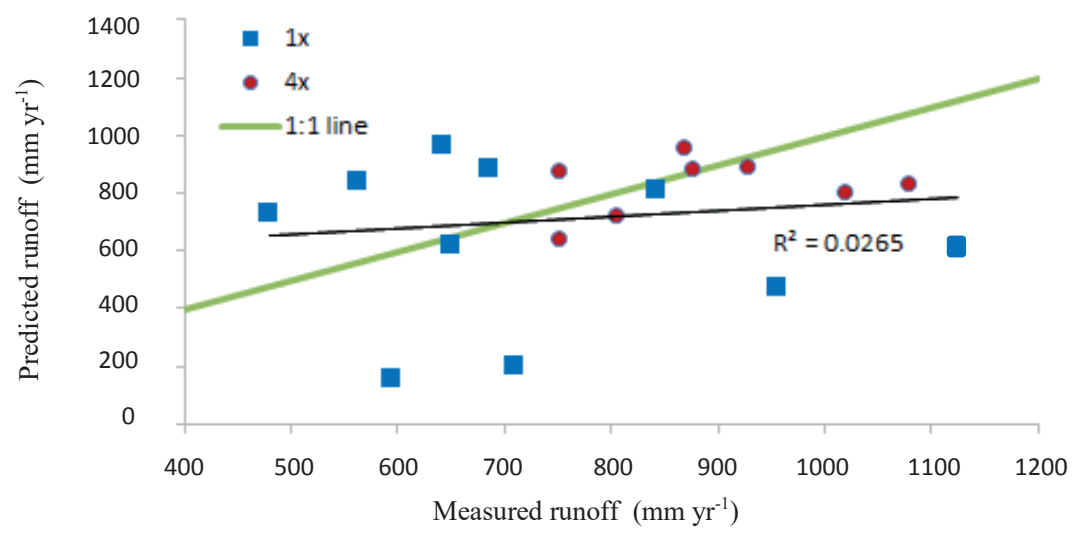

Figure 5.6a Measured vs. simulated annual runoff for the $4 \times$ and $1 \times$ burnt sites.



Figure 5.6b Measured vs. simulated annual erosion for the $4 \times$ and $1 \times$ burnt sites.

\subsubsection{Annual runoff and erosion rates}

Statistics for the simulation of overall runoff and soil erosion rates are shown in Table 5.2. Simulated annual runoff for the individual plots were plotted against the observed values in Fig. 5.6a. The modelling approach did not provide accurate estimates for the differences between plots nor between fire recurrence sites. A similarly poor performance was achieved with the parameters of Vieira et al. (2014), sharply contrasting with their good model performance in the original study.

Model performance for annual soil loss estimations was much better than that for runoff, as shown in Fig. 5.6b and Table 5.2. The model was able to simulate reasonably well the 
markedly higher soil losses at the $4 \mathrm{x}$ burnt sites when compared with the $1 \mathrm{x}$ burnt sites (Table 5.2), although it achieved worse results in differentiating between individual plots inside the $4 x+1 x$ sites. The most sensitive parameter to differentiate predictions between $4 x$ - and $1 x$ - burnt plots was EHD, while differences between plots of the same fire recurrence were mainly related to slope angle. The application with the parameters by Vieira et al. (2014) led to a marginally better, but still unsatisfactory, differentiation between plots, at the expense of a much worse performance in differentiating both sites. In any case, accuracy was much worse in this application with very low PBIAS.

\subsubsection{Seasonal runoff and erosion rates}

MMF also showed a poor performance for runoff when evaluating results at the seasonal scale (not shown, but as poor as the annual performance shown in Fig. 5.6a). MMF still performed reasonably well for simulated erosion at this scale, as shown in Figs. 5.7 and 5.8 (compare with rainfall in Fig. 5.4). For the $4 x$ burnt sites, the simulated amounts from this work tended to overestimate values in autumn 2012 while underestimating it in the autumn of 2013. The application with the parameters from Vieira et al. (2014) had a slightly better seasonal match $\left(r^{2}\right)$ at the expense of an larger overall underestimation (PBias), especially at the final season. Results from this research in the $1 \mathrm{x}$ burnt sites, however, had both a better fit and improved accuracy than by using the parameters of Vieira et al. (2014). 

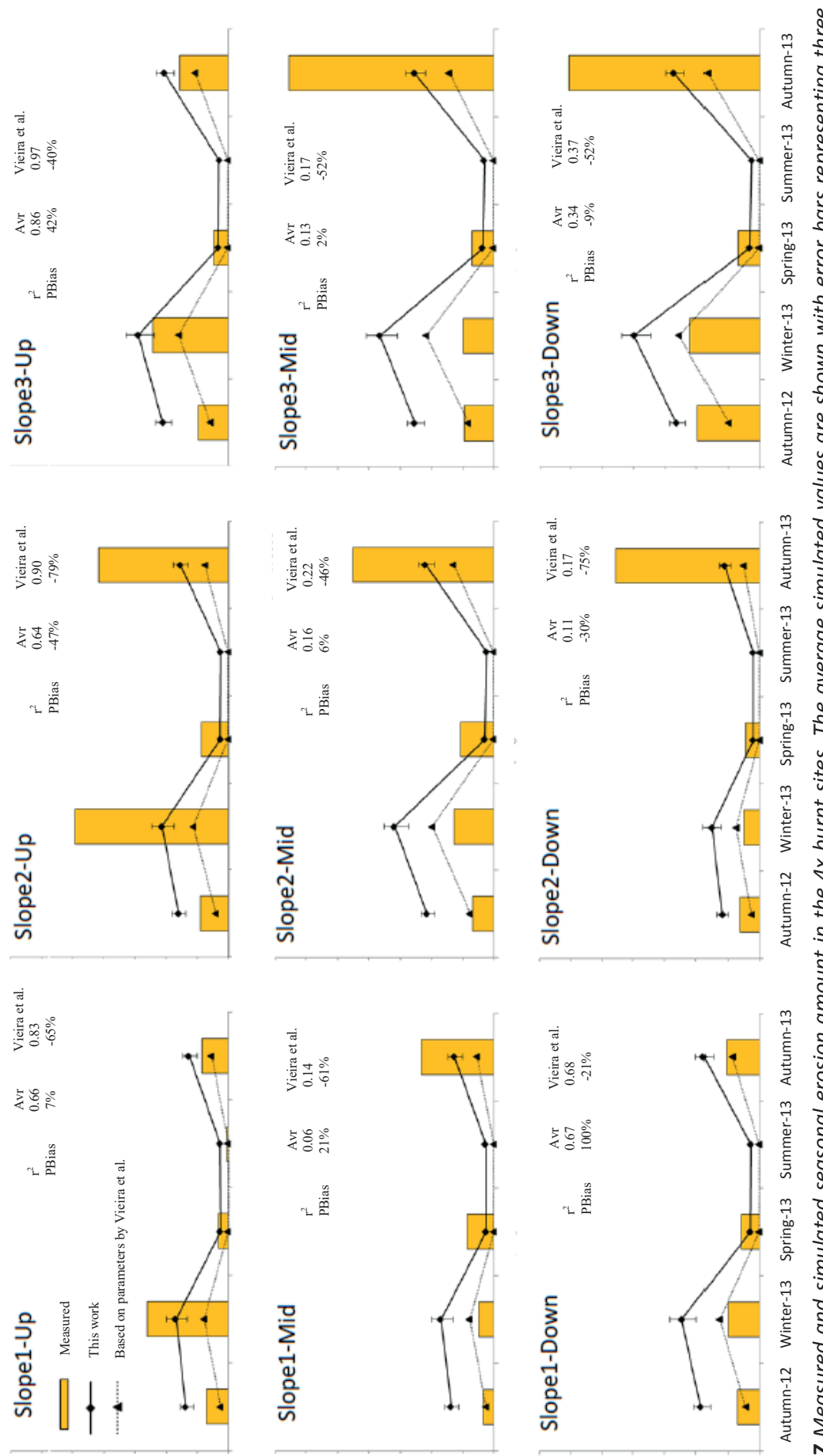

궁 궁

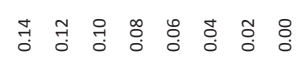

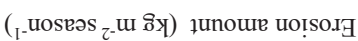

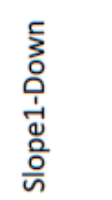




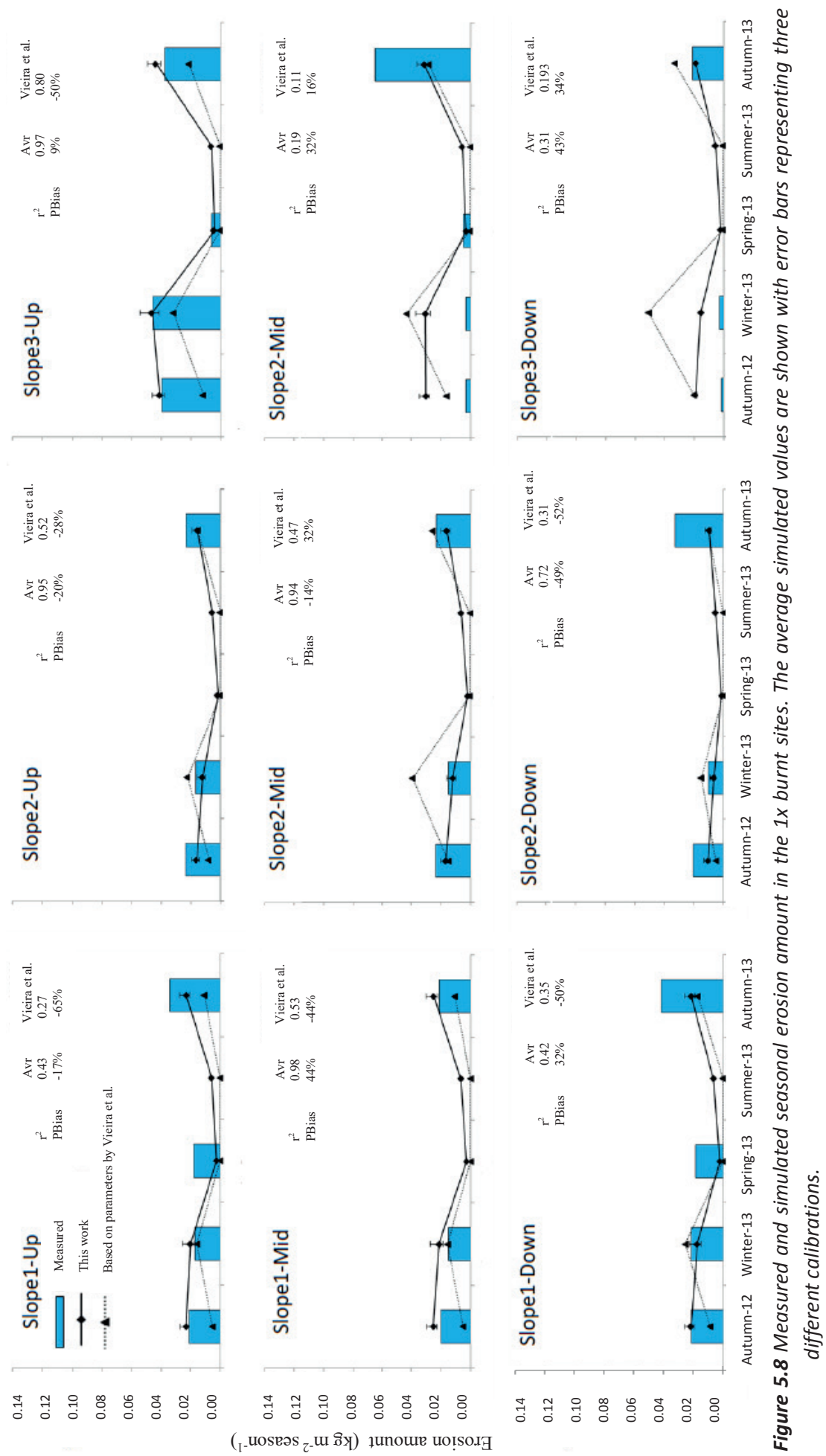




\subsection{Discussion}

\subsubsection{Evaluation and comparison with other studies}

A comparison between results in the present study and previous research using the MMF model is shown in Table 5.3, which indicates that the accuracy in modelling annual erosion was comparable to, or better than, results obtained with similar approaches for burned areas. This study achieved accurate efficiency for the prediction of post-fire soil erosion; model efficiency approached NSE $=0.54$ for annual erosion rates for the $4 x+1 x$ burnt sites . These results were comparable with those previously reported for the application of MMF to burned sites in Portugal (Vieira et al., 2014) and in north-western Spain (Fernández et al., 2010). Furthermore, this study supports the research done by Vieira et al. (2014) which mention that annual erosion predictions with MMF were acceptable using a seasonal modelling approach. Model proficiency for seasonal predictions was also lower than that for annual predictions in both studies.

Table 5.3 Overview of previous erosion modelling studies for post-fire erosion.

\begin{tabular}{cccccc}
\hline Study & Location & Land Use & Model & $\begin{array}{c}\text { NSE } \\
\text { (Erosion) }\end{array}$ & $\begin{array}{c}\text { RMSE } \\
\text { (kg m-2) }\end{array}$ \\
\hline This study & North-Central Portugal & Pine & MMF & 0.54 & 0.55 \\
(Vieira et al., 2014) & North-Central Portugal & Pine & MMF & 0.20 & 0.24 \\
& & Eucalypt & & 0.50 & 0.21 \\
(Fernández et al., 2010) & North-Western Spain & Pine forest and & RUSLE & 0.87 & 0.63 \\
& & shrubland & MMF & 0.74 & 0.90 \\
\hline
\end{tabular}

Other approaches to model post-fire runoff and erosion in this region have had limited success. Simulations with PESERA have led to overestimations of erosion due to not considering specific factors behind the hydrological response of burnt soils, such as repellency or ash (Esteves et al., 2012), and improvements require a careful parameterization of these soil properties (Fernández and Vega, 2016). Simulations of runoff with LISEM also had limited success due to the poor representation of the properties of burnt soils, especially soil water repellency (van Eck et al., 2016).

Given these results, it would be expected that a successful runoff simulation would be required for a successful erosion simulation, especially when considering that the validation of runoff could be a pre-condition to validate erosion simulations, as mentioned by Morgan (2005). This was not, however, the case for this work, as shown in Table 5.2; MMF was not able to distinguish runoff between individual microplots, possibly since runoff is dependent mostly on values which are constant for each set of slopes, mainly rainfall, EHD and soil 
related properties (see Fig. 5.3). However, runoff simulations were still in the range of measured values (Fig. 5.6a).

Furthermore, erosion in MMF is affected not only by the amount of runoff, but also by other factors such as slope, soil erodibility or vegetation cover (Morgan, 2001). Here, the similarity of runoff measurements between different sites could indicate that differences in erosion rates were a function of the remaining factors. In particular, the differences in slope between plots could be the driving factor for the observed differences in runoff detachment rates and transport capacity. Additionally, the absence of concentrated flow processes at this scale (and probably at larger scales as well, as discussed below) could have made the runoff prediction less relevant for the erosion prediction. Therefore, a prediction of runoff in the same range as observed values was sufficient to correctly simulate erosion, which explains the need for EHD calibration described above as this parameter mostly affects runoff.

In seasonal terms, MMF tended to have a mismatch with seasonal erosion values, especially at the end of the simulation period. A similar mismatch was observed in the application by Vieira et al. (2014), and could indicate that MMF is unable to take into account the evolution of vegetation and soil parameters with post-fire recovery. Model parameters such as EHD could be modified to take this into account, which could lead to notable improvement of model results.

The present application of the MMF model has allowed the identification of causes for the different hydrologic responses of the $4 x$ and $1 x$ burnt sites. This was mainly due to differences in the effective hydrological depth, with lower EHD in the $4 x$ burnt sites leading to slightly higher runoff rates than in the $1 x$ burnt sites, and hence to more erosion. This would be a foreseeable result, as the $4 x$ burnt sites would have experienced more post-fire erosion episodes than the $1 x$ burnt sites, therefore having shallower soils with lower water holding capacity. Soils in the area are generally under $30 \mathrm{~cm}$ (Hosseini et al., 2016) and, in such shallow soils, variations in soil depth can have a strong effect on runoff response, as demonstrated by Tavares Wahren et al. (2016) for a nearby region.

The remaining differentiation between plots was most likely due to slope angle, with relatively small impact of vegetation cover. A recent study by van Eck et al. (2016) also suggested low importance of vegetation cover for successfully simulating post-fire runoff in this region, due to the relatively overall low canopy cover and interception storage capacity. 


\subsubsection{Limitations of modelling after wildfires}

Prediction errors can originate from errors in model structure and implementation, model input data and model parameterization but also in the data used for model assessment (Vieira et al., 2014; Nearing et al., 1999). The accurate predictions reached with the MMF model for other burned study sites (Vieira et al., 2014; Fernández et al., 2010) indicate that the model structure is valid for burned areas, although it had to be adapted to reflect some site-specific conditions, like seasonal changes in the soil and surface cover.

Rainfall, vegetation cover and runoff and erosion rates are typically the main sources of measurement errors (Vieira et al., 2014; Larsen and MacDonald, 2007; Pietraszek, 2006). In this work, rainfall figures can be regarded as accurate as there were negligible differences between the various rainfall gauges across the study area. Surface cover measurements were done by the same observer, thus reducing potential errors. Runoff and erosion monitoring provided independent and reliable data on the hydrological response of each plot.

Finally, the estimate of the effective hydrological soil depth (EHD) is a potential source of error; guidelines from Morgan (2001) were used in this work, but they might not be very accurate for very thin soils (Vieira et al., 2014), and the model is therefore dependent on a strong calibration of this parameter. This can also help explain the poorer seasonal performance for the $4 \mathrm{x}$ burnt sites, with lower EHD, when compared with that for the $1 \mathrm{x}$ burnt sites.

\subsubsection{Limitations of using microplots for model parameterization}

Despite the fact that the MMF equations do not explicitly distinguish concentrated flow erosion (Morgan, 2001), models should generally be developed separately for interill and rill processes (e.g. Nearing, 1989). Therefore, the parameterization performed in this work using $0.25 \mathrm{~m}^{2}$ plots might not be valid for hillslopes where rill erosion might be dominant (Morgan, 2005).

However, this is not usually the situation in burnt Portuguese forests, as discussed in length by Prats et al. (2016b) for runoff and Prats et al. (2016a) for erosion. Prats et al. (2016b) note the decrease of runoff with increasing slope length, due to the increasing variability of infiltration which allows for more opportunities for runoff re-infiltration; in consequence, runoff connectivity decreases with length, which constitutes a strong limitation to the generation of concentrated flow and hence to rill erosion. 
This could occasionally be counteracted by the seasonal occurrence of soil water repellency (Prats et al., 2016b; Ferreira et al., 2008), which would incidentally explain its importance for post-fire runoff generation in Mediterranean regions. However, even in these conditions Prats et al. (2016a) found that scale did not affect erosion rates from scales between 0.25 and $10 \mathrm{~m}^{2}$, indicating that interill erosion was the dominant process between these scales, possibly due to the limited occurrence of concentrated flow. This is not a unique result; the absence of widespread rilling in burnt areas has been observed elsewhere in Portugal (Ferreira et al., 2008), and in other regions of the the Mediterranean also (Shakesby, 2011). In fact, in a recent review, Moody et al. (2013) discuss how certain environmental conditions favour the dominance of interill erosion in several burnt hillslopes across the globe.

These facts suggest that the microplot data collected and used in this work can be representative of larger patches of burned forests, possibly even up to the hillslope scale. In support of this, it should be noted that the parameters developed by Vieira et al. (2014) for $16 \mathrm{~m}^{2}$ plots were easily applied to the microplots used in this study despite the difference in scale.

\subsubsection{Modelling as a post-fire management tool}

Using the revised MMF model for burnt areas to predict erosion risk is an important longterm objective of this research. The present results show that the revised MMF seasonal approach with EHD calibration performs better than earlier attempts by Vieira et al. (2014). Accurate soil depth measurements can support the estimation of EHD for different study areas; in the absence of these, estimation methods based on auxiliary variables such as topography, geology and land use can be used, such as the one presented for this area by Tavares Wahren et al. (2016).

Moreover, the potential representativity of microplot data for entire slope-scale conditions, as described above, opens interesting possibilities for modelling as a fire management tool. Historically, microplots have been used for erosion assessment in burnt areas in Mediterranean regions, and there is a wealth of data both from natural and simulated rainfall experiments (e.g. Hosseini et al., 2016; Malvar et al., 2015b; Martins et al., 2013). Such data might support larger-scale applications, an assumption which should be tested thoroughly (Prats et al., 2016a and b). Morgan (2001) and López-Vicente et al. (2013; 2015) demonstrated that MMF application calibrated at the plot scale potentially can serve as a basis for simulation of sediment transport at larger scales. 


\subsection{Conclusions}

The main conclusions of the current study on runoff and erosion after wildfires in maritime pine plantations in north central Portugal are the following:

- The MMF model performed reasonably well for soil erosion predictions (NSE > 0.5) at small plots;

- Slope angle and the effective hydrological depth were the main parameters that require accurate data to acquire reliable model output results;

- MMF performed unsatisfactory for predicting runoff, and more attention is required to improve the MMF model for this purpose;

- Seasonal predictions were less accurate than annual predictions due to the variability of rainfall;

- Applying MMF to different regions in Portugal and elsewhere require accurate field observations and related model input data collection. 
Acknowledgements

This research was supported and carried out in the framework of the CASCADE project (number 5120959001), funded by the European Union. Additional support was provided by the Portuguese Foundation for Science and Technology through individual research grants attributed to J.P. Nunes (SFRH/BPD/87571/2012 and IF/00586/2015) and funding for the CESAM centre (UID/AMB/50017), co-funded by the European Social Fund and the European Regional Development Fund within the PT2020 Partnership Agreement and Compete 2020. Further funding was granted through COST (European Cooperation in Science and Technology) through the Action ES1306 CONNECTEUR. The authors gratefully acknowledge Diana Vieira, Astrid Mous, Ayşe Betül Baytürk, Ariët Kieskamp, Daniela Varandas, Liliana Santos and Martinho Martins for their help with the fieldwork and laboratory analyses, and the University of Aveiro, CESAM centre in Portugal, and SAR-UAF Netherlands are in particularly acknowledged for their kind support. 


\section{Synthesis}




\subsection{General discussion}

Important aspects of Mediterranean ecosystems such as vegetation dynamics, nutrient cycling, and soil and water retention are widely affected by wildfires. Therefore, studying the impacts of fire on soil properties and dynamics, runoff, organic matter and nutrient loss, water repellency, surface cover and vegetation recovery is important in order to better manage fire prone areas. Although a lot of research has been done on the general effects of fires (Shakesby, 2011; Shakesby and Doerr, 2006), little attention has been given to the effects of fire frequency on the burnt areas. During this PhD project, various studies were conducted to advance the understanding of the effects of fire occurrence and, particularly, fire frequency on surface cover, runoff, soil erosion, and organic matter and nutrient losses. Model application to simulate observed runoff and erosion in microplots in the field received also the required attention. Furthermore, specific trials have been deployed to test a range of possible treatments to regreen fire affected plots. The overal findings of the PhD study are summarized in Figure 6.1 and discussed in greater detail below.

\subsubsection{The effect of fire frequency on runoff, soil erosion, loss of organic matter and surface cover at micro-plot scale in north-central Portugal}

Post-fire runoff, sediment transport, and OM losses have been studied regularly (Stoof et al., 2015; Ebel, 2012; Shakesby, 2011; Stoof, 2011), however, less attention has been given to the consequences of repeated fires on these processes. Repeated forest fires are either started accidentally by humans or by natural occurrences, such as lightning strikes, or caused by climate change which has been increasing the length of the fire season (Malkisnon et al., 2011). A single fire can damage part of the vegetation and humus layer leaving a small layer of ash on top of the soil (Badía and Martí 2003). Repeated fires however, can burn the vegetation cover and humus layer more severely and deeply thus increasing the amount of ash formed and deposited on the soil surface. In addition, soil water repellency tends to be increased also under these conditions. This can increase the risk of runoff, ash transport, soil erosion and organic matter (OM) losses, especially after a heavy rainfall $\left(I_{30}\right)$ (Shakesby, 2011). During the course of this PhD research (Chapter 2), we have confirmed that repeated wildfires in a given area result in more soil degradation than individual wildfires. The degradation included the disappearance of the $\mathrm{O}$ horizon in these areas as well as an increase in the average ash cover in the burnt sites, which measured approximately $10 \mathrm{~cm}$ in the area under consideration. The depth of the $O$ horizon in the unburnt sites was $7-10 \mathrm{~cm}$. No vegetation remained in the repeatedly $(4 \times)$ burnt sites. The 
shrub layer and some pine trees were destroyed in the sites which burnt only once. Annual vegetation, pine trees, and shrub layers covered the unburnt sites.

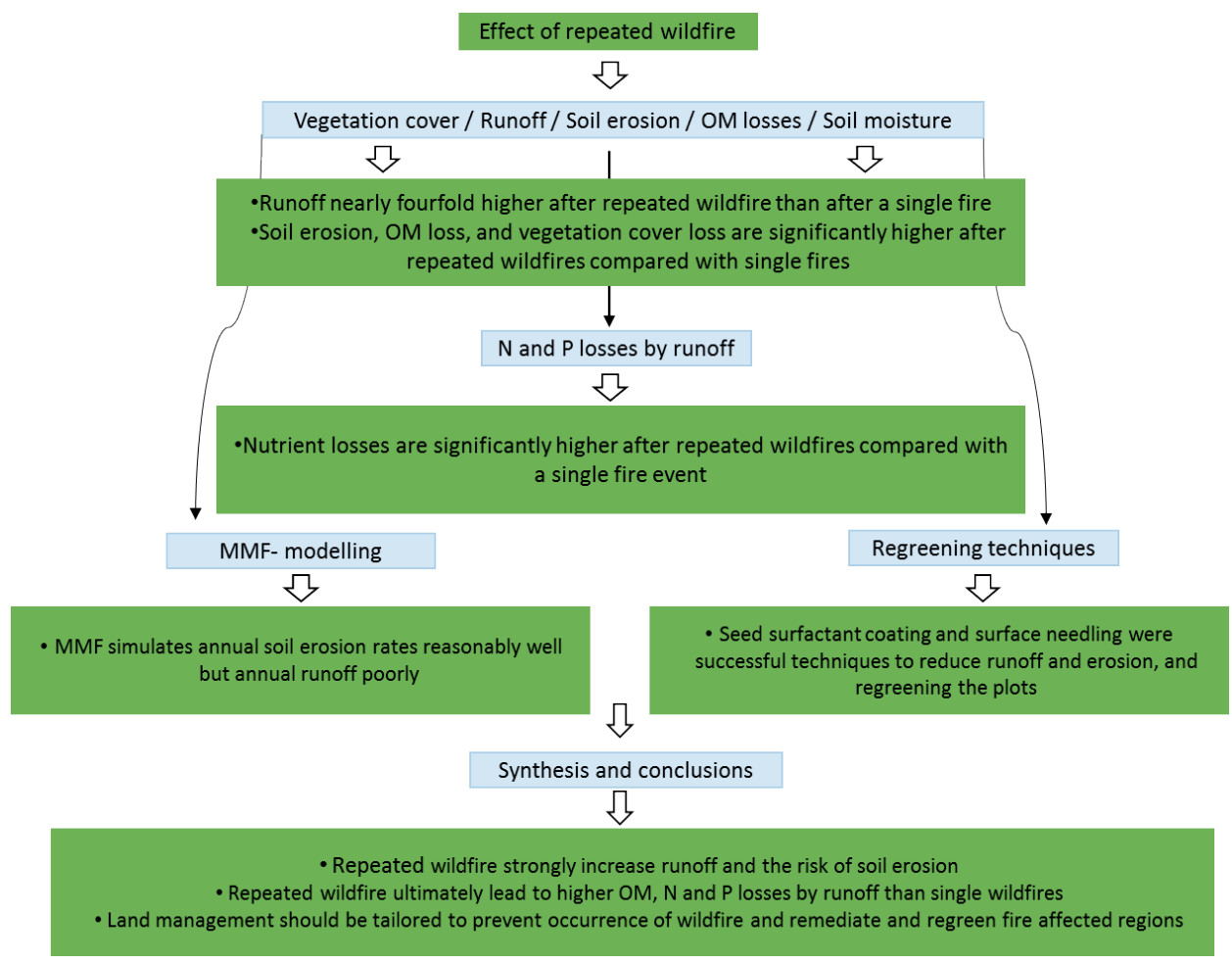

Figure 6.1 Key findings from the PhD study.

Heat, which is a direct effect of fire on the soil, can change the physical properties of the soil (Stoof et al., 2015), and plant-water-soil processes. For example, wildfire severity and fire frequency can have negative effects on soil structure (Stoof et al., 2015; Martínez-Aznar et al., 2013; Alauzis et al., 2004; García-Corona et al., 2004). Frequent wildfires can also change the water cycle, increasing soil water repellency (SWR) and reducing soil infiltration rates (Caon et al., 2014; Carreiras et al., 2014). Increased SWR due to wildfires has been reported in the Mediterranean (Ferreira et al., 2005a). However, similar levels of repellency have also been found in long unburnt and recently burnt soils in Pinus pinaster and $E$. globulus plantations (Doerr et al., 1998). Our study also provides interesting insights into the effect of fire frequency on SWR. We found that repellency was initially high in both sites, the one affected by frequent fires and the one affected by a single fire, but the repellent layer washed away very quickly in the $4 x$ burnt sites due to the lack of surface cover and related high runoff. This suggests that wildfire frequency adds further complexity to effects of fire on soil-water-plant dynamics. 
Wildfires can increase the runoff coefficient and the risk of downstream flooding after heavy rains. Our research showed that repeated wildfires worsen the situation. We found that the runoff coefficient was significantly higher in the $4 x$ burnt sites (25-40\%) than in the $1 x$ burnt (6-10\%) and $0 x$ burnt sites (2-4\%), respectively. A number of studies conducted in the Mediterranean have noted higher overland flow and runoff coefficients after wildfires as compared to unburnt areas (e.g. Shakesby, 2011; Ferreira et al., 2005a and b), however, fire severity can also be a factor. Úbeda and Sala (1998) found higher runoff coefficients in a previously unburnt forest in north-east Spain after a single high to moderate wildfire (33.6-37.4\%) than after a low to moderate fire (6.3-10.0\%). The findings of this PhD project agree with this other research and additionally shows that the runoff coefficient for areas subject to multiple fires is significantly higher than for areas exposed to just one fire.

Our research showed that the increased runoff and sediment loss following a fire are ultimately linked to $I_{30}$, soil moisture and soil cover in all sites. Others have also recognized that as a result of the changes in soil properties and cover, erosion is likely to increase after wildfires as compared to unburnt sites (Moody et al., 2013; Malkisnon et al., 2011; Wittenberg and Inbar, 2009a). However, in this project, we looked deeper into the reasons for this as well as the impact of repeated fires. Our findings clearly indicate that fire frequency plays a role in soil losses as these were higher in the $4 x$ than in the $1 x$ burnt sites ( 2.57 vs. $0.31 \mathrm{Mg} \mathrm{ha}{ }^{-1}$ in the first year, and 3.79 vs. $0.84 \mathrm{Mg} \mathrm{ha}^{-1}$ in the second year, respectively). Our soil loss results for single burnt sites was less in the first year after a fire as compared to the research done by Vega et al. (2005) in north-west of Spain, showing an erosion amount of $0.56 \mathrm{Mg} \mathrm{ha}^{-1}$ in the intensively burnt sites and $0.22 \mathrm{Mg} \mathrm{ha}^{-1}$ in lightly burnt sites.

Runoff and soil losses in this study occurred not only after erosive rainstorms following a fire but also after a subsequent period of drought. Infrequent but intense rainstorms, having high $I_{30}$ values, can cause high runoff and soil losses within short periods of time, especially if soil stability is low. Caon et al. (2014) reported that high soil loss after frequent fire could be due to the reduced stability of soil, which is linked to a decrease in soil organic matter. Additionally, soil water repellency (SWR), which can occur both after fire and after periods of drought, can decrease infiltration (Martin and Moody, 2001; Stoof et al., 2015), and the retention of soil water (Stoof et al., 2015; Ebel, 2012; Shakesby, 2011) resulting in increased runoff and soil erosion in both wet and dry periods. While $I_{30}$ and soil moisture were regulating factors in runoff and sediment loss, lack of vegetation cover was of utmost important.

It was clear in our study that the differences in vegetation cover were important in the increased runoff and erosion in the $4 \mathrm{x}$ sites compared to the $1 \mathrm{x}$ and $0 \mathrm{x}$ burnt sites. These 
differences in soil cover are linked to frequency of fire. Fire burns vegetation and organic matter (OM) resulting in accumulation of ash on the soil surface (Stoof et al., 2015; González-Pelayo et al., 2010). This reduces infiltration, increases runoff and soil erodibility (Stoof et al., 2015; Moody and Ebel, 2014; Onda et al., 2008; Nunes et al., 2005). As presented in Chapter 2, OM losses by runoff made up nearly half the volume of the eroded soil from the $4 \mathrm{x}$ burnt sites. The effects of fire on OM are highly dependent upon fire duration and intensity, soil moisture, soil type and vegetation (Caon et al., 2014). Our research shows that fire frequency is also an important factor. OM losses in the first and second years were significantly higher in the frequently burnt sites as compared to the single burnt sites (1.29 vs. $0.14 \mathrm{Mg} \mathrm{ha}^{-1}$ in the first year and 2.23 vs. $0.37 \mathrm{Mg} \mathrm{ha}^{-1}$, in the second year respectively). Erosion and OM losses were significantly lower for the unburnt sites mainly due to the vegetation and surface cover. OM losses by runoff were higher in this study than in the study of Prats et al., (2012), which was carried out in the same study region on a single burnt site, amounting to 0.21 and $0.12 \mathrm{Mg} \mathrm{ha}^{-1}$ for the first and the second year after a fire.

The low sediment and OM losses in the single burnt sites could be explained by the significantly higher litter cover found here than in the frequently burnt sites. Litter plays an important role in reducing erosion by interrupting and slowing water and sediment flow (Malvar et al., 2015b; Prats et al., 2012). Even though ash cover can reduce soil erosion by holding the water from rainfall (Pereira et al., 2014), our study shows that, due to the bare soil conditions, frequent wildfires lead to increased ash and soil losses by runoff during the first year after a fire thus exposing the destabilized soil to further erosion in the second year under conditions of high $I_{30}$. The significant differences in sediment load between the frequently and single burnt sites agreed with the findings by Wittenberg and Inbar (2009a) and Malkisnon et al. (2011) who reported that the lack of vegetation cover in repeatedly burnt sites is the main reason for observed sediment losses. What this project confirms is that higher fire frequency results in a continued loss of vegetation and soil cover and this caused increased sediment and OM losses thereafter.

6.1.2 The effects of fire occurrence and recurrence on nitrogen and phosphorus losses by overland flow in maritime pine plantations in northcentral Portugal

Nitrogen $(\mathrm{N})$ and phosphorous $(\mathrm{P})$ are important elements for the growth of plants, but can cause problems if they are lacking or available on the wrong place. Therefore, studying the effects of fire on $\mathrm{N}$ and $\mathrm{P}$ losses is important for assessing the effects of wildfires on soil fertility and on the quality state of downstream aquatic habitats. Most studies have 
evaluated the impact of single fires on soil nutrients changes rather than the potentially more significant impact of repeated fire regimes (Ferreira et al., 2016a; Ferreira et al., 2016b; Machado et al., 2015; Badía et al., 2014). In this study, we found that the effect of fire on $\mathrm{N}$ and $\mathrm{P}$ losses varies, especially over time, and that repeated fire can have a compounded impact.

Some studies have reported that, with increased fire frequency, the cumulative loss of nutrients - particularly $\mathrm{N}$ and $\mathrm{P}$ - led to soil nutrient deficits in fire affected areas (Caon et al., 2014; Eugenio and Lloret, 2007; Eugenio and Lloret, 2004). We were interested to learn more about the processes involved. Frequent fire destroys not only vegetation cover, but also burns part of the humus layer, which is the main source of $\mathrm{N}$ and $\mathrm{P}$. This increases the amount of nutrient rich ash deposited on the top of the soil, and can increase the risk of its loss via transport by runoff after a high rainfall intensity $\left(\mathrm{I}_{30}\right)$ (Caon et al., 2014). Our research also suggests that vegetation recovery and the re-establishment of the litter layer was more delayed by repeated wildfires than by an individual fire. This could be related to the cumulative loss of nutrients in these areas.

In our research immediately after the fire, the nutrient content in both the $\mathrm{O}$ and $\mathrm{A}$ horizons of the $4 x$ burnt sites was higher because of the increased ash deposition at these sites. This was also due to the lack of vegetation after a fire which leads to the loss of nutrients that are transported along with suspended sediment in runoff (Badía et al., 2014; Badia and Marti, 2008). However, due to the lack of vegetation cover and a litter layer on these sites, the ash layer washed away easily with the first rainfall resulting in high nutrient losses due to runoff.

Our research supports the study of Carreira et al. (1994) and Castelli and Lazzari (2002) who measured a significant increase in soil nutrient content with increasing fire recurrence. Also, according to Hamman et al. (2008) both early and late season burns significantly increase the nutrient content in the first $0-5 \mathrm{~cm}$ of soil. Rodríguez et al. (2009) reported that in the short-term, the occurrence of low, medium and high intensity wildfires significantly increased the nutrient content in the A horizon $(0-5$ and $0-10 \mathrm{~cm})$ of pine forests. On the other hand, significantly lower nutrient contents were measured by Johnson et al. (2007) one year after the fire in a pine forest, which contrasts with our research.

Changes in soil $\mathrm{P}$ content depend on fire intensity and duration, which are related to the temperature reached in the soil during a fire. If the ash is not washed away by surface runoff or blown away by wind, higher amounts of phosphorus could be found in the burned soil than in the unburned soil (Ekinci and Kavdir, 2005). In our research conducted after the fire, the phosphorus content in the $4 x$ burnt sites was higher than in the $1 x$ and $0 x$ burned sites, 
respectively. By burning pine forests at low, medium and high fire intensities, the phosphorus content did not significantly increase in the A horizon $(0-5 \mathrm{~cm})$ (Hernández et al., 1997; Kutiel and Shaviv, 1992), which contrasts with our findings. The same result was measured in pine forests by Johnson et al. (2007) for the $0-10 \mathrm{~cm}$ soil depth, one year after a fire.

Our research in Chapter 3 provides a better understanding of the effects of single and repeated fires on post-fire $\mathrm{N}$ and $\mathrm{P}$ losses by overland flow in maritime pine plantations in north-central Portugal. Comparing the two burnt sites ( $4 \mathrm{x}$ and $1 \mathrm{x}), \mathrm{N}$ and $\mathrm{P}$ exports by overland flow at the frequently burned site were significantly higher than those at the single burnt site, most likely because the needle layer at the single burnt sites was able to effectively reduce runoff generation and soil erosion. This was also confirmed in other studies in the same study region (Ferreira et al., 2016a; Ferreira et al., 2016b; Martins et al., 2013; Prats et al., 2012). However, in the frequently burnt sites, the lack of vegetation cover increased overland flow, and $\mathrm{N}$ and $\mathrm{P}$ losses after rainfall events.

In this research, at the two burnt sites ( $4 \mathrm{x}$ and $1 \mathrm{x}$ ), a peak in $\mathrm{N}$ and $\mathrm{P}$ exports by runoff was observed immediately after the first high l $_{30}$ post-fire rainfall event, most likely due to the transport of the easily-erodible nutrient-enriched ash layer (Caon et al., 2014; Pereira et al., 2012; Murphy et al., 2006). Peaks in N and P exports were mainly observed during the autumn and winter seasons associated with major rainfall events with high I $_{30}$. This was not surprising since these are the events generating the highest runoff amounts and sediment losses. $\mathrm{N}$ losses of $2779 \mathrm{mg} \mathrm{m}^{-2}$ in the $4 \mathrm{x}$ burnt site vs. $702 \mathrm{mg} \mathrm{m}^{-2}$ in in the $1 \mathrm{x}$ burnt sites and $\mathrm{P}$ losses of $1507 \mathrm{mg} \mathrm{m}^{-2}$ in the $4 \mathrm{x}$ burnt site vs. $655 \mathrm{mg} \mathrm{m}^{-2}$ in the $1 \mathrm{x}$ burnt sites, show that soil fertility losses are higher with recurrent fires than with single fires (Figure 6.2). The existence of a needle cover reduced overland flow and the associated sediment and nutrient transport. Other studies in the same study region have also found that pine needles are highly effective in reducing runoff and especially erosion (Martins et al., 2013; Prats et al., 2012, 2013; Pereira et al., 2012), which of course influence nutrient dynamics. The study of Ferreira et al. (2016a, 2016b) included some maritime pine stands in the same region, and they found lower $\mathrm{N}$ and $\mathrm{P}$ losses due to runoff ( $\mathrm{N}$ losses amount to $350 \mathrm{mg} \mathrm{m}^{-2}$ and $\mathrm{P}$ losses $150 \mathrm{mg} \mathrm{m}^{-2}$ ). 




Figure 6.2 Average $N$ and $P$ losses due to runoff and erosion for unburnt, $1 x$ burnt and $4 x$ burnt plots.

This study confirms that wildfires induce marked changes on nutrient cycles, which could lead to serious degradation of ecosystems on-site, and affect water quality off-site also.

\subsubsection{The short-term effectiveness of surfactant seed coating and pine needle (mulch) treatment in reducing post-fire runoff and erosion}

The implementation of fire management practices such as keeping burnt woody materials on the soil surface, sowing and mulching are essential for reducing post fire runoff and protecting soil fertility and helping vegetation recovery (Fernandez-Manso et al., 2016). Although fires play an important role in the regulation and development of Mediterranean forest ecosystems, they also can result in desertification by increasing runoff and erosion which leads to the physical degradation of land (Shakesby, 2011).

Since the lack of surface cover is a key factor affecting the increased runoff and erosion rates in many settings (Chapter 2), a promising and regularly applied mitigation treatment is mulching (Prats et al., 2016b). Mulching often consists of log slash, bark or pine needles (Prats et al., 2012; Shakesby, 2011) which directly prevent soil erosion by creating a protective cover over the soil. However, mulching has rarely been used in post-fire land management (Prats et al., 2016b; Prats et al., 2012). In this research, we tried to compare and test methods to reduce runoff and erosion in the $4 x$ burnt sites by using pine needles as a mulch to cover the soil. Since the needles serve as a 'carpet' over the soil, the rain is intercepted and therefore is less able to transport underlying sediment. Indeed, the pine needle mulch significantly reduced (to almost one sixth) the total erosion as compared to the control plots in our study. This was also assessed by Pannkuk and Robichaud (2003), although their study was a laboratory experiment with simulated rainfall on granitic soil using different species of vegetation. 
Another post-fire management method is sowing grass or pine seeds, which contributes to restoring soil cover with vegetation, and subsequently reduce runoff and erosion potentials. The recent development of coating seeds with a soil surfactant has shown promise for improved seedling survival, and therefore could be applied in burnt areas also (Madsen et al., 2012). Soil surfactants reduce the surface tension of water and enhance the wettability of the soil, resulting in improved infiltration and retention of water and a reduction of runoff (Moore et al., 2010). Although it is rather well documented that soil surfactants alone can reduce the soil-water repellency and enhance infiltration (Moore et al., 2010; Leighton Boyce et al., 2007), their application via surfactant-coated seeds has received less attention. We examined the effect of sowing pine seeds alone, pine seeds + mulch, and grass seed with or without a surfactant coating.

In our research, sowing pine seeds alone was not effective for reducing runoff, however, the pine seeds plus mulch treatment and the surfactant-coated grass seed treatment were both quite effective. Total runoff in areas treated with surfactant-coated grass seed application was significantly lower (67\%) compared to areas sown with non-coated grass seeds. Where pine seeds + mulch was applied, total runoff was about $40 \%$ lower than from the bare soil plots. In areas where it is possible to apply revegetation measures, the treatments assessed might offer effective and promising options.

The treatments pine seeds plus mulch and surfactant-coated grass seed also substantially decreased erosion induced soil and OM losses. This supports what has also been reported by Madsen et al. (2013a) and Prats et al. (2013), respectively. Furthermore, the application of seeds alone, either grass or pine, did not result in significantly lower total runoff and erosion, which is in line with findings of MacDonald and Larsen (2009) stating that the most effective methods to reduce erosion rates are those that immediately cover the soil. However, based on our findings and previous work of others, it might be concluded that a combination of mulching and revegetation with surfactant coated seeds could be the most effective treatment for minimizing runoff and erosion, both on the short and long term.

\subsubsection{Developing generalized parameters for post-fire erosion risk assessment using the revised Morgan-Morgan-Finney (MMF) model for north-central Portuguese pine stands}

Post-fire erosion is an important societal concern due to the loss of soil fertility, impact on downstream water resources, as well as resulting social-economic impacts. Better insights in post-fire erosion dynamics might offer more accurate information or related on and off site environmental impacts. Simulation modelling might be helpful from this perspective. 
Modelling efforts for burned areas, including erosion predictions after fires, have been a research goal of several studies. However, there is still a need to improve representation of interacting processes in burnt areas and determination of appropriate model parameters. So far, model applications tend to focus on specific study sites and single fires vs frequent/recurrent fires, and are not necessarily generally applicable. In Chapter 5 of this thesis simulation of the impact of recurrent wildfires on runoff and erosion using the revised Morgan-Morgan-Finney (MMF) model has been presented. The MMF model was selected for this purpose due to its suitable set-up, limited data demand and easy applicability.

In our study, the MMF modelling approach did not provide accurate estimates of annual runoff for different plots or between fire recurrence sites. However, the model was capable to simulate the markedly higher soil losses at the frequently burnt sites reasonably well when compared to the single burnt sites. The model also achieved reasonable efficiency for the prediction of post-fire soil erosion. For annual erosion rates in single and frequent burnt sites model efficiency was rather good with a Nash-Sutcliffe coefficient of efficiency of NSE $=0.54$.

These results are comparable to previously reported data derived from MMF applications in burnt areas in Portugal (Vieira et al., 2014), and in north-western Spain (Fernández et al., 2010). Erosion loss in the MMF model is a function of soil detachment and transport, which are affected not only by the amount of runoff, but also by other regulating factors such as slope, soil erodibility and vegetation cover (Morgan, 2001). Therefore, simulated erosion rates might fit well to observed data, despite that runoff simulations shows poor resemblance with field observations. This clearly shows limitations of the current version of the MMF model, which needs further attention and improvements in the future.

\subsubsection{Implications for post-fire land management}

The results of this study confirmed that recurrent wildfires have more adverse environmental impacts than sporadic ones. Furthermore, the importance of finding ways to quickly create a protective soil layer in order to minimize post-fire erosion and soil nutrient losses has been revealed and highlighted clearly. Areas that have experienced or are prone to recurrent wildfires need other types of land management actions than areas that have experienced just one fire in several decades.

Although our studies were conducted on the microplot scale, it is clear that repeated wildfires delayed vegetation recovery and the re-establishment of the litter layer. Repeated wildfires also strongly increased the runoff coefficient and the risks for soil erosion, OM 
losses and nutrient transport by runoff to downstream regions. Therefore, short term protection of the surface layer could be a fast and effective way to save soil and soil fertility after a fire. Applications have been tested and shown to be effective. These practices might be applicable on the wider special scale and should receive further attention by land managers, land users, and governmental institutions.

\subsection{Conclusions and recommendations}

Based on the findings of this thesis project, a number of conclusions and recommendation can be made particularly with regard to areas susceptible to high wildfire frequency. Fire frequency has a pronounced effect on the environment and deserves further attention in research, land use planning and management. When areas experience recurrent fires over several decades, the typical post-fire problems are more severe and the risk of desertification is greater than in areas exposed to sporadic fire. This has implications for the management of these areas. Although our findings that the impact of frequent fires is greater than that of individual fires seem logical, this is the first time that this has been systematically investigated and quantified.

In addition to the main conclusion that multiple wildfires cause more erosion than single fires, other conclusions and recommendations of this PhD study are the following:

- Forest fire prevention is the best land management strategy to preserve valuable natural resources;

- Repeated wildfires strongly increase runoff due to absence of vegetation and/or litter cover;

- OM loss is really high in the frequently burnt sites due to deeper burning into the humus layer. This degrades and destabilizes the soil more than in cases where there is surface vegetation as fuel, and also leads to higher $\mathrm{N}$ and $\mathrm{P}$ losses by runoff than single wildfires. This changes nutrient cycles, which may lead to severe degradation of ecosystems;

- Repeated wildfires obstruct the recovery of vegetation and the re-establishment of the litter layer to a greater extent than single fires. This enhances to a vicious cycle of runoff and soil and nutrient loss that further decrease recovery potential of the soil cover needed to reduce soil loss and support plant growth;

- In addition to fire frequency, surface cover, soil moisture, soil water repellency and rain intensity also affected runoff, soil erosion, and OM losses;

- Soil cover is the primary factor in decreasing runoff and protecting slopes against erosion after fire. Therefore, mitigation strategies should focus on promoting the recovery and regrowth of vegetation; 
- Use of surfactant-coated seeds and/or pine needle mulch in a burnt area after fire will protect the bare soil and promote rapid regrowth of vegetation, as well as effectively minimising runoff and erosion risks;

- The MMF model has been shown to be a valuable tool to simulate runoff and erosion dynamics after single or multiple wildfire, although the model has limitations also.

\subsection{Limitations and research challenges}

The present work evaluated the effects of fire frequency on runoff and soil and nutrient losses by overland flow at the micro-plot scale in a burnt Mediterranean area, addressing a topic that has recieved limited attention so far. Nonetheless, the results of the current work should be looked at with some caution, since the micro-plot scale on which our research was done may not be representative of post-fire hydrological and erosive processes at the entire hillslope or catchment scale. An additional limitation of the project is that it only focused at fire frequencies of 0,1 and $4 x$ burnt sites in a 37-year period, and didn't explore other frequencies and/or sequences. Despite these limitations, the present findings advance the current state of knowledge on effects of repeated fire on post-fire runoff, soil erosion and soil fertility in the Mediterranean region.

In order to further increase our understanding on relations between fire frequency and changes on soil-vegetation systems, the following deserves to be explored in the near future:

- Studies on other spatial and temporal scales than addressed in this thesis;

- Besides fire frequency, also investigate effects of fire intensity on soil and vegetation changes during and after wildfire;

- Attention to more integrated, physically based, modelling of soil-vegetation systems exposed to one or multiple wildfires;

- Testing of other restoration and regreening measures for wildfire affected areas, including related cost-benefit analysis;

- Designing land management systems, accounting for minimizing wildfire risk occurrence;

- Developing and testing of innovative, low-cost and widely applicable wildfire prevention and remediation technologies;

- Defining science-based recommendations for policy makers to improve land management and land use, to minimize wildfire risk, and maximize restoration and regreening potentials of fire affected areas. 


\section{Literature cited}

Alauzis, M. V., Mazzarino, M. J., Raffaele, E., Roselli, L., 2004. Wildfires in NW Patagonia: long-term effects on a Nothofagus forest soil. Forest Ecology and Management 192, 131-142.

Almeida, D.R.A., Nelson, B.W., Schietti, J., Gorgens, E.B., Resende, A.F., Stark, S.C., Valbuena, R., 2016. Contrasting fire damage and fire susceptibility between seasonally flooded forest and upland forest in the Central Amazon using portable profiling LiDAR. Remote Sensing of Environment 184, 153-160.

Aponte, C., de Groot, W. J., \& Wotton, B. M. 2016. Forest fires and climate change: causes, consequences and management options. International Journal of Wildland Fire, 25, i-ii.

APHA, 1999. Standard methods for the examination of water and wastewater (20 ed.). American Public Health Association, Washington D. C.

Aznar, J.M., González-Pérez, J.A., Badía, D., Martí, C., 2016. At what depth are the properties of a gypseous forest topsoil affected by burning? Land Degradation and Development. 27, 1344-1353.

Badía-Villas, D., González-Pérez, J.A., Aznar, J.M., Arjona-Gracia, B., Martí-Dalmau, C., 2014. Changes in water repellency, aggregation and organic matter of a mollic horizon burned in laboratory: Soil depth affected by fire. Geoderma 213, 400-407.

Badía, D., Martí, C., 2003. Plant ash and heat intensity effects on chemicaland physical properties of two contrasting soils. Arid Land Research and Management 17, 23-41.

Badia, D., Marti, C., 2008. Fire and rainfall energy effects on soil erosion and runoff generation in semi-arid forested lands. Arid Land Research and Management 22, 93 108.

Badia, D., Marti, C., Aguirre, J., Echeverria, M.T., Ibarra, P., 2008. Erodibility and hydrology of arid burned soils: soil type and revegetation effects. Arid Land Research and Management 22, 286-295.

Badía, D., Martí, C., Aguirre, A.J., Aznar, J.M., González-Pérez, J.A., De la Rosa, J.M., León, J., Ibarra, P., Echeverría, T., 2014. Wildfire effects on nutrients and organic carbon of a Rendzic Phaeozem in NE Spain: Changes at cm-scale topsoil. Catena 113, 267-275.

Ball, D.F., 1964. Loss-on-ignition as an estimate of organic matter and organic carbon in noncalcareous soils. Journal of Soil Science 15, 84-92.

Baartman, J.E.M., Masselink, R., Keesstra, S.D., Temme, A.J.A.M., 2013. Linking landscape morphological complexity and sediment connectivity. Earth Surf. Process. Landforms 38, 1457-1471.

Benavides-Solorio, J.D., MacDonald, L.H., 2005. Measurement and prediction of post-fire erosion at the hillslope scale, Colorado Front Range. International Journal of Wildland Fire 14, 457-474. 
Bento-Gonçalves, A., Vieira, A., Úbeda, X., Martin, D., 2012. Fire and soils: Key concepts and recent advances. Geoderma, 191, 3-13.

Blake, G.R., Hartge, K., 1986. Bulk density, In: Klute, A. (Ed.), Methods of Soil Analysis, Part 1, 2nd edition Agronomy Monograph vol. 9. America Society of Agronomy, Madison, Wis, USA, pp. 363-375.

Bray, R.H., Kurtz, L., 1945. Determination of total, organic, and available forms of phosphorus in soils. Soil science $59,39-46$.

Bremner, J., 1965. Total nitrogen. Methods of soil analysis. Part 2. Chemical and microbiological properties, 1149-1178.

Cannon, S., Boldt, E., Laber, J., Kean, J., Staley, D., 2011. Rainfall intensity-duration thresholds for postfire debris-flow emergency-response planning. 59, 209-236.

Caon, L., Vallejo, V.R., Ritsema, C.J., Geissen, V., 2014. Effects of wildfire on soil nutrients in Mediterranean ecosystems. Earth-Science Reviews 139, 47-58.

Carreira, J.A., Niell, F.X., Lajtha, K., 1994. Soil nitrogen availability and nitrification in Mediterranean shrublands of varying fire history and successional stage. Biogeochemistry 26, 189-209.

Carreiras, M., Ferreira, A.J.D., Valente, S., Fleskens, L., Gonzales-Pelayo, Ó., Rubio, J.L., Stoof, C.R., Coelho, C.O.A., Ferreira, C.S.S., Ritsema, C.J., 2014. Comparative analysis of policies to deal with wildfire risk. Land Degradation and Development. 25, 92-103.

Carter, M.C., Darwin Foster, C., 2004. Prescribed burning and productivity in southern pine forests: a review. Forest Ecology and Management 191, 93-109.

Castelli, L., Lazzari, M., 2002. Impact of fire on soil nutrients in central semiarid Argentina. Arid Land Research and Management 16, 349-364.

Cerdà, A., 1999. Seasonal and spatial variations in infiltration rates in badland surfaces under Mediterranean climatic conditions. Water Resources Research 35, 319-328.

Cerdà, A., Doerr, S.H., 2005. Influence of vegetation recovery on soil hydrology and erodibility following fire: an 11-year investigation. International Journal of Wildland Fire 14, 423-437.

Cerdà, A., Robichaud, P.R., 2009. Fire effects on soils and restoration strategies. Land reconstruction and management series;vol. 5. Science Publishers, Enfield, NH.

Cerda, A., 2009. Fire effects on soils and restoration strategies, 5. CRC, 511-535.

Cerdà, A., González-Pelayo, O., Giménez-Morera, A., Jordán, A., Pereira, P., Novara, A., Brevik, E.C., Prosdocimi, M., Mahmoodabadi, M., Keesstra, S.K., 2015. The use of barley straw residues to avoid high erosion and runoff rates on persimmon plantations in Eastern Spain under low frequency-high magnitude simulated rainfall events. Soil Research 54, 154-165.

Cerdan, O., Govers, G., Le Bissonnais, Y., Van Oost, K., Poesen, J., Saby, N., Gobin, A., Vacca, A., Quinton, J., Auerswald, K., Klik, A., Kwaad, F.J.P.M., Raclot, D., Ionita, I., Rejman, J., 
Rousseva, S., Muxart, T., Roxo, M.J., Dostal, T., 2010. Rates and spatial variations of soil erosion in Europe: A study based on erosion plot data. Geomorphology 122, 167-177.

Certini, G., 2005. Effects of Fire on Properties of Forest Soils: A Review. Oecologia 143, 1-10. Christensen, N.L., 1993. Fire regimes and ecosystem dynamics. Fire in the environment: The ecological, atmospheric, and climatic importance of vegetation fires, 233-244.

Cunningham, K., Barry, J., Walkingstick, T., 2008. Managing loblolly pine stands...from A to Z. University of Arkansas, United States department of agriculture, and county governments cooperating.

De Haan, J.D., Icove, D.J., 2011. Kirk's fire investigation. Pearson higher Ed.

DeBano, L.F., Rice, R.M., Eugene, C.C., 1979. Soil heating in chaparral fires: effects on soil properties, plant nutrients, erosion, and runoff. Res. Paper PSW-RP-145. Berkeley, CA: U.S. Department of Agriculture, Forest Service, Pacific Southwest Forest and Range Experiment Station. $21 \mathrm{p}$.

DeBano, L.F., 1981. Water repellent soils: a state-of-the-art. General technical report PSW46. U.S. Department of agricultur, forest service, pacific southwest forest and ranae experiment station, Berkely, California, USA.

DeBano, L.F., Neary, D.G., Folliott, P.F., 1998. Fire effects on ecosystems. John Wiley \& Sons. Deguchi, A., Hattori, S., Park, H.-T., 2006. The influence of seasonal changes in canopy structure on interception loss: Application of the revised Gash model. Journal of Hydrology 318, 80-102.

Dekker, L.W., Ritsema, C.J., Oostindie, K., 2000. Extent and significance of water repellency in dunes along the Dutch coast. Journal of Hydrology 231-232, 112-125.

Díaz-Delgado, R., Lloret, F., Pons, X., 2003. Influence of fire severity on plant regeneration by means of remote sensing imagery. International Journal of Remote Sensing 24, 17511763.

Díaz-Raviña, M., Martín, A., Barreiro, A., Lombao, A., Iglesias, L., Díaz-Fierros, F., Carballas, T., 2012. Mulching and seeding treatments for post-fire soil stabilisation in NW Spain: short-term effects and effectiveness. Geoderma 191, 31-39.

Doerr, S.H., Shakesby, R.A., Walsh, R.P.D., 1996. Soil hydrophobicity variations with depth and particle size fraction in burned and unburned Eucalyptus globulus and Pinus pinaster forest terrain in the Águeda Basin, Portugal. Catena 27, 25-47.

Doerr, S.H., 1998. On standardizing the 'Water Drop Penetration Time' and the 'Molarity of an Ethanol Droplet' techniques to classify soil hydrophobicity: A case study using medium textured soils. Earth surf. process. Landforms 23, 663-668.

Duguy, B., Rovira, P., Vallejo, R., 2007. Land-use history and fire effects on soil fertility in eastern Spain. European journal of soil science 58, 83-91.

Dunkerley, D.L., 2010. How do the rain rates of sub-event intervals such as the maximum 5and 15 -min rates ( $i_{5}$ or $i_{30}$ ) relate to the properties of the enclosing rainfall event? Hydrol. process. 24, 2425-2439. 
Ebel, B.A., 2012. Wildfire impacts on soil-water retention in the Colorado Front Range, United States. Water resources research 48, 1-12.

Ekinci, H., Kavdir, Y., 2005. Changes in soil quality parameters after a wildfire in Gelibolu (Gallipoli) National Park, Turkey. Fresenius Environmental Bulletin 14, 1184-1191.

Esteves, T.C.J., Kirkby, M.J., Shakesby, R.A., Ferreira, A.J.D., Soares, J.A.A., Irvine, B.J., Ferreira, C.S.S., Coelho, C.O.A., Bento, C.P.M., Carreiras, M.A., 2012. Mitigating land degradation caused by wildfire: Application of the PESERA model to fire-affected sites in central Portugal. Geoderma 191, 40-50.

Eugenio, M., Lloret, F., 2004. Fire recurrence effects on the structure and composition of Mediterranean Pinus halepensis communities in Catalonia (northeast Iberian Peninsula). Écoscience 11, 446-454.

Eugenio, M., Lloret, F., 2007. Fire recurrence effects on Pinus halepensis Mill. communities of Catalonia. Universitat Autònoma de Barcelona.

FAO, 2007. Fire management-Global assessment 2006. FAO Forestry Paper 151. Rome, Food and agriculture organization of the United Nations.

Fernandes, P.M., Barros, A.MG., Pinto, A., Santos, A., 2016. Characteristics and controls of extremely large wildfires in the western Mediterranean Basin. Journal of Geophysical Research: Biogeosciences 121, 2141-2157.

Fernández, C., Vega, J., Vieira, D., 2010. Assessing soil erosion after fire and rehabilitation treatments in NW Spain: performance of RUSLE and revised Morgan-Morgan-Finney models. Land Degradation and Development. 21, 58-67.

Fernández, C., Vega, J.A., 2016. Evaluation of RUSLE and PESERA models for predicting soil erosion losses in the first year after wildfire in NW Spain. Geoderma 273, 64-72.

Fernandez-Manso, A., Quintano, C., Roberts, D.A., 2016. Burn severity influence on post-fire vegetation cover resilience from Landsat MESMA fraction images time series in Mediterranean forest ecosystems. Remote Sensing of Environment 184, 112-123.

Ferreira, A.J.D., Coelho, C.O.A., Boulet, A.K., Leighton-Boyce, G., Keizer, J.J., Ritsema, C.J., 2005a. Influence of burning intensity on water repellency and hydrological processes at forest and shrub sites in Portugal. Soil Research 43, 327-336.

Ferreira, A.J.D., Coelho, C.O.A., Boulet, A.K., Lopes, F.P., 2005b. Temporal patterns of solute loss following wildfires in Central Portugal. International Journal of Wildland Fire 14, 401-412.

Ferreira, A.J.D., Coelho, C.O.A., Ritsema, C.J., Boulet, A.K., Keizer, J.J., 2008. Soil and water degradation processes in burned areas: Lessons learned from a nested approach. Catena 74, 273-285.

Ferreira, A.J.D., Prats, S.A., Coelho, C.O.A., Shakesby, R.A., Páscoa, F.M., Ferreira, C.S.S., Keizer, J.J., Ritsema, C.J., 2015. Strategies to prevent forest fires and techniques to reverse degradation processes in burned areas. Catena 128(0), 224-237. 
Ferreira, R., Serpa, D., Cerqueira, M., Keizer, J.J., 2016a. Short-time phosphorus losses by overland flow in burnt pine and eucalypt plantations in north-central Portugal: A study at micro-plot scale. Science of The Total Environment 551, 631-639,.

Ferreira, R., Serpa, D., Machado, A., Rodríguez-Blanco, M., Santos, L., Taboada-Castro, M., Cerqueira, M., Keizer, J.J., 2016b. Short-term nitrogen losses by overland flow in a recently burnt forest area in north-central Portugal: A study at micro-plot scale. Science of The Total Environment.

García-Corona, R., Benito, E., de Blas, E., Varela, M., 2004. Effects of heating on some soil physical properties related to its hydrological behaviour in two north-western Spanish soils. International Journal of Wildland Fire 13, 195-199.

Gash, J.H.C., Lloyd, C.R., Lachaud, G., 1995. Estimating sparse forest rainfall interception with an analytical model. Journal of Hydrology 170, 79-86.

Giglio, L., van der Werf, G.R., Randerson, J.T., Collatz, G.J., Kasibhatla, P., 2006. Global estimation of burned area using MODIS active fire observations. Atmos. Chem. Phys. 6 , 957-974.

Giglio, L., Randerson, J.T., van der Werf, G.R., Kasibhatla, P.S., Collatz, G.J., Morton, D.C., DeFries, R.S., 2010. Assessing variability and long-term trends in burned area by merging multiple satellite fire products. Biogeosciences 7, 1171-1186.

Giovannini, G., Lucchesi, S., Giachetti, M., 1990. Beneficial and detrimental effects of heating on soil quality. Fire in ecosystem dynamics. SPB Academic publishing, The Hague, 95102.

González-Pelayo, O., Andreu, V., Gimeno-García, E., Campo, J., Rubio, J.L., 2010. Rainfall influence on plot-scale runoff and soil loss from repeated burning in a Mediterraneanshrub ecosystem, Valencia, Spain. Geomorphology 118, 444-452.

González-Pelayo, O., Gimeno-García, E., Ferreira, C.S.S., Ferreira, A.J.D., Keizer, J.J., Andreu, V., Rubio, J.L., 2015. Water repellency of air-dried and sieved samples from limestone soils in central Portugal collected before and after prescribed fire. Plant and Soil 394, 199-214.

González-Pérez, J.A., González-Vila, F.J., Almendros, G., Knicker, H., 2004. The effect of fire on soil organic matter-a review. Environment International 30, 855-870.

Gralewicz, N.J., Nelson, T.A., Wulder, M.A., 2012. Factors influencing national scale wildfire susceptibility in Canada. Forest Ecology and Management 265, 20-29.

Granged, A.J.P., Jordán, A., Zavala, L.M., Bárcenas, G., 2011a. Fire-induced changes in soil water repellency increased fingered flow and runoff rates following the 2004 Huelva wildfire. Hydrol. Process. 25, 1614-1629.

Granged, A.J.P., Zavala, L.M., Jordán, A., Bárcenas-Moreno, G., 2011b. Post-fire evolution of soil properties and vegetation cover in a Mediterranean heathland after experimental burning: A 3-year study. Geoderma 164, 85-94. 
Guitián-Ojea, F., Carballas, T., 1976. Técnicas de análisis de suelos. Pico Sacro, Santiago de Compostela, Spain.

Hamman, S.T., Burke, I.C., Knapp, E.E., 2008. Soil nutrients and microbial activity after early and late season prescribed burns in a Sierra Nevada mixed conifer forest. Forest Ecology and Management 256, 367-374.

Hargreaves, G.H., Samani, Z.A., 1985. Reference crop evapotranspiration from ambient air temperature. American Society of Agricultural Engineers (Microfiche collection) (USA). no. fiche no. 85-2517.

Heiniger, R.W., McBride, R.G., Clay, D.E., 2003. Using soil electrical conductivity to improve nutrient management. Agronomy Journal 95, 508-519.

Hernández, T., García, C., Reinhardt, I., 1997. Short-term effect of wildfire on the chemical, biochemical and microbiological properties of Mediterranean pine forest soils. Biology and Fertility of Soils 25, 109-116.

Hosseini, M., Keizer, J.J., Pelayo, O.G., Prats, S.A., Ritsema, C.J., Geissen, V., 2016. Effect of fire frequency on runoff, soil erosion, and loss of organic matter at the micro-plot scale in north-central Portugal. Geoderma 269, 126-137.

Hosseini, M., Geissen, V., González-Pelayo, O., Serpa, D., Machado, A.I., Ritsema, C.J, Keizer, J.J., 2017. Effects of fire occurrence and recurrence on nitrogen and phosphorus losses by overland flow in maritime pine plantations in north-central Portugal. Geoderma, 289, 97-106.

Hoyningen-Huene, J.V., 1981. Die Interzeption des Niederschlags in landwirtschaftlichen Pflanzenbeständen. Arbeitsbericht Deutscher Verband für Wasserwirtschaft und Kulturbau, DVWK.

ICNF, 2016. Instituto da Conservação da Natureza e das Florestas, (Available at: http://www.icnf.pt/portal/icnf).

Imeson, A.C., Verstraten, J.M., van Mulligen, E.J., Sevink, J., 1992. The effects of fire and water repellency on infiltration and runoff under Mediterranean type forest. Catena 19, 345-361.

Inbar, A., Lado, M., Sternberg, M., Tenau, H., Ben-Hur, M., 2014. Forest fire effects on soil chemical and physicochemical properties, infiltration, runoff, and erosion in a semiarid Mediterranean region. Geoderma 221-222, 131-138.

Inbar, M., Tamir, M., Wittenberg, L., 1998. Runoff and erosion processes after a forest fire in Mount Carmel, a Mediterranean area. Geomorphology 24, 17-33.

Janssen, P.H.M., Heuberger, P.S.C., 1995. Calibration of process-oriented models. Ecological Modelling 83, 55-66.

Jin-yan, Y., Jing, F., 2003. Review of study on mineralization, saturation and cycle of Nitrogen in forest ecosystems. Journal of Forestry Research 14, 239-243.

Johnson, D., Murphy, J.D., Walker, R.F., Glass, D.W., Miller, W.W., 2007. Wildfire effects on forest carbon and nutrient budgets. Ecological Engineering 31, 183-192. 
Jordán, A., Zavala, L.M., Mataix-Solera, J., Nava, A.L., Alanís, N., 2011. Effect of fire severity on water repellency and aggregate stability on Mexican volcanic soils. Catena $84,136-$ 147.

Keeley, J.E., 2009. Fire intensity, fire severity and burn severity: a brief review and suggested usage. International Journal of Wildland Fire 18, 116-126.

Keesstra, S.K., Pereira, P., Novara, A., Brevik, E.C., Azorin-Molina, C., Parras-Alcántara, L., Jordán, A., Cerdà, A., 2016. Effects of soil management techniques on soil water erosion in apricot orchards. Science of The Total Environment 551-552, 357-366.

Keizer, J.J., Doerr, S.H., Malvar, M.C., Prats, S.A., Ferreira, R.S.V., Oñate, M.G., Coelho, C.O.A., Ferreira, A.J.D., 2008. Temporal variation in topsoil water repellency in two recently burnt eucalypt stands in north-central Portugal. Catena 74 (3), 192-204.

Knoepp, J.D., DeBano, L.F., Neary, D.G., 2005. Soil chemistry. Wildland fire in ecosystems: effects of fire on soils and water. Edited by DG Neary, KC Ryan, and LF DeBano. US Department of Agriculture, Forest Service, Rocky Mountain Research Station, Ogden, Utah. Gen. Tech. Rep. RMRS-GTR-42-vol 4, 53-72.

Krebs, P., Pezzatti, G.B., Mazzoleni, S., Talbot, L.M., Conedera, M., 2010. Fire regime: history and definition of a key concept in disturbance ecology. Theory in Biosciences 129, 53 69.

Kutiel, P., Shaviv, A., 1992. Effects of soil type, plant composition and leaching on soil nutrients following a simulated forest fire. Forest Ecology and Management 53, 329343.

Langhans, C., Smith, H.G., Chong, D.M.O., Nyman, P., Lane, P.N.J., Sheridan, G.J., 2016. A model for assessing water quality risk in catchments prone to wildfire. Journal of Hydrology 534, 407-426.

Larsen, I.J., MacDonald, L.H., 2007. Predicting postfire sediment yields at the hillslope scale: Testing RUSLE and Disturbed WEPP. Water Resources Research 43, 1-18.

Leighton Boyce, G., Doerr, S.H., Shakesby, R., Walsh, R., 2007. Quantifying the impact of soil water repellency on overland flow generation and erosion: a new approach using rainfall simulation and wetting agent on in situ soil. Hydrol. Process. 21, 2337-2345.

Léonard, J., Richard, G., 2004. Estimation of runoff critical shear stress for soil erosion from soil shear strength. Catena 57, 233-249.

López-Vicente, M., Navas, A., Gaspar, L., Machín, J., 2013. Advanced modelling of runoff and soil redistribution for agricultural systems: the SERT model. Agricultural water management 125, 1-12.

López-Vicente, M., Quijano G.L., Palazón T.L., Gaspar F.L., Navas I.A., 2015. Assessment of soil redistribution at catchment scale by coupling a soil erosion model and a sediment connectivity index (central spanish pre-pyrenees), Cuadernos de Investigacion Geografica 41, 127-147. 
Lozano, F.J., Suárez-Seoane, S., de Luis-Calabuig, E., 2012. Does fire regime affect both temporal patterns and drivers of vegetation recovery in a resilient Mediterranean landscape? A remote sensing approach at two observation levels. International Journal of Wildland Fire 21, 666-679.

MacDonald, L.H., Larsen, I.J., 2009. Effects of forest fires and post-fire rehabilitation: a Colorado, USA case study. Fire effects on soils and restoration strategies. Enfield, $\mathrm{NH}$, USA: Science Publishers, Inc, 423-452.

Machado, A.I., Serpa, D., Ferreira, R.V., Rodríguez-Blanco, M.L., Pinto, R., Nunes, M.I., Cerqueira, M.A., Keizer, J.J., 2015. Cation export by overland flow in a recently burnt forest area in north-central Portugal. Science of The Total Environment 524-525, 201212.

Madsen, M.D., Petersen, S.L., 2010. Seed coating compositions and methods for applying soil surfactants to water-repellent soil. Google Patents. US 9554502 B2.

Madsen, M.D., Kostka, S.J., Inouye, A.L., Zvirzdin, D.L., 2012. Postfire restoration of soil hydrology and wildland vegetation using surfactant seed coating technology. Rangeland Ecology \& Management 65, 253-259.

Madsen, M., Kostka, S., Hulet, A., Mackey, B., Harrison, M., Mcmillan, M., 2013a. Surfactant seed coating-a strategy to improve turfgrass establishment on water repellent soils, International Symposium on Adjuvants for Agrochemicals, pp. 205-210.

Madsen, M., Zvirzdin, D., Kostka, S., 2013b. Improving reseeding success after catastrophic wildfire with surfactant seed coating technology, European Geosciences Union General Assembly Proceedings, STP 1569, 44-55.

Maia, P., Pausas, J.G., Arcenegui, V., Guerrero, C., Pérez-Bejarano, A., Mataix-Solera, J., Varela, M.E.T., Fernandes, I., Pedrosa, E.T., Keizer, J.J., 2012a. Wildfire effects on the soil seed bank of a maritime pine stand - The importance of fire severity. Geoderma 191, 80-88.

Maia, P., Pausas, J.G., Vasques, A., Keizer, J.J., 2012b. Fire severity as a key factor in post-fire regeneration of Pinus pinaster (Ait.) in Central Portugal. Annals of Forest Science 69(FOSS-PO4-P), 489-498.

Maia, P., Keizer, J.J., Vasques, A., Abrantes, N., Roxo, L., Fernandes, P., Ferreira, A., Moreira, F., 2014. Post-fire plant diversity and abundance in pine and eucalypt stands in Portugal: Effects of biogeography, topography, forest type and post-fire management. Forest Ecology and Management 334, 154-162.

Malkisnon, D., Wittenberg, L., Beeri, O., Barzilai, R., 2011. Effects of repeated fires on the structure, composition, and dynamics of mediterranean maquis: short- and long-term perspectives. Ecosystems 14, 478-488.

Malvar, M.C., Prats, S.A., Nunes, J.P., Keizer, J.J., 2015a. Soil water repellency severity and its spatio-temporal variation in burnt eucalypt plantations in North-Central Portugal. Land Degradation and Development 27, 1463-1478. 
Malvar, M.C., Prats, S.A., Keizer, J.J., 2015b. Runoff and inter-rill erosion affected by wildfire and pre-fire ploughing in eucalypt plantations of North-Central Portugal. Land Degradation and Development 27, 1366-1378.

Martin, D.A., Moody, J.A., 2001. Comparison of soil infiltration rates in burned and unburned mountainous watersheds. Hydrol. Process. 15, 2893-2903.

Martínez-Aznar, J., González-Pérez, J.A., Badía-Villas, D., Martí Dalmau, C., 2013. At what depth are the properties of gypseous foprest soil affected by fire? Artículo Publicado Online.

Martins, M.A., Machado, A.I., Serpa, D., Prats, S.A., Faria, S.R., Varela, M.E., González-Pelayo, Ó., Keizer, J.J., 2013. Runoff and inter-rill erosion in a maritime pine and a eucalypt plantation following wildfire and terracing in north-central Portugal. Journal of Hydrology and Hydromechanics 61, 261-268.

Mataix-Solera, J., Cerdà, A., Arcenegui, V., Jordán, A., Zavala, L.M., 2011. Fire effects on soil aggregation: A review. Earth-Science Reviews 109, 44-60.

Mayor, A.G., Bautista, S., Llovet, J., Bellot, J., 2007. Post-fire hydrological and erosional responses of a Mediterranean landscpe: Seven years of catchment-scale dynamics. Catena 71, 68-75.

Moench, R., Fusaro, J., 2012. Soil Erosion Control after Wildfire, Natural Resources Series, Forestry Fact Sheet No. 6.308.

Moody, J.A., Martin, D.A., Cannon, S.H., 2008. Post-wildfire erosion response in two geologic terrains in the western USA. Geomorphology 95, 103-118.

Moody, J.A., Shakesby, R.A., Robichaud, P.R., Cannon, S.H., Martin, D.A., 2013. Current research issues related to post-wildfire runoff and erosion processes. Earth-Science Reviews 122, 10-37.

Moody, J.A., Ebel, B.A., 2014. Infiltration and runoff generation processes in fire-affected soils. Hydrol. Process. 28, 3432-3453.

Moore, D., Kostka, S., Boerth, T., Franklin, M., Ritsema, C.J., Dekker, L., Oostindie, K., Stoof, C., Wesseling, J., 2010. The effect of soil surfactants on soil hydrological behavior, the plant growth environment, irrigation efficiency and water conservation. Journal of Hydrology and Hydromechanics 58, 142-148.

Moreira, F., Viedma, O., Arianoutsou, M., Curt, T., Koutsias, N., Rigolot, E., Barbati, A., Corona, P., Vaz, P., Xanthopoulos, G., Mouillot, F., Bilgili, E., 2011. Landscape - wildfire interactions in southern Europe: Implications for landscape management. Journal of Environmental Management 92, 2389-2402.

Moreira, F., Ferreira, A., Abrantes, N., Catry, F., Fernandes, P., Roxo, L., Keizer, J.J., Silva, J., 2013. Occurrence of native and exotic invasive trees in burned pine and eucalypt plantations: Implications for post-fire forest conversion. Ecological Engineering 58, 296302. 
Morgan, R.P.C., 2001. A simple approach to soil loss prediction: a revised Morgan-MorganFinney model. Catena 44, 305-322.

Morgan, R.P.C., 2005. Soil erosion and conservation. Blackwell, Malden, MA.

Moriasi, D.N., Arnold, J.G., Van Liew, M.W., Bingner, R.L., Harmel, R.D., Veith, T.L., 2007. Model evaluation guidelines for systematic quantification of accuracy in watershed simulations. Transactions of the ASABE 50, 885-900.

Murphy, J.D., Johnson, D.W., Miller, W.W., Walker, R.F., Carroll, E.F., Blank, R.R., 2006. Wildfire effects on soil nutrients and leaching in a Tahoe Basin watershed. Journal of Environmental Quality 35.

Nash, J.E., Sutcliffe, J.V., 1970. River flow forecasting through conceptual models part I - A discussion of principles. Journal of Hydrology 10, 282-290.

Naveh, Z., 1974. Effects of fire in the Mediterranean region. Fire and ecosystems 321, 364.

Nearing, M.A., Foster, G.R., Lane, L.J., Finkner, S.C., 1989. Process-based soil erosion model for USDA-water erosion prediction project technology. Transactions of the American Society of Agricultural Engineers 32, 1587-1593.

Nearing, M.A., Govers, G., Norton, L.D., 1999. Variability in Soil Erosion Data from Replicated Plots. Soil Science Society of America Journal 63, 1829-1835.

Neary, D.G., Klopatek, C.C., DeBano, L.F., Ffolliott, P.F., 1999. Fire effects on belowground sustainability: a review and synthesis. Forest Ecology and Management 122, 51-71.

Neary, D.G., Ryan, K.C., DeBano, L.F., 2005. Wildland fire in ecosystems: effects of fire on soils and water, USDA, 19-27.

Novara, A., Gristina, L., Bodí, M., Cerdà, A., 2011. The impact of fire on redistribution of soil organic matter on a Mediterranean hillslope under maquia vegetation type. Land Degradation and Development. 22, 530-536.

NRCS, 2000. Soil Quality Resource Concerns: Hydrophobicity. Natural resource conservation service (Soil quality information sheet), USDA.

Nunes, M.C.S., Vasconcelos, M.J., Pereira, J.M.C., Dasgupta, N., Alldredge, R.J., Rego, F.C., 2005. Land cover type and fire in Portugal: Do fires burn land cover selectively? Landscape Ecology 20, 661-673.

Nunes, J.P., Seixas, J., Keizer, J.J., Ferreira, A.J.D., 2009. Sensitivity of runoff and soil erosion to climate change in two Mediterranean watersheds. Part I: model parameterization and evaluation. Hydrological Processes 23, 1202-1211.

Nunes, J.P., Malvar, M., Benali, A.A., Rial Rivas, M.E., Keizer, J.J., 2015. A simple water balance model adapted for soil water repellency: application on Portuguese burned and unburned eucalypt stands. Hydrol. Process. 30, 463-478.

Onda, Y., Dietrich, W.E., Booker, F., 2008. Evolution of overland flow after a severe forest fire, Point Reyes, California. Catena 72, 13-20.

Pannkuk, C.D., Robichaud, P.R., 2003. Effectiveness of needle cast at reducing erosion after forest fires. Water Resources Research 39, 1-9. 
Pausas, J.G., Llovet, J., Rodrigo, A., Vallejo, R., 2008. Are wildfires a disaster in the Mediterranean basin? - A review. International Journal of Wildland Fire 17, 713-723.

Pereira, P., Úbeda, X., Martin, D.A., 2012. Fire severity effects on ash chemical composition and water-extractable elements. Geoderma 191, 105-114.

Pereira, P., Úbeda, X., Martin, D., Mataix-Solera, J., Cerdà, A., Burguet, M., 2014. Wildfire effects on extractable elements in ash from a Pinus pinaster forest in Portugal. Hydrol. Process. 28, 3681-3690.

Pierson, F.B., Carlson, D.H., Spaeth, K.E., 2002. Impacts of wildfire on soil hydrological properties of steep sagebrush-steppe rangeland. International Journal of Wildland Fire $11,145-151$.

Pietraszek, J.H., 2006. Controls on post-fire erosion at the hillslope scale, Colorado Front Range, Colorado State University.

Piñol, J., Terradas, J., Lloret, F., 1998. Climate warming, wildfire hazard, and wildfire occurrence in coastal eastern Spain. Climatic change 38, 345-357.

Prats, S.A., MacDonald, L.H., Monteiro, M., Ferreira, A.J.D., Coelho, C.O.A., Keizer, J.J., 2012. Effectiveness of forest residue mulching in reducing post-fire runoff and erosion in a pine and a eucalypt plantation in north-central Portugal. Geoderma 191, 115-124.

Prats, S.A., Malvar, M.C., Vieira, D.C.S., MacDonald, L., Keizer, J.J., 2013. Effectiveness of hydromulching to reduce runoff and erosion in a recently burnt pine plantation in central Portugal. Land Degradation and Development 27, 1319-1333.

Prats, S.A., dos Santos Martins, M.A., Malvar, M.C., Ben-Hur, M., Keizer, J.J., 2014. Polyacrylamide application versus forest residue mulching for reducing post-fire runoff and soil erosion. Science of the Total Environment 468, 464-474.

Prats, S.A., Malvar, M.C., Vieira, D.C.S., MacDonald, L., Keizer, J.J., 2016a. Effectiveness of hydromulching to reduce runoff and erosion in a recently burnt pine plantation in central Portugal. Land Degradation and Development 27, 1319-1333.

Prats, S.A., Wagenbrenner, J.W., Martins, M.A.S., Malvar Cortizo, M., Keizer, J.J., 2016b. Hydrologic implications of post-fire mulching across different spatial scales. Land Degradation and Development 27, 1440-1452.

Prosdocimi, M., Jordán, A., Tarolli, P., Keesstra, S., Novara, A., Cerdà, A., 2016a. The immediate effectiveness of barley straw mulch in reducing soil erodibility and surface runoff generation in Mediterranean vineyards. Science of The Total Environment 547, 323-330.

Prosdocimi, M., Tarolli, P., Cerdà, A., 2016b. Mulching practices for reducing soil water erosion: A review. Earth-Science Reviews 161, 191-203.

Quinton, J.N., 1997. Reducing predictive uncertainty in model simulations: a comparison of two methods using the European Soil Erosion Model (EUROSEM). Catena 30, 101-117.

Raison, R.J., 1979. Modification of the soil environment by vegetation fires, with particular reference to nitrogen transformations: a review. Plant and soil 51, 73-108. 
Renard, K. G. 1997. Predicting soil erosion by water: a guide to conservation planning with the revised universal soil loss equation (RUSLE).

Richards, A.E., Brackin, R., Lindsay, D.A.J., Schmidt, S., 2012. Effect of fire and tree-grass patches on soil nitrogen in Australian tropical savannas. Austral Ecology 37, 668-677.

Ritsema, C., Dekker, L., Oostindie, K., Moore, D., Leinauer, B., 2008. A practical field method for determining soil water repellency and critical soil water content. Soil Science Society of America, 97-112.

Robichaud, P.R., Elliot, W.J., Pierson, F.B., Hall, D.E., Moffet, C.A., 2007. Predicting postfire erosion and mitigation effectiveness with a web-based probabilistic erosion model. Catena 71: 229-241.

Robichaud, P.R., Wagenbrenner, J.W., Lewis, S.A., Ashmun, L.E., Brown, R.E., Wohlgemuth, P.M., 2013. Post-fire mulching for runoff and erosion mitigation. Part II: Effectiveness in reducing runoff and sediment yields from small catchments. Catena 105, 93-111.

Robichaud, P.R., Elliot, W.J., Lewisk, S.A., Miller, M.E., 2016. Validation of a probabilistic postfire erosion model. International Journal of Wildland Fire 25, 337-350.

Rodríguez, A., Durán, J., Fernández-Palacios, J.M., Gallardo, A., 2009. Short-term wildfire effects on the spatial pattern and scale of labile organic- $\mathrm{N}$ and inorganic- $\mathrm{N}$ and $\mathrm{P}$ pools. Forest Ecology and Management 257, 739-746.

Sadeghi, S.H.R., Gholami, L., Sharifi, E., Khaledi Darvishan, A., Homaee, M., 2015. Scale effect on runoff and soil loss control using rice straw mulch under laboratory conditions. Solid Earth 6, 1-8.

Samanta, A., Anderson, B.T., Ganguly, S., Knyazikhin, Y., Nemani, R.R., Myneni, R.B., 2010. Physical climate response to a reduction of anthropogenic climate forcing. Earth Interactions 14, 1-11.

San-Miguel-Ayanz, J., Schulte, E., Schmuck, G., Camia, A., Strobl, P., Liberta, G., Giovando, C., Boca, R., Sedano, F., Kempeneers, P., 2012. Comprehensive monitoring of wildfires in Europe: the European Forest Fire Information System (EFFIS). DOI:10.5772/28441.

Scott, J.H., Burgan, R.E., 2005. Standard fire behavior fuel models: a comprehensive set for use with Rothermel's surface fire spread model. The Bark Beetles, Fuels, and Fire Bibliography, 66.

Shakesby, R.A., Boakes, D.J., de OA Coelho, C., Gonçalves, A.B., Walsh, R.P., 1996. Limiting the soil degradational impacts of wildfire in pine and eucalyptus forests in Portugal: a comparison of alternative post-fire management practices. Applied Geography 16, 337355.

Shakesby, R.A., Doerr, S.H., 2006. Wildfire as a hydrological and geomorphological agent. Earth-Science Reviews 74, 269-307.

Shakesby, R.A., 2011. Post-wildfire soil erosion in the Mediterranean: Review and future research directions. Earth-Science Reviews 105, 71-100. 
SNIRH, 2014. Serviço Nacional de Informação dos Recursos Hídricos, (Available at: http://www.snirh.pt).

Spigel, K.M., Robichaud, P.R., 2007. First-year post-fire erosion rates in Bitterroot National Forest, Montana. Hydrol. Process. 21, 998-1005.

Stoof, C.R., 2011. Fire effects on soil and hydrology, Wageningen University, Netherlands.

Stoof, C.R., Vervoort, R., Iwema, J., Elsen, E., Ferreira, A., Ritsema, C.J., 2012. Hydrological response of a small catchment burned by experimental fire. Hydrology and Earth System Sciences 16, 267-285.

Stoof, C.R., Ferreira, A.J.D., Mol, W., Van den Berg, J., De Kort, A., Drooger, S., Slingerland, E.C., Mansholt, A.U., Ferreira, C.S.S., Ritsema, C.J., 2015. Soil surface changes increase runoff and erosion risk after a low-moderate severity fire. Geoderma 239-240, 58-67.

Tessler, N., Sapir, Y., Wittenberg, L., \& Greenbaum, N. 2016. Recovery of Mediterranean vegetation after recurrent forest fires: insight from the 2010 forest fire on Mount Carmel, Israel. Land Degradation and Development, 27, 1424-1431.

Thomas, A.D., Walsh, R.P.D., Shakesby, R.A., 1999. Nutrient losses in eroded sediment after fire in eucalyptus and pine forests in the wet Mediterranean environment of northern Portugal. Catena 36, 283-302.

Thomas, A.D., Walsh, R.P.D., Shakesby, R.A., 2000a. Post-fire forestry management and nutrient losses in eucalyptus and pine plantations, Northern Portugal. Land Degradation and Development. 11, 257-271.

Thomas, A.D., Walsh, R.P.D., Shakesby, R.A., 2000b. Solutes in overland flow following fire in eucalyptus and pine forests, northern Portugal. Hydrol. Process. 14, 971-985.

Tiessen, H., Chacon, P., Cuevas, E., 1994. Phosphorus and nitrogen status in soils and vegetation along a toposequence of dystrophic rainforests on the upper Rio Negro. Oecologia 99, 145-150.

Úbeda, X., Sala, M., 1998. Variations in runoff and erosion in three areas with different fire intensities. Geoökodynamik 19, 179-188.

Van Eck, C.M., Nunes, J.P., Vieira, D.C.S., Keesstra, S.K., Keizer, J.J., 2016. Physically-based modelling of the post-fire runoff response of a forest catchment in Central Portugal: using field versus remote sensing based estimates of vegetation recovery. Land Degradation and Development 27, 1535-1544.

Vega, J.A., Fernández, C., Fonturbel, T., 2005. Throughfall, runoff and soil erosion after prescribed burning in gorse shrubland in Galicia, NW Spain. Land Degradation and Development 16, 37-51.

Vega, J.A., Fernández, C., Fonturbel, T., 2015. Comparing the effectiveness of seeding and mulching + seeding in reducing soil erosion after a high severity fire in Galicia, NW Spain. Ecological Engineering 74, 206-212. 
Vieira, D.C.S., Prats, S.A., Nunes, J.P., Shakesby, R.A., Coelho, C.O.A., Keizer, J.J., 2014. Modelling runoff and erosion, and their mitigation, in burned Portuguese forest using the revised Morgan-Morgan-Finney model. Forest Ecology and Management 314, 150165.

Vlassova, L., Pérez-Cabello, F., 2016. Effects of post-fire wood management strategies on vegetation recovery and land surface temperature (LST) estimated from Landsat images. International Journal of Applied Earth Observation and Geoinformation 44, 171-183.

Wahren, F.T., Julich, S., Nunes, J.P., Gonzalez-Pelayo, O., Hawtree, D., Feger, K.-H., Keizer, J.J., 2016. Combining digital soil mapping and hydrological modeling in a data scarce watershed in north-central Portugal. Geoderma 264, 350-362.

Westerling, A.L., Hidalgo, H.G., Cayan, D.R., Swetnam, T.W., 2006. Warming and earlier spring increase western US forest wildfire activity. Science 313 (5789), 940-943.

Wilkinson, S., Wallbrink, P., Blake, W., Doerr, S., Shakesby, R., 2006. Impacts on water quality by sediments and nutrients released during extreme bushfires: Report 3: Post-fire sediment and nutrient redistribution to downstream waterbodies, Nattai National Park. CSIRO Land and Water Science Report 64, 06-31.

Wittenberg, L., Inbar, M., 2009a. The Role of Fire Disturbance on Runoff and Erosion Processes-a Long-Term Approach, Mt. Carmel Case Study, Israel. Geographical Research 47(1), 46-56.

Wittenberg, L., Malkinson, D., Barzilai, R., 2014. The differential response of surface runoff and sediment loss to wildfire events. Catena 121, 241-247.

Woods, S.W., Birkas, A., Ahl, R., 2007. Spatial variability of soil hydrophobicity after wildfires in Montana and Colorado. Geomorphology 86(3-4), 465-479.

WRB, 2014. World Reference Base for Soil Resources. FAO, Rome (145 pp.). 


\section{English summary}

Wildfires, especially in Mediterranean settings, are causing substantial environmental damage. Numerous studies have investigated the short-term impacts of single wildfires, but few studies have explored the effects of repeated wildfires on the soil-vegetation system. Changes in vegetation cover and soil properties as a result of repeated wildfires have important hydrological and geomorphological consequences, in particular in relation to runoff, erosion and nutrient losses.

Chapter 2 focuses on unraveling the effects of fire frequency on runoff, soil erosion, and loss of organic matter at the micro-plot scale. Field experiments showed that repeated wildfires strongly increased the loss of vegetation and litter cover, and resulted in distinct soil property changes. Furthermore, especially, the loss of litter cover strongly influenced runoff generation, soil erosion and organic matter losses during high intensity rainfall events.

Chapter 3 investigates soil fertility losses caused by post-fire overland flow. Results show that $\mathrm{N}$ and $\mathrm{P}$ content in runoff water were significantly higher in the burnt sites than in the control. Furthermore, the impacts of fire frequency revealed that both $\mathrm{N}$ and $\mathrm{P}$ losses were significantly higher for the $4 \times$ burnt sites than for both the $1 \times$ burnt and unburnt sites. Nutrient losses were especally high after high intensity rainfall events.

Chapter 4 reports on testing of regreening techniques and post-fire management. Runoff and erosion after repeated wildfires in a maritime pine forest were investigated under different remediation treatments. The effectiveness of four runoff and soil erosion mitigation methods were examined, namely: i) sowing pine seeds, ii) sowing pine seeds combined with pine needles, iii) sowing grass seeds and, iv) sowing surfactant-coated seeds. Results indicate that treatment T2 and T4 performs best in reducing runoff and erosion, while treatments $\mathrm{T} 1$ and $\mathrm{T} 3$ had marginal efects only. Especially, treatment T2 provide a valuable strategy for wide-scale implementation after successive wildfire to minimize further environmental deterioration.

In Chapter 5 the revised Morgan-Morgan-Finney (MMF) model was used to simulate the impact of recurrent wildfires on runoff and erosion. The MMF model performed reasonably well for soil erosion predictions but poor for runoff. In particular, the effective hydrological depth and slope angle are main model parameters requiring accurate data to acquire reliable model outputs. Due to the limitations of the current MMF modelling approach, further attention and improvements are needed in the future. 
Chapter 6 presents an extensive synthesis covering discussion, conclusions, recommendations, and future research priorities. In short, the study done provides a better understanding of the effects of fire frequency on runoff generation and soil erosion losses. Also, a range of promising remediation treatments have been tested intended to recover fire-affected sites as quickly as possible. With this respect, enhancing soil coverage, e.g. by applying pine needle and/or surfactant coated seeds, have proven to be effective strategies. Furthermore, the revised MMF modelling approach used in this study has potential for further application, for instance as a post-fire land management decision tool. 


\section{Acknowledgements}

I wish to express my sincere appreciation to those who have contributed to this thesis and supported me during this amazing journey.

First of all, I am extremely grateful to my promoter, Professor Coen Ritsema, for his guidance and all the useful discussions and brainstorming sessions, especially during the difficult conceptual development stage. His deep insights helped me at various stages of my research. I also remain indebted for his understanding and support during my study.

My sincere gratitude is reserved for my other promoter, Professor Violette Giessen for her invaluable insights and suggestions. I really appreciate her willingness to meet me at short notice every time and going through several drafts of my thesis. I remain amazed that despite her busy schedule, she was able to go through the final drafts of my thesis multiple times.

Furthermore, I would like to thank my co-supervisor, Dr. Jan Jacob Keizer for his continuous support during my PhD study, and for his patience, motivation, and overall guidance. I would like to say a very big thank you to Dr. Oscar González-Pelayo for all the support and encouragement during the long and exhaustive field campaigns in Portugal, and the time spent together at the University of Aveiro, Portugal.

I greatly appreciate the support received from friends and colleagues in the Earth Surface Processes Team, Centre for Environmental and Marine Studies (CESAM), Department of Environment and Planning, University of Aveiro, for making those months of data collection an enjoyable adventure. I would also like to thank the staff members of the library for guiding me through the large amount of international scientific publictions, relevant for this respective $\mathrm{PhD}$ research.

A special group of PhD students, called the "Atlas-Gang" is acknowledged for the overall support and understanding, providing an once in a lifetime experience, resulting in long lasting friendships. Also, I want to thank Demie Moore, Klaas Oostindie, Anita Kok, Esther van den Brug, Annelies van de Bunte and Marnella van der Tol for dedicated support during my research.

Leonie Zweekhorst-de Rooij and Waltraut Stroh are acknowledhed for their continued support and assistance, which was indispensable for succesfully concluding my thesis. 
This research was embedded in and financially supported by the EC funded CASCADE project (FP7 - ENV.2011.2.1.4-2/283068), which offered me to work in a truly international context. Also SAR-UAF Netherlands provided valuable and essential support during the course of my PhD project.

Financial support from Soil Physics and Land Management Group, Wageningen University, for printing this thesis is gratefully acknowledged.

Last but not the least, distinctive thanks go to my family for all the sacrifices that they made on my behalf. Your prayer for me kept me going, and helped me to reach my goal. Most importantly, I would like to thank my wife Mona for her support, encouragement, quiet patience and unwavering love.

Thank you all.

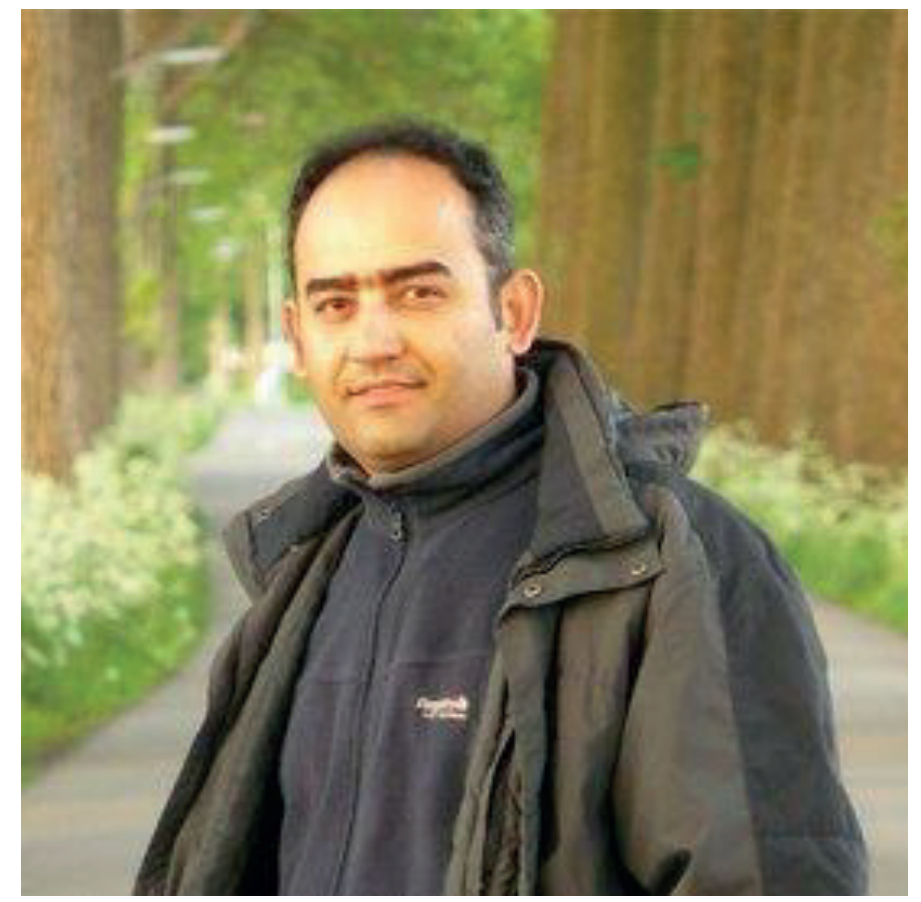




\section{About the author}

Mohammadreza (Kaveh) Hosseini was born in Shiraz, Iran, on 02 December 1979. From 1994 to 1998 he attended the high school in Shiraz, where he recieved a diploma, with majors in physics and mathematics.

In 1998, he started the Bachelor research programme at Estahban University in the civil engineering faculty. After graduation from the University he started his work as a project officer in Shiraz. In 2008, he started his Master programme Hydraulic Engineering and River Basin Development at UNESCO-IHE, Delft, the Netherlands, and concluded his study with a master thesis about optimizing agricultural production in water scarce regions in the Fars province of Iran.

He shortly continued working at UNESCO-IHE, and thereafter started his PhD research at Wageningen University in the content of EC funded CASCADE project (FP7 - ENV.2011.2.1.42/283068) focusing on degradation of dryland areas in southern Europe.

During his $\mathrm{PhD}$ research, Kaveh attended several international conferences and presented his research via posters and oral speeches. Furthermore, Kaveh (co)authored multiple publications and conference papers since starting his $\mathrm{PhD}$ research, see below.

Email contact: m.rhosseini11@gmail.com

\section{Publication related to this thesis:}

Hosseini, M., Keizer, J.J., Pelayo, O.G., Prats, S.A., Ritsema, C.J., Geissen, V., 2016. Effect of fire frequency on runoff, soil erosion, and loss of organic matter at the micro-plot scale in north-central Portugal. Geoderma 269, 126-137.

Hosseini, M., Geissen, V., González-Pelayo, O., Serpa, D., Machado, A.I., Ritsema, C.J., Keizer, J.J., 2017. Effects of fire occurrence and recurrence on nitrogen and phosphorus losses by overland flow in maritime pine plantations in north-central Portugal. Geoderma 289, 97-106.

Hosseini, M., González-Pelayo, O., Vasques, A., Ritsema, C.J., Geissen, V., Keizer, J.J., 2017. The short-term effectiveness of surfactant seed coating and mulching treatment in reducing post-fire runoff and erosion. Geoderma 307, 231-237. 
Hosseini, M., Nunes, J.P., González-Pelayo, O., Keizer, J.J., Ritsema, C.J., Geissen, V., 2018. Developing generalized parameters for post-fire erosion risk assessment using the revised Morgan-Morgan-Finney model: a test for north-central Portuguese pine stands. Catena 165, 358-368.

González-Pelayo, O., Malvar, M,. van den Elsen, E., Hosseini, M., Coelho, C.O.A., Ritsema, C.J., Bautista, S., Keizer, J.J.,. Impacts of single and recurrent wildfires on topsoil moisture regime. In press.

Santos, L., Machado, A.I., Hosseini, M., González-Pelayo, O., Coelho, C.O.A., Keizer, J.J., Efeitos de fogos repetidos na concentração e na mobilização dos nutrientes do solo 2015. Recursos Hídricos, Associação Portuguesa dos Recursos Hídricos, Volume 36-02 Portuguese.

\section{Conference Paper and Presentation:}

Hosseini, M., Nunes, J.P., González-Pelayo, O., Keizer, J.J., Ritsema, C.J., Geissen, V., 2017. Modelling the effect of fire frequency on runoff and erosion in north-central Portugal using the revised Morgan-Morgan-Finney, EGU.

González-Pelayo, O., Malvar, M,. van den Elsen, E., Hosseini, M., Coelho, C.O.A., Ritsema, C.J., Bautista, S., Keizer, J.J., 2017. Impacts of single and recurrent wildfires on topsoil moisture regime, EGU.

Hosseini, M., Keizer, J.J., González-Pelayo, O., Prats, S.A., Martins, M., Santos, L., Ritsema, C.J., Geissen, V., Keizer, J.J., 2015. Impact of fire frequency on runoff, soil and organic matter losses at the micro-plot scale in North-Central Portugal, EGU.

Hosseini, M., González-Pelayo, O., Machado, A.I., Geissen, V., Ritsema, C.J., Keizer, J.J., 2015. Effect of fire frequency on nutrient losses in burned pine forest of north-central Portugal, Wageningen soil conference.

Regensburg, t., González-Pelayo, O, Martins, M., Hosseini, M., Keesstra, S.K., Keizer, J.J., 2015. The role of vegetation patches and antecedent soil moisture conditions in runoff and erosion connectivity in a 4-times burnt pine stand, EGU.

González-Pelayo, O., Malvar, M,. van den Elsen, E., Hosseini, M., Coelho, C.O.A., Ritsema, C.J., Bautista, S., Keizer, J.J., Cerdà, A., 2015. Soil wetting patterns of vegetation and inter-patches following single and repeated wildfires, EGU.

González-Pelayo, O., Hosseini, M., Varandas, D., Machado, A.I., Prats, S.A., Coelho, C.O.A., Geissen, V., Ritsema, C.J., Keizer, J.J., 2014. Total N exports from once vs. repeatedly burnt Pine plantations, EGU. 
Hosseini, M., González-Pelayo, O., Buchspies, B., Maia, P., Martins, M., Varandas, D., Geissen, V., Coelho, C.O.A., Ritsema, C.J., Keizer, J.J., 2013. Post-fire runoff and soil (fertility) losses in long-unburnt vs. repeatedly-burnt maritime pine stands, northcentral Portugal, EGU.

Hosseini, M., González-Pelayo, O., Geissen, V., Coelho, C.O.A., Ritsema, C.J., Keizer, J.J., 2013. Effect of wildfire regime on runoff, FESP4. 


\section{Acknowledgements of financial support}

This research was embedded in and financially supported by the EC funded CASCADE project (FP7 - ENV.2011.2.1.4-2/283068), which offered me to work in a truly international context. Also SAR-UAF Netherlands provided valuable and essential support during the course of my PhD project.

Financial support from Soil Physics and Land Management Group, Wageningen University, for printing this thesis is gratefully acknowledged. 


\section{SENSE}

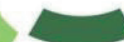

Netherlands Research School for the Socio-Economic and Natural Sciences of the Environment

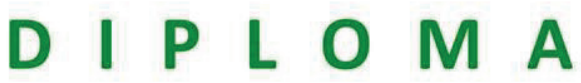

For specialised PhD training

The Netherlands Research School for the

Socio-Economic and Natural Sciences of the Environment

(SENSE) declares that

\section{Mohammadreza Hosseini}

born on 2 December 1979 in Shiraz, Iran

has successfully fulfilled all requirements of the Educational Programme of SENSE.

Wageningen, 9 April 2018



Dr. Ad van Dommelen

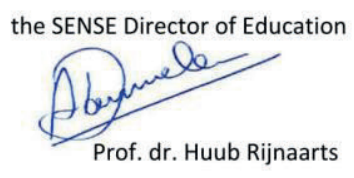

The SENSE Research School has been accredited by the Royal Netherlands Academy of Arts and Sciences (KNAW)

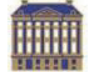

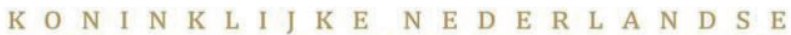

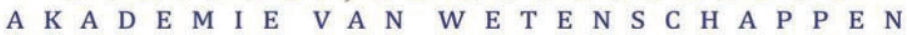




\section{(sisse)}

The SENSE Research School declares that Mr Mohammadreza Hosseini has successfully fulfilled all requirements of the Educational PhD Programme of SENSE with a work load of $40.5 \mathrm{EC}$, including the following activities:

\section{SENSE PhD Courses}

- Environmental research in context (2012)

- Research in context activity: 'Co-organising SENSE-WIMEK symposium on hazard, risk and sustainability in the soil environment' (2015)

\section{Other PhD and Advanced MSc Courses}

- Mobilising your scientific network, Wageningen University (2012)

- Interpersonal communication for PhD students, Wageningen University (2012)

- Generalised linear models, Wageningen University (2012)

- Project \& time management, Wageningen University (2012)

- Research methodology: From topic to proposal, Wageningen University (2013)

\section{Management and Didactic Skills Training}

- Lecturing BSc course 'Technology, development and natural resources' (2012)

- Supervising BSc student with thesis entitled 'Recurrence of wildfires its effects on runoff and erosion at the micro-plot scale in pine stands' (2012-2013)

- Supervising three MSc students with thesis entitled 'Effects of repeated forest fires on nutrient exports', 'Effects of repeated fires on soil nutrients and their mobilisation', and 'Runoff and erosion in a Maritime pine forest in North Central Portugal after repeated wildfires: mitigation methods and off-site effects' (2013-2014)

\section{Oral Presentations}

- Impact of fire frequency on runoff, soil and organic matter losses at the micro-plot scale in North-Central Portugal. European Geosciences Union, General Assembly, 12-17 April 2015, Vienna, Austria

- Effect of fire frequency on nutrient losses in burned pine forest of north-central Portugal. Wageningen Soil Conference, 23-27 August 2015, Wageningen, the Netherlands

SENSE Coordinator PhD Education

Dr. ing. Monique Gulickx 


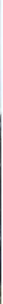

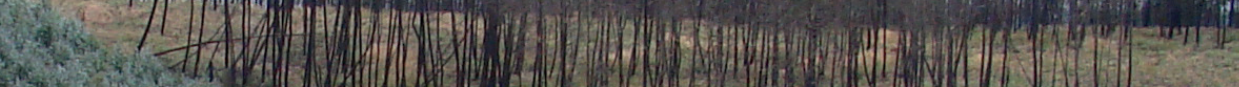

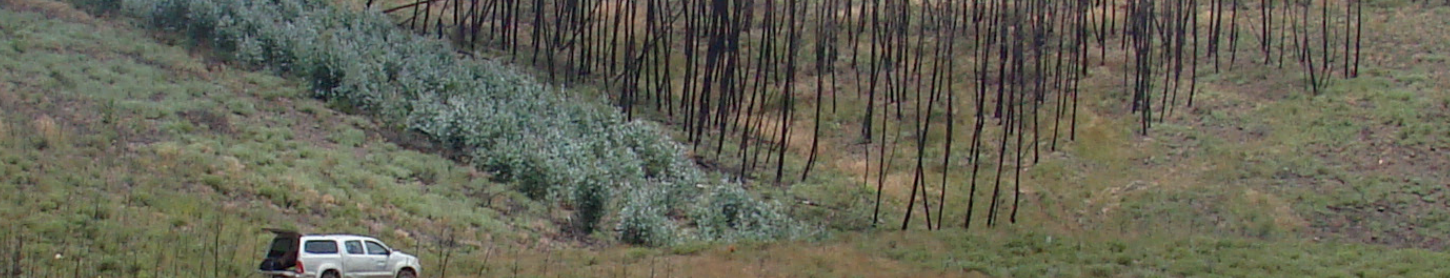

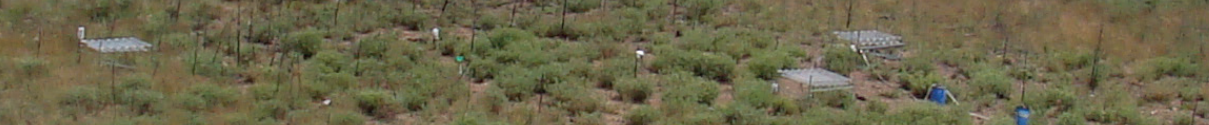

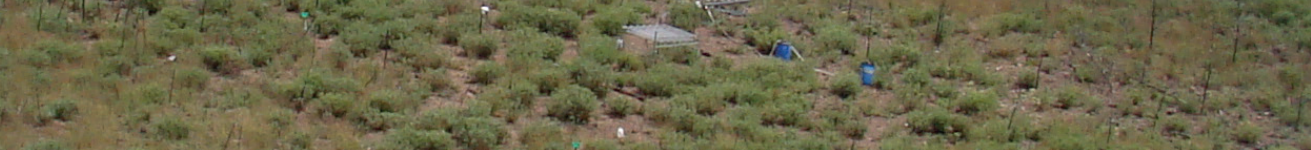

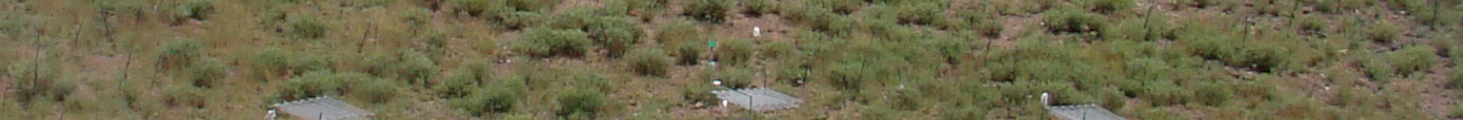
$-x+2-5-x+2-3 x-$

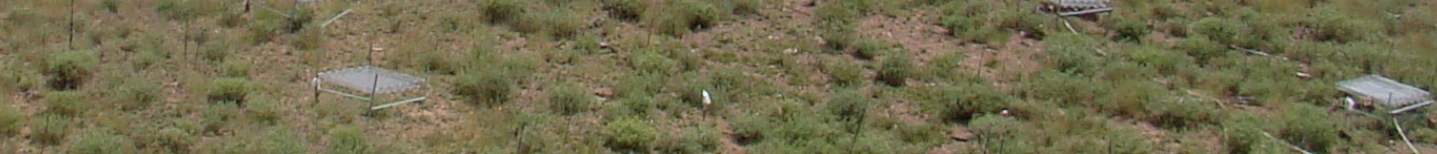

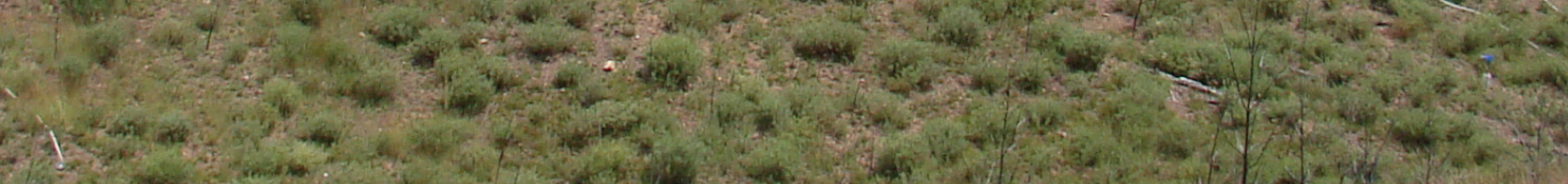

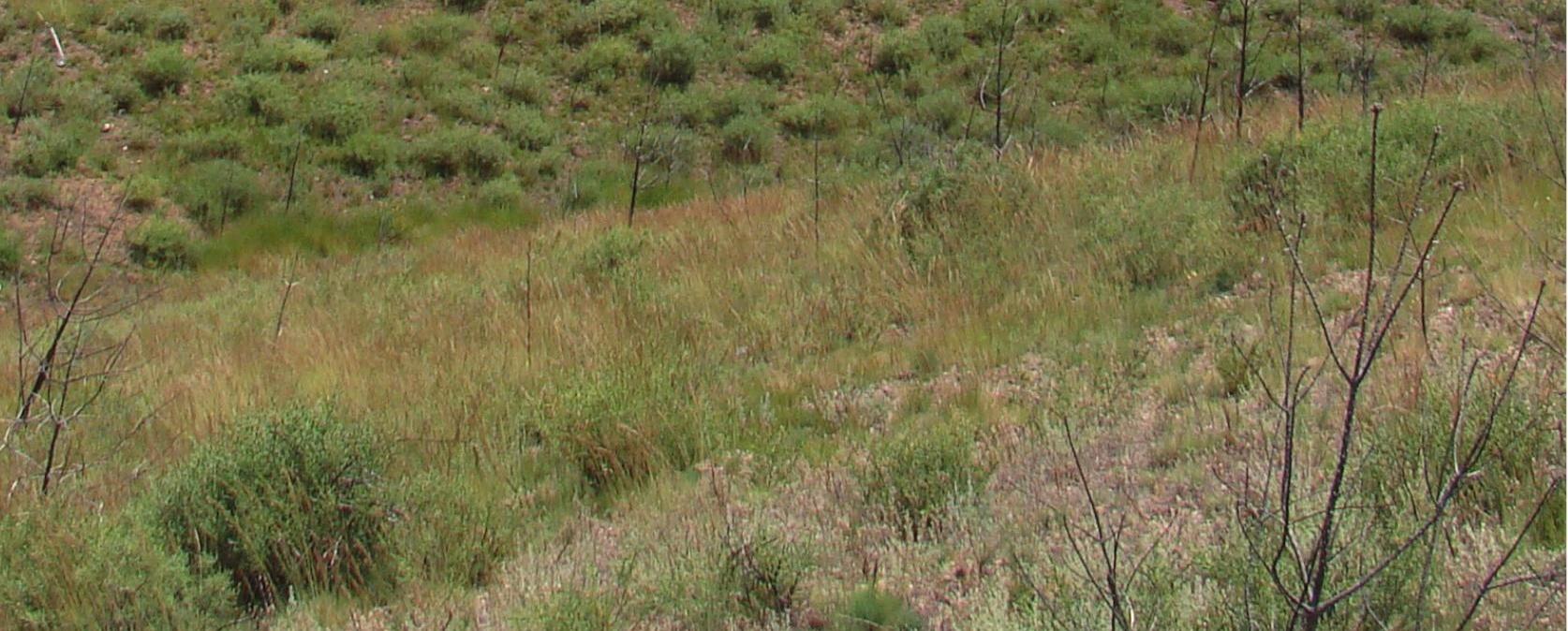

